Portland State University

PDXScholar

Spring 6-5-2018

\title{
News Work: the Impact of Corporate Newsroom Culture on News Workers \& Community Reporting
}

Carey Lynne Higgins-Dobney

Portland State University

Follow this and additional works at: https://pdxscholar.library.pdx.edu/open_access_etds

Part of the Broadcast and Video Studies Commons, Journalism Studies Commons, and the Mass Communication Commons Let us know how access to this document benefits you.

\section{Recommended Citation}

Higgins-Dobney, Carey Lynne, "News Work: the Impact of Corporate Newsroom Culture on News Workers \& Community Reporting" (2018). Dissertations and Theses. Paper 4410.

https://doi.org/10.15760/etd.6307

This Dissertation is brought to you for free and open access. It has been accepted for inclusion in Dissertations and Theses by an authorized administrator of PDXScholar. Please contact us if we can make this document more accessible: pdxscholar@pdx.edu. 
News Work: The Impact of Corporate Newsroom Culture on News Workers

\& Community Reporting

by

Carey Lynne Higgins-Dobney

A dissertation submitted in partial fulfillment of the requirements for the degree of

\author{
Doctor of Philosophy \\ in \\ Urban Studies
}
Dissertation Committee:
Gerald Sussman, Chair
Greg Schrock
Priya Kapoor
José Padín

Portland State University

2018 
(C) 2018 Carey Lynne Higgins-Dobney 


\begin{abstract}
By virtue of their broadcast licenses, local television stations in the United States are bound to serve in the public interest of their community audiences. As federal regulations of those stations loosen and fewer owners increase their holdings across the country, however, local community needs are subjugated by corporate fiduciary responsibilities. Business practices reveal rampant consolidation of ownership, newsroom job description convergence, skilled human labor replaced by computer automation, and economically-driven downsizings, all in the name of profit. Even so, the people laboring under these conditions are expected to keep their communities informed with democracyand citizenship-enhancing information.

This study uses a critical political economy framework to focus on the labor aspects of working in commercially-run local television newsrooms in the United States. Surveys and interviews with news workers from the 25 largest local television markets highlight the daily challenges of navigating the dichotomy of labor in the space between corporate profiteering and public enlightenment. In addition to their more well-known and well-studied on-air reporter and anchor peers, "behind the scenes" workers and those with newly converged job descriptions also share their news work stories, thus filling a gap in the literature. Corporate capital incentives affect all who gather and disseminate the news.
\end{abstract}

While all of these workers generally strive for high journalistic quality, the pressures of increased workloads and constant deadlines imposed by shrinking news staffs and growing digital media expectations mean journalists have to make craft work 
compromises in the race to report news faster and first. Owners push experienced news veterans with deep community connections out in favor of younger, cheaper, more techsavvy workers. Financially beneficial content trumps deep policy investigations. These outcomes not only worry those in the journalistic trenches of local television news, but also potentially deprive the public of the information they seek from these outlets. As local television newsrooms remain the most popular sources of information for Americans, particularly in times of crisis, such outcomes are not in the community's best interest. 
News Work iii

\section{Dedication}

For Milo \& Vera,

the best study buddies a Mommy could ever want 


\section{Acknowledgments}

As my personal, news, and academic worlds collide, I find myself surrounded by some of the best people on the planet. I am forever grateful to all of those who have crossed my path, providing encouragement, laughter, inspiration, love, humanity, and the occasional much-needed kick in the backside.

A few in particular have made an indelible mark on my personal, television, and academic existences.

First off, to the faculty, staff, and students of the Urban Studies department at Portland State University for embracing the oddball tv newscast director who landed in your midst. Never let it be said I did things the "normal” way! Thank you for your patience and inspiration.

To Professor Gerald Sussman, my Chair and co-author on multiple research projects: 15+ years ago I landed in your Critical Theories class, and the rest is history. Thank you.

To Dr. Greg Schrock, committee member and ever-patient presence through this project: Thank you for pointing me in the right direction in labor studies. Again, the rest is history.

To Dr. Priya Kapoor, committee member and the instructor of the first-ever grad class I took at Portland State. 15+ years later the tv director is looking at Ph.D. Thank you.

To Dr. José Padín, committee member: Thank you for your patience and expertise during this project. 
News Work v

To my tv families at WBBH \& WZVN in Fort Myers, Florida and KPDX, KPTV, and KGW in Portland, Oregon: Our discussions (good, bad, and ugly) are the inspiration behind my studies of the crazy business we are part of. Thank you for your support, your humor, and your griping. And rock on with your bad selves.

To the fabulous local television news professionals who took my survey or agreed to chat with me for interviews: This project never could have happened without your insight. Thank you!

To the library crew at UGA Main Library: Our time together changed my life. I cherish each of you and I am so proud of what we have accomplished in the last 20 years. I can't believe how many advanced degrees we've managed to accumulate amongst ourselves! Thank you for your advice, encouragement, and friendship throughout this process.

To UGA: WOOF! As a first-generation college student, I had no idea what I was in for, but I knew the second I stepped foot on campus that academia was where I was meant to be. Thank you for changing my life.

To David Hazinski: Thank you for planting the love of tv news in my being and providing a starter set of colorful phrases appropriate for control room usage. My 20-year career is all your fault! (Enjoy your retirement!)

To the University News crew of 1997: Thanks for a great show. 
To the fabulous folks of BEA: Y'all have no idea how much your acceptance, enthusiasm, ideas, and feedback have meant to me in getting this project finished. Thank you. I look forward to April in Las Vegas.

To my students at Clackamas Community College: Thank you for being such fantastic, enterprising, creative broadcasters. You have cemented my love for teaching. I expect business cards from wherever you end up!

To "Dr. Scott": Who would have thought the former academic would be among those pushing the grad student to the finish line? Thank you for your wisdom and storytelling abilities.

To the Blue Man Group: Your musical oddities have powered me through not one, but two graduate degrees. Nothing like a little Mandelbrot and Drumbone to get the brain waves moving!

To my Twitter friends: While many of us have not met in person, our discussions have been invaluable to surviving the trials of life, local television, parenthood, and grad school. Thank you for sharing a wacky sense of humor through it all.

To the fine folks at Fresno State: Thank you for taking a chance on the newscast director with an Urban Studies degree. I look forward to the next set of academic adventures together.

To my fabulous little book worms, Milo and Vera. You weren’t around when I started this journey, but my life sure is better with your arrivals. Keep on being open, inquisitive, and adventurous. You are my inspirations. (Yes, we can go to the zoo now!) 
News Work vii

And finally: To my always-supportive best friend and spouse who encouraged this academic adventure from its beginnings. This portion of the journey comes to an end almost 9 years, 2 kids, and multiple simultaneously-held jobs later. I couldn’t have done it without you. I can’t wait to see what we come up with next! 


\section{Table of Contents}

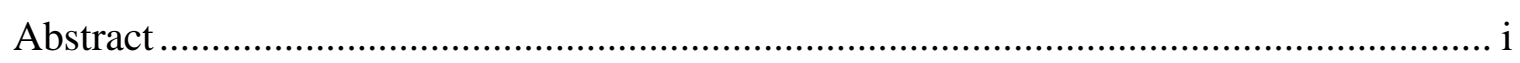

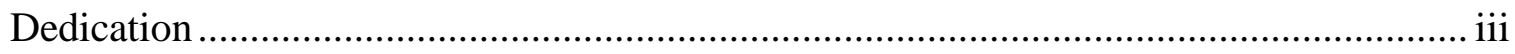

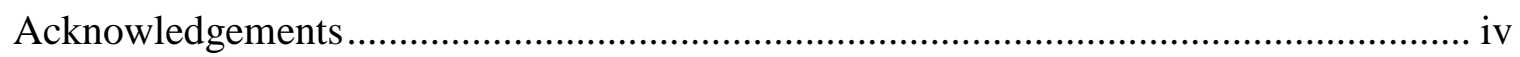

List of Tables .................................................................................................... xii

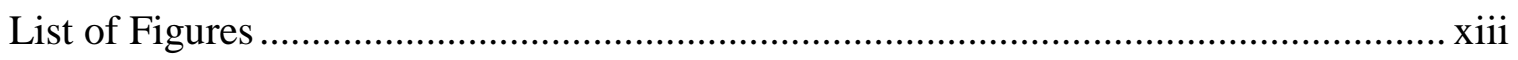

Chapter 1: The Place of Local Television News in the Community ............................... 1

A Changing Media Environment ..............................................................

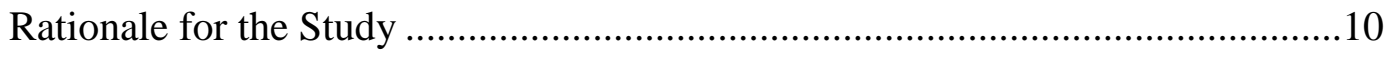

Research Questions ......................................................................... 14

Organization of the Rest of the Study ......................................................... 17

Chapter 2: Theories of Community, Political Economy, and Labor Affecting Local

Television News Production and Dissemination ......................................................21

The Role of Place in Community.................................................................21

The role of journalism.................................................................26

The Political Economy of the Mainstream Mass Media.....................................31

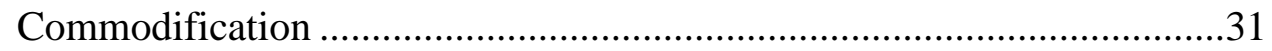

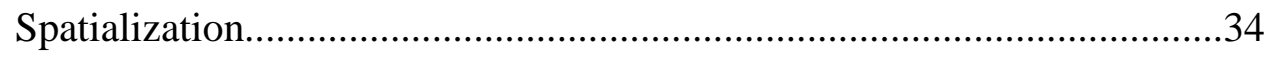

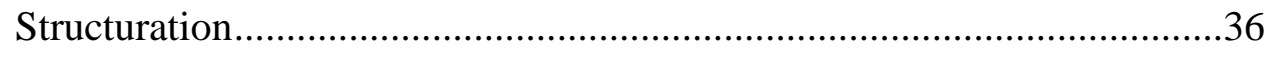

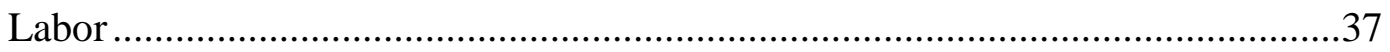

Labor process theory and the division of labor.....................................38

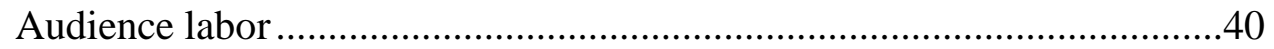


Chapter 3: The State of the Local Television News Business in 2017, and How It Got to be this Way

Regulating in the Public Interest......................................................................43

Deregulating in the Business Interest .................................................................46

Competition + diversity + localism $=$ public interest? ................................48

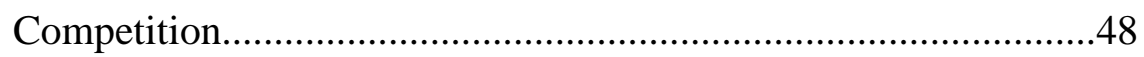

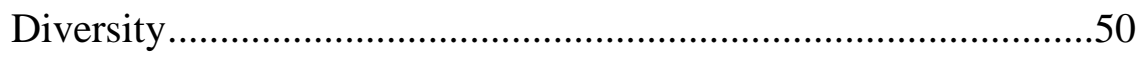

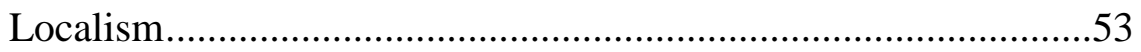

Equals public interest? ..................................................................5

The Place of Journalism in the Marketplace ..........................................................58

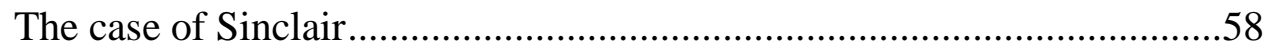

Positive outcomes of corporate ownership on local newsrooms ................61

Chapter 4: Research Methodology ...............................................................................63

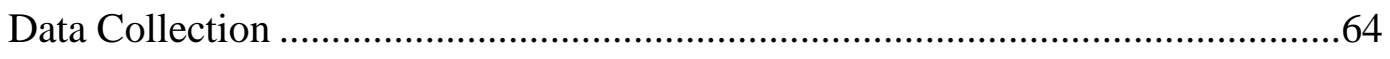

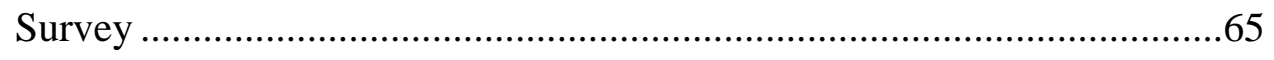

Email distribution..........................................................................66

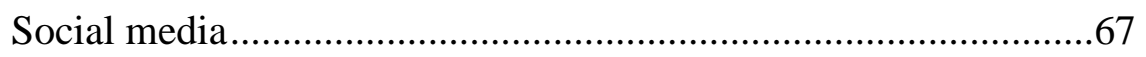

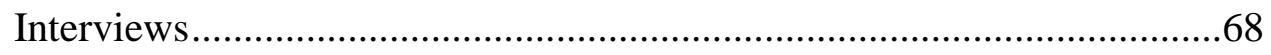

Author Background ..........................................................................................69

Considerations of Confidentiality ………………............................................

Chapter 5: Corporate Power and Its Influence on News Construction................................73

Filter 1: Size, Ownership, and Profit ................................................................74

Filter 2: Advertising as a Primary Income Source....................................................76 


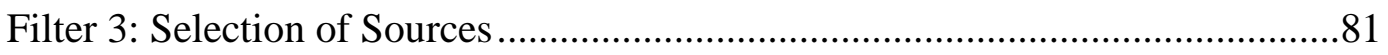

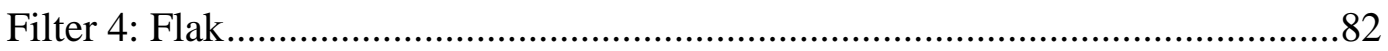

Filter 5: Ideology as a Control Mechanism..........................................................84

Chapter 6: Technology, the Division of Labor, and the Impact on Newsrooms ................87

Technology in Information Gathering and Dissemination .....................................87

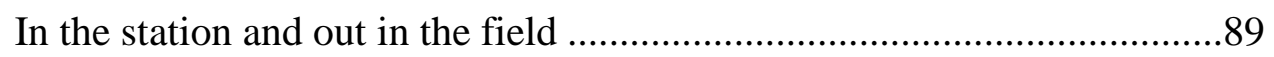

Social Media and Digital Overload.....................................................................93

Connecting with the social media ................................................................99

Training and Equipment Selection..................................................................101

Consequences of Forced Technology Implementation.........................................104

Chapter 7: Converging Job Descriptions in a Compressed Labor Force ...........................107

Downsizing for Economic Advantage .............................................................107

Numerically flexible workers ................................................................109

Scheduling complications .....................................................................111

Newsroom tenure ………………………………………....................113

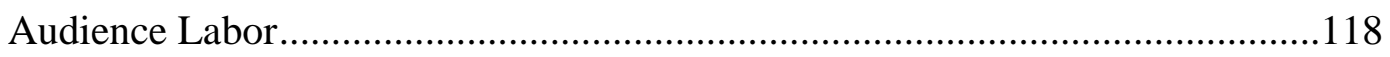

Increasing Workloads and Job Convergence....................................................120

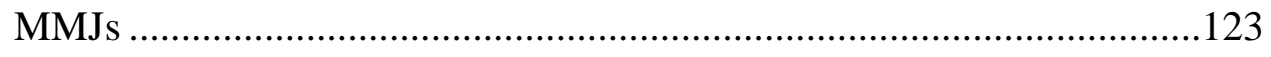

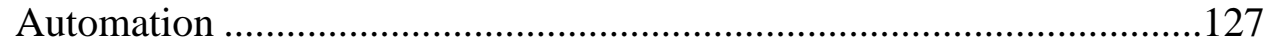

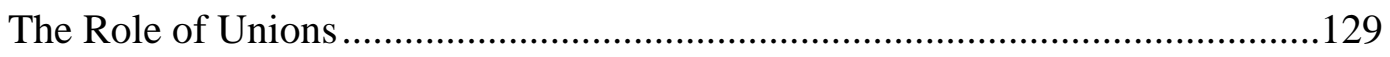

Proposed Solutions.......................................................................................133 
Chapter 8: Serving in the Public Interest or the Market Interest? Conclusions, Limitations, and Future Research Directions............................................................140

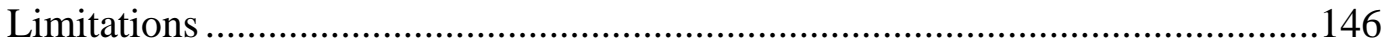

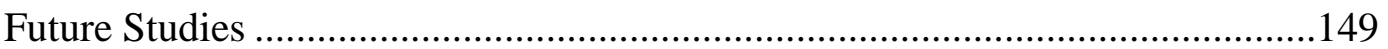

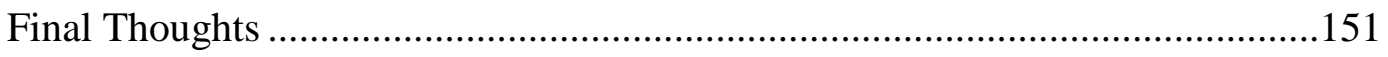

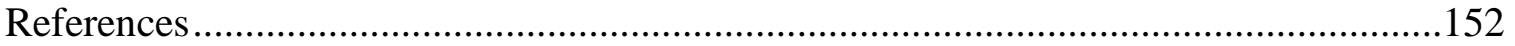

Appendix A. Stations with Local Television Newscasts in Targeted Markets................185

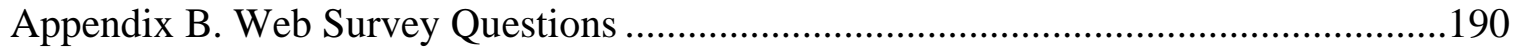

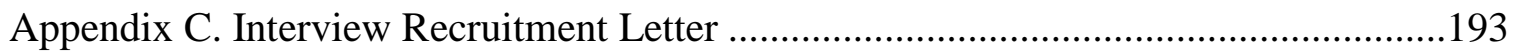

Appendix D. Interview Consent Form .................................................................195

Appendix E. Potential Base Interview Questions ........................................................197 


\section{List of Tables}

Table 1. The largest local television owners nationwide ..............................................5

Table 2. Study participants for both surveys and interviews ........................................65

Table 3. Number of respondents from each targeted market .......................................148 


\section{List of Figures}

Figure 1. Percentage of relevant surveyed workers that felt pressure to cover or not cover a story for station financial gain.................................................................

Figure 2. Worker attitudes about technology in their newsrooms ................................89

Figure 3. Pay changes for news workers versus work load ......................................120

Figure 4. Perceptions of job performance by workers with increased workloads ...........121

Figure 5. How surveyed workers think workplace changes have affected their news

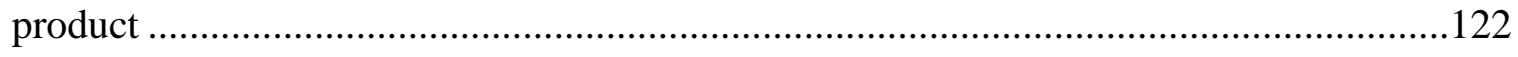

Figure 6. Comparison of union versus nonunion workers by job description ................131 
News Work 1

\section{Chapter 1: The Place of Local Television News in the Community}

On August 25, 2017, Hurricane Harvey came ashore in Southern Texas as a major Category 4 storm. In the hard-hit areas of Corpus Christi and Houston, 89\% of surveyed residents indicated they used local broadcast television newscasts as their source for information during and after the storm to keep their families safe (TVB, 2017a, 2017b). Sixteen days later, a similar scenario played out in Florida, as Irma made landfall twice in that state as a major hurricane. There, $85 \%$ of those in affected areas used local television news stations as their information sources, and spent more than 5 hours watching for updated information (Tsoflias, 2017).

Even in non-crisis times, local television newscasts remain the primary way for Americans to receive their daily news, in spite of the ever-growing number of sources for acquiring information (Mitchell, Gottfried, Barthel, \& Shearer, 2016). Local television broadcast stations are considered so important to the community, federal law requires them to broadcast in the "public interest, convenience, and necessity" in order to maintain their licenses to use the publicly-owned airwaves for transmission (U.S. Congress, 1934). Journalism outlets promote community culture and citizen freedom through "reliable, accurate, and comprehensive information” (Kovach \& Rosenstiel, 2001, p. 11). Although what is specifically meant by the "public interest” has never been explicitly defined by Congress or the Federal Communications Commission (FCC), traditionally, ideas of educating the audience, keeping an eye on the powerful, and providing information for public discussion for the betterment of society are mainstays of responsible journalism, and have, on occasion, found their way into regulatory guidelines (see, for instance, 
News Work 2

Bennett, Lawrence, \& Livingston, 2007; Blanchard \& Association for Education in Journalism., 1977; Habermas, 1991; Schudson, 2008). Indeed, those who use media sources to keep up-to-date about political information and current events tend to participate in a higher capacity in society. Those who engage more with local news tend to have strong connections to their communities and consistently vote in local elections (Barthel, Holcomb, Mahone, \& Mitchell, 2016; Gil de Zúñiga, 2009).

Since the Communications Act of 1934, the Federal Communications Commission (FCC) has legally maintained this standard of public interest for the industry, even as it has succumbed to a neoliberal mindset by deregulating station ownership structures, eliminating news and public affairs guidelines, and allowing business interests to rule the airwaves. Broadcasters still offer news and public affairs shows to their audiences to demonstrate their commitment to the public and are devoting more time to content labeled "news" than ever before. In 2016, the average weekday held 5.7 hours of local news programming, up 12 minutes from the previous high (Bishop \& Hakanen, 2002; Papper, 2017b; Pickard, 2011).

While this may seem like a positive move by local stations for their communities, the behind-the-scenes circumstances are not as encouraging. While the time labeled “news” is increasing, the number of local stations originating their own news programming dropped by 9 stations overall. Those 705 stations then also provided news programming for an additional 357 stations, another all-time high, meaning the number of news programming originators is actually shrinking (Papper, 2017b). This has been shown to decrease the diversity of programming and information provided to the 
audiences, as many of these shared service agreements amount to little more than simulcasting the same content across multiple television stations within a community (Stearns \& Wright, 2011; Yanich, 2010).

Such consolidation has been a mainstay in the industry for decades, not only in content sharing, but in ownership and labor relations as well. Political economy is the framework that examines such consolidation via the social and power structures that oversee the production, distribution, and consumption of resources, including those in mass media. It critically examines questions of ownership and finance, how government or other regulation affect media output, and the alignment of political and economic interests and structural conditions under which institutions operate. It includes the examination of labor processes, managerial control, and worker autonomy, and looks at the relationships between media content and society (Hardy, 2014; Mosco, 2009b; Murdock \& Golding, 1973). This is the approach taken throughout this study.

Particularly since the 1980s, the FCC and U.S. Congress have worked to deregulate many of the rules governing communications companies. Prior to this neoliberal era, government agencies had played a more active role in the regulation of commercial media. Rules were put in place to keep competition, diversity, and localism as major components of local broadcasting. But the breakup of AT\&T in 1984 signaled the beginning of the elimination of national oversight of information and communication fields. This eventually led to the fall of the Financial Interest and Syndication rules in 1995 and the enactment of the Telecommunications Act of 1996, allowing previously entertainment-oriented companies to buy up media newsrooms, produce and distribute 
News Work 4

their own programming, and increase their audiences across the country. As deregulation and consolidation has grown, converged corporations have expanded beyond the horizontal integration of similar properties (i.e., acquiring more television stations); they have vertically integrated with production, distribution, and syndication divisions, and added various media formats (newspapers, television stations, web sites) and media products (advertising, entertainment, news) to their portfolios as well (Bielby \& Moloney, 2008; Federal Communications Commission, 1996; McAllister, 2014; McKercher, 2002).

By allowing for this consolidation of programming and distribution resources, the FCC's deregulation has exacerbated the power imbalance between those with the means to buy and operate media holdings and those who work under their deregulated rule structures. This affects not only the ownership of the media properties, but also the labor conditions of those who work under more concentrated, large scale corporate ownership, decision-making, and control.

For instance, the use of consolidated job descriptions is on the rise, with "multimedia journalists,” or MMJs, growing by 3\% in local tv newsrooms each year (Papper, 2017c). These journalists combine the skills of television reporter, photographer, editor, and social media manager into a one-person reporting machine. The quality of the stories provided to the audience has become a concern (see, for example, Perez \& Cremedas, 2014). Since television newsrooms are no longer strictly television-based, the work load of filling space on other dissemination platforms, namely web pages, mobile apps, and 
various social media outlets, has also fallen onto the shoulders of those performing other job descriptions within these newsrooms (Smith, Tanner, \& Duhé, 2007).

The Ajit Pai-era FCC has continued to loosen ownership and oversight legislation, setting up a scenario in which one company, Sinclair Broadcast Group, may be able to reach 72\% of the broadcast audience in the United States as early as 2018 (Ember, 2017a; Johnson, 2017a). While Sinclair may be the largest local television ownership corporation, it is certainly not alone in its ambitions for ownership domination. In 2004, the five largest local media companies combined owned 179 television stations. In 2016, they owned 443 (Matsa, 2017a, see Table 1). Sinclair alone held 193 at the end of 2017 (sbgi.net, 2017). Many cut staff or offered veteran employees “early retirement” plans to save money post-acquisition. Those employees remaining often received newly converged job titles as they picked up the slack (see, for example, Bark, 2016; Eck, 2017; Farhi, 2017).

\begin{tabular}{|l|l|l|l|}
\hline Station Owner & 2004 & 2014 & 2017 \\
\hline Sinclair & 62 & 150 & 193 \\
\hline Gray & 28 & 58 & 85 \\
\hline Nexstar & 42 & 82 & 171 \\
\hline TEGNA & 21 & 46 & 46 \\
\hline Tribune & 26 & 42 & 42 \\
\hline Total & 179 & 378 & 517 \\
\hline
\end{tabular}

Table 1. The largest local television owners nationwide (Matsa, 2017a; tribunemedia.com; sbgi.net).

As a result of this ever-increasing corporate conglomeration, news for enlightenment in the public's interest is taking a backseat to news for profit. Promoting goods or services offered by a station's parent company or network, a practice called plugola, takes up time in television newscasts across the United States that should be 
News Work 6

used to cover more pressing community issues. Similarly, product placement is a regular part of local morning newscasts, with conspicuous branded cups of coffee on set as a way to bring in extra advertising dollars. Video news releases are essentially public relations materials repurposed as news footage, and often not flagged as promotional in nature (Broaddus, Harmon, \& Mounts, 2011; Clifford, 2008; Higgins \& Sussman, 2007; McAllister, 2002). By filling time with such content, less original reporting time by a paid crew is needed, and the station, its parent company, and its stockholders reap the financial benefits.

It is within this framework that this project develops. In the United States, local broadcasters are bound by their federally-provided licenses to serve in the "public interest, convenience, and necessity” of their audiences (U.S. Congress, 1934). Often known as the "public trustee" model, broadcast stations are to be run as if by the public: It is as if people of a community should own a station and turn it over to the best man in sight with this injunction: 'Manage this station in our interest.' The standing of every station is determined by that conception. (The Federal Radio Commission, as quoted in: "The Public Interest Standard in Television Broadcasting,” n.d.)

Yet these "local" stations are largely owned by national or transnational corporate conglomerates, whose main function is to create profit for owners and stockholders (Croteau \& Hoynes, 2006). What is profitable is not always most beneficial to audiences (see, for example, Entman, 1989; Pickard, 2014). Therefore, these profit functions are 
often at odds with those of the public interest, in spite of the efforts of those newsroom workers trying to serve local information needs.

As these television newsroom workers provide the product for the audience, it is their work conditions that form the basis of this study. What is the place of local television news workers within the given political economic structure of U.S. media? Labor issues such as job security, control over work conditions, salaries, job precarity, and how industry changes a news product, and the consequences for the community are rarely addressed in the literature (Mosco, 2009b; Örnebring, 2010). Such conditions affect not only how people work, but also how they assimilate into their communities (Storper \& Walker, 1983). As journalists rely on community members for tips and as information sources, not putting down roots can affect not only the workers themselves, but also their contributions to their audience.

Ideally, newsrooms act as purveyors of information for the benefit of the public sphere, functioning as springboards for public debate and discussion on communitydefining issues, and acting as watchdogs over those with power in the community to hold them publicly accountable for their actions. But within an increasingly monopolistic broadcast economic system, the relationships between local stations and their workers have changed. Subsequently, the relationship between the news stations and the publics they are bound to serve have become more profit-motivated at the expense of citizen interests. 
News Work 8

\section{A Changing Media Environment}

The Radio Act of 1927 established commercial media policy to ensure various communities were effectively covered within a broadcast zone through "fair, efficient, and equitable radio service” (Radio Act of 1927, section 9, as quoted in Napoli, 2001, p. 203). The Communications Act of 1934 expanded these protections to television, and established "the public interest, convenience, and necessity" (section 309a) as the standard for broadcast licensees to follow. Since that time, there have been numerous attempts to clarify what the "public interest" might mean, which will be outlined in more detail in Chapter 3. But the public interest standard has been upheld throughout, including in the Telecommunications Act of 1996, the first major overhaul of U.S. federal communications regulations since 1934. Therefore, the public interest standard remains the pillar around which broadcasters must operate.

The passage of the Telecommunications Act of 1996 signaled the opening of communications businesses to the marketplace. Congress loosened the restrictions on the total number of stations a company could control, setting up a subsequent era of corporate super groups buying up as many stations as they could purchase, and exploiting various loopholes to grow their holdings as large as possible. This includes expansion via “sidecar” agreements, in which one owner has nearly total control of numerous properties while keeping the license legally in another’s name (Hagey, 2013; Malone, 2013).

To keep profits up, these corporate conglomerates buffer their coffers through economic downturns by downsizing employees while simultaneously increasing local broadcast output to collect more advertising dollars. During the Great Recession in 2008, 
News Work 9

1,200 people lost their local television news jobs while their newsrooms increased their programming to then-record levels. Simultaneously, ownership companies cut the salaries of those workers who remained (Papper, 2009). When the economy stabilized, the corporate owners began rapidly accumulating stations. In 2013, a record 290 stations changed hands at a cost of $\$ 8.8$ billion (Papper, 2009; Potter \& Matsa, 2014b). Staffing and salaries, however, were inconsistent for most of the decade following the recession (Papper, 2008-2017a, 2008-2017b).

Technological advances have also made it easier for station owners to replace living labor with computerized automation and consolidated job descriptions. In the realm of television news, this means newscasts are put on the air by one "operator," eliminating workers who run cameras, video, audio, and graphics. Field equipment is smaller and lighter, allowing one person the physical ability to do the jobs previously completed by two or three, eliminating the "need" for photographers and engineers. Mobile devices allow for continuous updating online in between local television live broadcasts, giving those gathering news out in the field another task to complete. Station programming is often controlled by operators hundreds or thousands of miles away, removing master control crews at the local level (Higgins-Dobney \& Sussman, 2013).

In 2017, the FCC eliminated decades-old ownership rules that originally had been put in place to prevent the monopolization of the airwaves by one set of ideas (Johnson, 2017a). By implementing the relaxation of duopoly rules (dual-station ownership within a market), cross-ownership (radio-television-newspaper) rules, and potentially allowing two of the four largest networks in a market to combine, the number of independent news 
voices is set to shrink, many journalists will be out of jobs, and audiences will face the consequences of fewer information choices for their communities.

This ongoing contraction of the ownership of television news squeezes laborers out of the market and pressures those that remain to do more work with earlier deadlines and multiple platforms, including web and television, to cover. The computerization of news work can be seen as a profound shift from highly specialized craft talent to simple labor. Many of the automated computer production systems used in news control rooms are sold based on their abilities to lower the technical skill level operators require to put news on the air (see, for example, Grass Valley, n.d.; Ross Video, n.d.). Braverman (1974) describes similar labor processes as ways to deskill workers, taking away the craft

of their work, while empowering their capitalist bosses, who reap the financial benefits of their labor. The loss of autonomy and control is a loss of professionalism, as the craftwork becomes part of a flexible yet routinized process to extract more work from an employee for little to no professional gain (Deuze \& Fortunati, 2011).

This has the potential of not only diminishing the worker, but also short-changing the audience which relies on these news workers to provide the information they need to make informed judgements and decisions about their lives in their communities. More consolidation means fewer news station workers to keep the "local” in local television news.

\section{Rationale for the Study}

Local television newscasts in the United States remain the most utilized source of community information, both on a daily basis and during times of crisis. Ninety-six 
percent of U.S. homes have a television set that can receive over-the-air, cable, satellite, or broadband connection (Lynch, 2016; Mitchell, Gottfried, et al., 2016). This makes local television news potentially critical to the safety and knowledge of millions of Americans each day.

As the following chapters will further illustrate, the business aspects of media ownership impose substantial constraints on the resources available for newsgathering. As fewer owners add more properties to their portfolios, they look for ways to increase their profits while reducing expenditures. This is done through a combination of methods, including newsroom technology upgrades and staffing downsizings. As corporate capital aims to capture as much surplus value from its employees as possible, remaining newsroom employees do more work, both for broadcast and digital platforms.

Media workers face deskilling, downsizing, and loss of local focus as corporate consolidation swallows up media companies, merges work forces into hubs outside of the community, and substitutes living labor with computer-driven “dead” labor (Marx, 1887). Such conditions strip the craft skills of news workers as corporate owners demand fast, cheap, predictable output to increase capital accumulation. To meet these goals, station managers bring in technology to replace specialist journalism skills with homogenous labor procedures requiring little training. This labor process, as described by Braverman (1974), disempowers newsroom workers while increasing the power of the ownership corporation.

There is a dearth of literature that examines the people who are experiencing this labor process while putting local television news on the air. Few studies, if any, look for 
News Work 12

an overall picture of the impact of the political economy of the local television news business, from newsroom routines, to how these dynamics have changed over the careers of seasoned newsroom workers, to how this is potentially affecting the final news product broadcast to community audiences. Because Americans rely on these newscasts for information, it is critical that audiences receive what they need to know to actively participate in community and society.

This is not to say ideas of corporate ownership impacts on mass media work have been ignored in the literature; researchers so far have generally focused on specific labor sectors of the television news industry. For example, job consolidation in news work has been a focus in a number of studies. The installation and implementation of new technology by station owners often coincides with skill convergences. In a study examining the impact of technology on multi-tasking and multi-skilling in newsrooms, Saltzis and Dickinson (2008) determine that while new technology itself might perform faster, workers tasked with completing multiple assignments using the technology do not, and generally cannot, work as quickly. Additionally, increased workloads mean less time for analysis of filed stories. Journalists are concerned about effects of an “obsession” with speedy journalism and the push to be first with new information. Smith, Tanner, and Duhé (2007) also find that many of those providing additional content for web, radio, print, or a second television station feel the added work interferes with the quality of their main television job. The more time they dedicate to secondary media duties, the more likely they are to express such concerns. These studies raise questions about the 
News Work 13

information journalists are providing to audiences to perform their duties as citizens and community members.

The extent of these convergence trends is outlined in Bob Papper's annual reports on local television newsroom employment. Most significantly for this study of television news labor is the steadily increasing use of multi-media journalists (MMJs) in tv newsrooms across the country, putting the craft skills of individual reporters, photographers, and editors in jeopardy. Not without notice is the also steadily-growing pay gap associated with these convergent job descriptions compared to the formerly specialist reporter job, which averages \$12,000 higher pay annually (Papper, 2017d).

In addition to convergence are studies about the precariousness of newsroom labor. Ryan (2009a, 2009b) tracked down freelance television journalists at both the network and local levels. These non-permanent workers report somewhat higher satisfaction about their pay and autonomy of story choice compared to their more stablyemployed news counterparts. However, the permanent staffers indicate significantly greater satisfaction with their steady employment status. This is in fact the highest average satisfaction rate for any job category in Ryan's studies, indicating that steady employment is an important job characteristic for many workers, and one Kalleberg (2011) classifies as desirable for a "good” job. However, there are concerns that such stable employment is becoming more difficult in some sectors to secure. McKercher (2014) notes the increasingly piecemeal, sped-up labor process many freelancers experience, and the lack of ownership they have over their final product. 
News Work 14

These snapshots still miss the experiences of a large swath of newsroom personnel. Behind-the-scenes workers, such as photojournalists and newscast directors, video editors and digital content producers, are often left out of the mix. These workers have as much influence on the final news product outcome as more high-profile reporters, anchors, and producers. Higgins-Dobney and Sussman (2013) began addressing this gap through a case study of the top-25 media market of Portland, Oregon, finding newsroom workers are struggling with job consolidation, shorter story turnaround times, and added expectations for multiple-platform (i.e., web and mobile) output. This project wishes to expand beyond that case, to see if these experiences hold true in other larger-sized urban television markets around the country.

Given the profit-seeking nature of the business, a political economy framework can put these issues into the context of ownership and commercial impacts on what is supposed to be the public service nature of local television. Newsrooms hold the key to the information citizens need to know for civic and community involvement. This study allows those in the heart of the newsgathering process to address the pros and cons of changes they have encountered over their careers, and the impact of these outcomes on what is presented to an audience as "news.” This will promote greater understanding of how the media labor process and ownership and regulation circumstances potentially affect the community at large.

\section{Research Questions}

The central question guiding this research study is: How does the political economic structure of corporate-owned newsrooms affect how local television news 
workers do their jobs providing information to the community? The next two chapters will address more formally and thoroughly the theory and regulatory state of the business leading to this question. To help answer this overarching question, the following subquestions will be addressed:

Q1: How does changing ownership and station consolidation affect how newsroom workers are able to do their jobs?

Q2: How do budget pressures and commercial pressures affect how newsroom workers do their jobs?

The FCC has been loosening ownership regulations steadily for over three decades, leading to fewer corporate, non-local owners running more and more newsrooms across the country. Based on previous studies, the impact of such consolidation appears to lead to heavier workloads and fewer staffers in an effort to boost company profits and stock prices. These questions address how newsroom staff adjust their work flow and productivity to accommodate these and similar workplace demands. In turn, this will provide insight into a potential impact on newsroom output and what information the station's audience receives or does not receive.

Q3: What impact does the implementation of changing technology have on newsroom workflow?

Rapidly-changing technology is deployed by station owners in newsrooms to facilitate efficiency in news gathering and dissemination. Additionally, station mobile applications and online content spaces, such as web sites and social media portals, mean more platforms for news workers to fill with content. This question examines whether the 
implementation of various kinds of technology has made local television newsroom work easier, more difficult, or simply just provides a different means to getting information to the audience without negative consequences for newsroom workers or the quality of news production.

It also questions whether workload expectations evolve along with the technology. Does the use of technology make newsgathering easier for the employee? Or does it make exploitation of the employee easier for the news station owner, with unreasonable expectations of how much can get done in a shift? Again, these questions will provide insight not only into the mindset of the worker, but also the potential impact on the information provided to the audience.

Q4: What is the role of job stability in how newsroom personnel do their jobs?

Newsroom personnel are supposed to have their finger on the pulse of important events happening in their communities and provide that information to their audiences. Yet job precariousness can be a hindrance to journalists, or any workers, setting down deep roots in their communities, and for building a long-term professional reputation in their market. This question seeks an understanding of the role of stable employment in how news workers go about their business and lives in the community.

Q5: What other conditions impact how newsroom workers perform their jobs?

This final question opens other areas of concern to local television newsroom workers in terms of perceived effects on their jobs or how they report to the community. Together, these areas will provide a broad overview of the state of news work in large-market local television stations in the United States. The experiences as shared by 
workers can also provide a "deep dive” into some of the more pressing issues affecting workers and subsequently the audiences that rely on the information they are providing. As the Hurricane Harveys and Irmas wash ashore, and as citizens head to the polls and out into their communities, local television news plays a key role in the success of informed community and democracy in America. Through this study, news workers both in front of and behind the camera are able to share whether they have the time and resources available to properly address their responsibilities.

\section{Organization of the Rest of the Study}

The next chapter, chapter 2, provides an overview of the theoretical underpinnings of this study. The role of local television news in the community is put into context. Communities are where the social aspects of life convene and various forms of capital, from human to social to economic, accumulate. Journalism plays a key role in informing community members of issues, allowing them to participate more fully in society and democracy. But the underlying political economic features of the local television business affect what gets put to air. This includes labor market structures that have moved from relatively stable job markets to the more precarious situations many newsroom workers now find themselves in. Such structures potentially affect how workers go about their jobs, and what skills they are gaining and losing in the process.

Chapter 3 shows how these theories play out in reality in the U.S. local television news industry. It explores the background of local television station ownership regulation, from the progressive 1940s to the deregulatory policy initiatives ruling the market in the late 2010s. The narrative over the years highlights the changing ways 
News Work 18

broadcasters adhere to their commitment to serving in the public interest. It also demonstrates how loosening and sometimes eliminating business rules and allowing the exploitation of loopholes affects the business, and subsequently journalism for the community, as a whole.

Chapter 4 explains the methods used to gather data for this study. A two-part qualitative endeavor using surveys and in-depth interviews collects the stories and experiences of newsroom personnel in many of the United States' largest local television news markets. This effort begins to define how the political economic structure of local tv station ownership affects newsgathering and dissemination to communities.

Marketplace effects on news workers and their content output is the focus of Chapter 5. Input from study participants largely support Herman and Chomsky’s (2002) propaganda model, starkly depicting the importance of business sway over public enlightenment. News content is the focus of discussion here, highlighting issues of story selection criteria, newscast promotional opportunities, and information source appeasement. The chapter stresses the importance for newsrooms of keeping profitability and ease of resource access at the forefront of local broadcast journalism.

Chapter 6 looks at how the implementation of new technologies in a newsroom affects its workers. While the digital realm has made access to certain information much easier to gather for journalists, web and social media expectations have been added to their already-full broadcast plates. This leads to cutting corners to get all necessary duties completed by deadline. Similarly, equipment is lighter and more portable, but often comes at the expense of craft skill and downsized colleagues, again, adding more work 
through job description expansion to the agenda of those remaining after layoffs and “early retirements.” The use of technology is therefore considered both a help and a hindrance by those gathering and distributing information to the public, but a win for those trying to cut costs from a newsroom budget.

The afore-mentioned job convergence is the focus of Chapter 7. To cut living labor costs, station owners have taken to reducing staff size to a minimum while consolidating the extra work load into new job descriptions and scheduling procedures for those who remain. Human labor is being treated similarly to any other production resource, employing just-in-time work schedules and little work-life balance. Many workers now carry the weight of multiple converged and compressed job descriptions, from solo journalists in the field who write, report, shoot, and edit their own video in addition to posting to social media and setting up their own live shots, to automated production directors who also run audio, graphics, video, and cameras, to producers who edit their own show video. These extra job duties split the attention of the workers performing them and can lead to mistakes and sloppiness on air.

Chapter 8 takes a big picture look of the findings in the context of practice and in theory. Is the local television news business really operating in the community's public interest? Or has market-driven journalism taken over to the detriment of the audience and the society at large? Limitations of this study are discussed, and future research directions are considered. 
News Work 20

The business of local television news is a rapidly changing one. Through studies, surveys and interviews, this report aims to get to the heart of its changes on those that keep communities informed through the most used medium in the United States. 
News Work 21

\section{Chapter 2: Theories of Community, Political Economy, and Labor Affecting Local Television News Production and Dissemination}

In 1934, the FCC established that local television stations in the United States are obligated to serve their designated community’s “public interest, convenience, and necessity” in order to receive and maintain a broadcast license (U.S. Congress, 1934). Yet the local television business is often criticized for running as a profit-seeking entity. This chapter examines the theoretical underpinnings tying together information as a community need for promoting civic engagement and a fully functioning citizenry, the labor conditions found in the local television newsrooms serving these communities, and the corporate influences that affect how newsroom workers inform their audiences.

This theoretical framework will set up the main question guiding this project: How does the political economic structure of corporate-owned newsrooms affect how local television news workers do their jobs providing information to the community?

\section{The Role of Place in Community}

Local television broadcast licenses are distributed within “designated market areas,” the 210 geographical locations around the United States served by local stations (Nielsen, n.d.-a). Ali (2017, p. 7) defines media localism as "the belief that broadcasters should be responsive to the local, geographic communities to which they are licensed.” This is usually done through local news, public affairs programming, and engaging with the local community. The thousands of residents affected by Hurricanes Harvey and Irma relied on their local stations to provide factual and relevant information to keep them safe 
News Work 22

during the storms. Physical location therefore plays a key role in a station's relationship to its audience.

Communities come in many forms, some of them place-based with others more liberated from spatial limitations. The discussion here will focus mainly on those bound by place, much like current local television broadcast areas. Geographical areas provide platforms for the social goods necessary for successful community life. Public safety, volunteer associations, norms of trust and civility, and the socialization of the next generation all fall into this category. The spatial availability of social and economic resources varies based on physical location; therefore, to best understand a community and subsequently strengthen its foundation, it is essential to determine the underlying causes of these differences in the production, distribution and consumption of resources within capitalism (Mosco, 2009b; Murdock \& Golding, 1973, 2016; Sampson, 2012; Squires \& Kubrin, 2012; Wasko, 2014).

Harvey (2003), for instance, argues society is dominated by the accumulation of capital through market exchange. Those who cannot afford ownership must sell their labor power for survival in that community. Rights to private property override other rights when living under capitalism. Market forces allow those with capital to grow richer while those without grow poorer. Access to housing, education, health care, convenience shopping, and other activities keep the cycle of market transactions turning in favor of the accumulation of capital. Population reproduction within communities replenishes the labor force, thereby keeping capitalism alive (DeFilippis \& Saegert, 2012). 
While economic capital, which converts directly into money, dominates in capitalism, Bourdieu (1986) argues all forms of capital need to be considered to truly understand the functioning of society. Human capital, often embodied via education, is also a valuable measure for economic success in a city. Berry and Glaeser (2005) note that increased innovation follows increased education in an area, since educated business owners are more likely to hire more educated workers. Such workers embody the skills and capabilities needed to make the company financially successful (Coleman, 1988).

Both economic and human capital have roles in social capital. The value of social capital is in the size of the network that can be mobilized and the volume of capital each member possesses to help communal development. Social participation has been argued to strengthen community, providing valuable services such as volunteering, and improving social ties (Putnam, 2000), although some debate that notion. ${ }^{1}$

Advocates of social capital believe network connections build strong, functioning communities that work together through collective decision making, problem solving, mutual support, information sharing, and the creation and exchange of value (Saegert, 2012; Traynor, 2012). Therefore, strong member involvement is essential for strong communities. These are characteristics reminiscent of the idealized notion of gemeinschaft, where people "remain essentially united in spite of all separating factors”

\footnotetext{
${ }^{1}$ Scholars such as Florida (2002) believe strong social ties actually lead to complacency and insulation from outside influences, thereby crushing creative innovation. But studies find focusing on younger, more creative professionals as Florida advocates is more likely to lead to job loss, gentrification, and the departure of long-time residents and their networks from city centers, as was the case in Milwaukee, Wisconsin (Zimmerman, 2008). In contrast, Scranton, Pennsylvania revitalized its city center using the social capital connections of the town's organizations without driving residents away (Rich, 2013).
} 
News Work 24

(Tönnies, 1957 [1887], p. 65). Community can therefore be unified even in its diversity by working towards a common good (Sampson, 2012).

Active participation allows members to shape the future of their community (Adler \& Goggin, 2005, p. 241). Bhattacharyya (1995, 2004) argues that community and democracy both have solidarity and agency at their core; therefore, the ultimate goal of community development should be the promotion of these characteristics through empowerment and capacity building. Solidarity describes the common ties that bind people together, providing a context for shared culture. Deeply shared identities include common values, social controls, and codes of conduct. A degree of commitment, and often of history, is implicit (Bhattacharyya, 1995; Driskell \& Lyon, 2002; Sampson, 2012).

Defining community by using solidarity makes the term “community” universal. It is not bound by ethnicity, economy, religion, or other restrictive demands (Bhattacharyya, 1995, 2004). Solidarity, therefore, makes it possible to distinguish communities from all other forms of social relationships. If there is a shared identity and shared norms, the described group is a community. Friedland (2001) argues these communities form the backbone for deliberative democracy by providing networks for public discussion of issues and problems.

Agency is "the capacity of people to order their world...to create, reproduce, change, and live according to their own meaning systems” and the ability to define themselves (Bhattacharyya, 1995, p. 61). Self-help builds productivity in community, democracy, and society, and rejects dependence. Participation produces the collective 
News Work 25

meanings of the community, defines its problems and solutions, and decides the agenda for debate and decision within the community. This empowers community members during the pursuit of mutually agreed-upon goals (Adler \& Goggin, 2005; Bhattacharyya, 1995, 2004).

Instead of being “needs-driven,” and making communities rely on outside services to "fix" their problems, empowered citizens build on the assets they already have. Kretzmann and McKnight (1993) argue community development happens more readily when residents are committed to investing themselves and their resources in work. Collective action improves the quality of life in a community and strengthens connections among community organizations. Understanding of the political economy of the community, its distribution of resources, and its sociopolitical frameworks is critical to successful community empowerment (Perkins \& Zimmerman, 1995). As local television stations are supposed to broadcast in the "public interest, convenience, and necessity" of their area of license, supplying information to improve community understanding goes a long way towards helping its development and building.

Because ninety-six percent of homes in the United States have television sets, it is relatively easy to find a local newscast when needed (Lynch, 2016). This is particularly important for vulnerable populations that may not have other information sources easily at their disposal. As Klinenberg (2003) notes in Heat Wave, while many of the homebound, poor, and elderly residents suffering through the Chicago summer of 1995 could not afford to turn on air conditioners, many still ran their television sets for 
News Work 26

information, noise, and lighting. This was also the case during Hurricanes Irma and Harvey.

The role of journalism. Journalism has multiple important functions in community and democracy. Kovach and Rosenstiel (2001, pp. 17-18) argue the "primary purpose of journalism is to provide citizens with the information they need to be free and self-governing,” an argument Schudson (2008) also makes. Educating the audience comes in many forms, including through the investigation of powerful sources as the fourth estate. This oversight is supposed to keep those with power and influence in check and hold them accountable to their constituents. News media are also supposed to provide analyses of complicated events in a comprehensive manner, again educating the audience. These more time- and resource-consuming journalism functions are often lost in the money-saving labor shuffle of neoliberal newsrooms, issues that will be discussed further in the next section and throughout this study.

For Schudson (2008), journalism can also relay social empathy and mobilize audiences through cause and information. This includes advocacy for particular programs or perspectives, although mainstream commercial news media tend to feel the need to follow "objective" journalism, which precludes any notion of participating in events that might indicate bias (Bennett, 2012). This is an area often covered more by "alternative” media sources, discussed below.

Finally, journalism should also provide a public forum for dialogue among citizens and carefully cover institutions and relationships that are currently taken for granted, particularly when it comes to governmental checks and balances (Schudson, 
2008), echoing Habermas’ (1979, 1991) envisioned public sphere. The ideal public sphere is meant to be a social space allowing citizens to debate public community- and democracy-impacting issues without private interest oversight. Such discussions encourage citizens to freely form public opinion while highlighting problems that need to be solved for citizen empowerment and the public good. Media outlets make these discussions possible by circulating information and were originally considered by Habermas to be the pubic sphere's preeminent institutions. The ensuing citizen debate promotes freedom of expression, strengthens government accountability, and provides an outlet for political expression (Friedland, 2001; Norris, 2006).

Such functions inform and empower communities in a democratic society. Anderson, Dardenne, and Killenberg (1994, p. xx) believe the institution of journalism needs to "stimulate public dialogue on issues of common concern to a democratic public,” and supply a forum for “ongoing argument.” The United Nations Educational, Scientific and Cultural Organization (UNESCO, 2014) concurs, adding journalism “provides a platform for discussion across a range of issue pertaining to development” including science, poverty, and participation.

While this is an idealized notion of journalism and the public sphere, Kellner (2000) notes that Habermas' discussion is about the transformation of the public sphere. No longer dominated by public discussion and opinion formation, the public sphere has succumbed to mass cultural consumption dominated by market capitalism. Therefore, instead of focusing on rational debate, public discourse is now what is acceptable to media corporations for commercial consumption. Habermas (1979, p. 200) himself stated 
News Work 28

commercial interests "received special prominence" in the hands of the media to such ends.

Kellner (1990) applies this to broadcast media, arguing that U.S. television stations are growing in power and influence in society instead of serving the public's interest. This reduces their usefulness in building community and democracy. For Kellner, Habermas' focus is more about the transmission of messages to a public instead of a medium's role in democratic governance. By definition, most “mass” media are expected to disseminate information over a large area, a method Carey (1988) calls the "transmission” view. Wider transmission leads to wider control of message and audience. Indeed, the entire system of successful broadcasting is measured by how many people are watching a program and, more importantly, its advertisements, at any given moment, in what are known as "ratings.” Ratings measure not only how many overall people a message has reached, but also how many of a specifically-targeted ad demographic have witnessed a plea to purchase a consumer item. As per ratings company Nielsen (n.d.-b): "Knowing how and when to reach prospective consumers is the Holy Grail of audience measurement and helps media companies and brands make the right planning and programming decisions.”

To follow more in the spirit of the public sphere ideal, messages should use a "ritual" view. Information shared this way is for "participation, association, fellowship, and the possession of common faith” (Carey, 1988, p. 18). These messages draw people together in commonality, and not necessarily consumerism. The transmission and ritual views are not mutually exclusive; communication taken through both provides the basis 
News Work 29

for human fellowship and community. Yet much study about communication, particularly news, operates at a "transmission view" level. Alternative (non-commercial, nonmainstream) media might be the exception.

These "alternative” news media foster the processes of community. They make audiences aware of the spaces, institutions, resources, events, and ideas for sharing, and then facilitate that sharing process to make sense of community (Lowrey, Brozana, \& Mackay, 2008). These media are generally not the more well-known commercial media outlets, which are often affiliated with broadcast networks and traded on the stock exchange. Instead, Jankowski (2003) describes the founders of these alternative stations as passionate about their subject matter, and trying to connect with like-minded individuals. Many have a broad agenda, seeking community-relevant information, participation, and empowerment produced exclusively by community members.

Because most of these forums run outside of a corporate business model, they allow more critically-framed reports and reflections without fear of commercial retaliation. Many are run by the people for the people, giving community members firsthand experience in news and information distribution. They allow participation by those who might be shut out by other, more traditional, media forums (Armstrong, 1981). For example, citizen journalists who do not believe that mainstream journalism is doing its job encourage users to "post, comment, debate and argue" over information and add their own stories to the mix (Ryfe \& Mensing, 2010, p. 37). Small niche nonprofit news organizations focus on reports ranging from environmental matters to health features to government profiles to arts and culture (Mitchell, Jurkowitz, Holcomb, Enda, 
News Work 30

\& Anderson, 2013). Some fill the gap in longer-form, in-depth, investigative reports that many traditional news media no longer provide (Guensburg, 2008), bringing the role of watchdog of the powerful back to the community.

In the 1990s, the "public journalism" movement partnered professional (usually commercial-based) journalists with regular citizens to create a news agenda. Much like the public sphere model, those in public journalism believed that the dissemination of information is only the first step in the process; public deliberation of an event and its circumstances is also a necessary component for successful citizen engagement and empowerment. Professional newspaper and local television news organizations held town hall meetings and citizen forums to engage community members in the topics they identified as most important to their communities. The nature of the commercial journalism business, however, meant that cost-limiting measures, along with the spread of the internet, quickly doomed the public journalism movement (Forde, 2011; Merritt, 2010; Rosenberry \& St. John III, 2010; Sirianni \& Friedland, 2001).

But these movements illustrate that it is possible for mass media to move beyond the private corporate structure of mainstream commercial entities and bring information back to the community. It is rare, however, for an alternative news outlet to have the resources to compete with mainstream commercial stations. Even the Public Broadcasting Service (PBS) relies on corporate underwriting to keep up with its commercial counterparts. PBS also uses product tie-ins for many of its shows, particularly its children's programming. In the 1990s, it began using tactics similar to commercial media. PBS has since teamed up with commercial television companies to 
News Work 31

produce programming, and no longer markets itself as an alternative to commercial media offerings, but as a competitor (Hoynes, 2003).

Broadcasting for profit puts non-commercial media at a competitive disadvantage as widespread information sources. Budgetary considerations often derail alternative media enterprises, which do not have the steady advertising income commercial media enjoy (Armstrong, 1981; Mitchell et al., 2013). These outlets are often marginalized and have smaller audiences, making it more difficult to share alternative viewpoints with the mainstream (C. Ryan, 1991). But these less commercialized sources are often strictly focused on the needs of their communities, even if that might not be the most financially viable model (Jankowski, 2003).

\section{The Political Economy of the Mainstream Mass Media}

In contrast to community-oriented alternative media, commercial mainstream mass media often have profit motives underlying many of their journalism coverage and dissemination decisions. Murdock and Golding (1973, pp. 205-206) describe the mass media as "first and foremost industrial and commercial organizations which produce and distribute commodities,” linked through investments and advertising. These media are therefore intricately tied to the rest of the economy. Mosco (2009b) identifies three main characteristics of the political economy of communication: commodification, spatialization, and structuration.

Commodification. Commodification transforms products valued for use into things valued for rate of exchange. They are produced for the market by waged labor; their value, therefore, is tied to the human labor needed to create the objects (Marx, 
News Work 32

1887). In a communication context, this is how content, labor, and audiences are made marketable: courting advertising dollars and boosting ownership stock values.

The prevalence of mass media in today's society combined with its emphasis on profit-making and commodification have turned advertisements into "the official art of modern capitalist society” (Williams, 2009, p. 730). Advertisers hold the success of media outlets in their control. They pay for the programming by subsidizing the industry. Media outlets have to compete for business by providing not only the largest audiences, but also the correct audiences: those demographics with the means to buy the advertised products. This is part of the commodification process.

“Mainstream” programming, including newscasts, thus becomes more homogenized, as outlets compete for the largest viewership of similar demographics with similar programming. More radical or alternative programming becomes more marginalized through lack of funding, as advertisers seek out more capital-friendly outlets. Built-in promotional opportunities, such as product placement on news and entertainment sets, are exploited by corporate owners, adding to the commercialized nature of mass media and culture, a major part of Herman and Chomsky’s propaganda model, which will be explored more in chapter 5 (Herman \& Chomsky, 2002; McAllister, 2002; Mosco, 2009b; H. I. Schiller, 1989).

Many of the characteristics of journalism for community and democracy outlined in the previous section are lost to commodification. For instance, assuming a watchdog role over the powerful indicates a need for investigation and reporters with specialized knowledge of "the text behind the text, the story behind the story" (Schudson, 2008, p. 
News Work 33

15). “Beat” and investigative reporters often assume this role. These journalists are experts in a subject area and produce original investigative stories containing information based on relationships with sources years in the making. But this takes time and resources many station owners are not willing to provide (Waldman, 2011). In 2013, sports, weather, and traffic made up $40 \%$ of news time during local newscasts (Project for Excellence in Journalism, 2013). Case studies of local television news in Denver, a top25 market, showed $45 \%$ of stories not pertaining to weather, traffic, or sports were 30 seconds or shorter in length, a time frame that makes it nearly impossible to cover a subject in any depth (Pew Research Center: Journalism and Media Staff, 2015).

This opens questions about the media's role keeping an eye on the three branches of government, protecting the public from misinformation, government incompetence, and corruption, and ensuring elected officials are serving in the public's best interest (Bennett et al., 2007). Complex stories also become decontextualized, as quick and easyto-gather superficial stories take precedence over those exploring a bigger picture for the community and constituency (Bennett, 2012). These chunks of news are then surrounded by unrelated stories and commercials, further diffusing the importance of any individual story.

Studies indicate that audiences prefer stories that demonstrate journalistic enterprise and in-depth investigations. This preference translates into bigger audiences, higher ratings, and therefore higher ad revenues (as ad rates are based on ratings) for the media outlets involved (Belt \& Just, 2008). For media entities trying to balance a fiscally 
News Work 34

rewarding outcome while living up to public interest expectations, this would seem to be a win-win for both audience and station owner.

Spatialization. Information technologies overcome the constraints of geographic space and time, prompting the globalization and corporatization of media and communication industries. This is the embodiment of spatialization. Murdock and Golding (1973) identify strategies of integration, diversification, and internationalization used by large corporations as methods to increase their concentration, control, and market share of the business.

During horizontal integration, firms acquire additional units of the same level of production, such as purchasing more local television stations for a portfolio. Vertical integration aims to acquire various levels of production and distribution and can be seen in companies that own the rights to produce, syndicate, and distribute various types of media. Diversification goes beyond acquisitions to obtain "leisure and informationproviding facilities,” including restaurants and theme parks (Murdock \& Golding, 1973, p. 219). Diversification cushions company profits in times of recession, when the economic value of some holdings may plummet. Internationalization takes holdings beyond their home country, including exported film, print, and television offerings to bring in revenues from overseas.

Corporations with media holdings around the globe illustrate these points. Since the early 1980s, the number of global mega media owners with capital power has dwindled from over 50 to 6 (Lutz, 2012). In the United States, the enactment of the Telecommunications Act of 1996 prompted previously entertainment-oriented companies 
to take advantage of lax ownership rules to buy up newsrooms and increase their audience share across the country. The elimination of the Financial Interest and Syndication, or “Fin-Syn,” rules in 1995 allowed for all levels of production, programming, and distribution to be under the control of one broadcast owner.

Now, international media powerhouses, such as Viacom, Walt Disney, and Comcast, own not only the means to produce, distribute, and syndicate, but also control a wide range of media products, from television shows to film production companies to merchandizing rights, both in the U.S. and abroad. This vertical integration and diversification of media types decreases competition and consequently the diversity of programming and information available, while minimizing the loss risk to the ownership corporation (Mosco, 2009b; Murdock \& Golding, 1973; H. I. Schiller, 1989, 1992). Holdings of low profitability disappear, resulting in standardized content and restricted media options. This includes news: "Most generally news must be entertainment; it is, like all media output, a commodity, and to survive in the market-place must be vociferously inoffensive in the desperate search for large audiences attractive to advertisers” (Murdock \& Golding, 1973, p. 230).

For "local" media entities, owners run fewer stations physically on-site as conglomeration and agglomeration increase holdings. Instead, a centralized "hub" is built in a more geographically-desirable, and often incentive-laden, area. Advances in transportation and communication have made these endeavors not only possible, but attractive to parent companies from a fiscal standpoint (Mosco, 2009b), removing a piece of the local from community broadcasting. 
News Work 36

Structuration. Structuration creates social relations sorted by social class, gender, and race. Those with power are able to manipulate capital-enhancing opportunities in their favor (Mosco, 2009b). For instance, in the United States, corporate speech is protected under the First Amendment. In 2010, the U.S. Supreme Court ruled in Citizens United v. FEC that corporations have the right to spend as much money as they want to support or oppose a political candidate (U.S. Supreme Court, 2010). Unlimited election-related contributions are allowed to "independent-expenditure only" groups not associated with specific campaigns, better known as Super PACs (Federal Election Commission, 2010).

The outcome is that while most ordinary citizens cannot afford broadcast time to support or decry an issue or candidate during election season, corporate interests have the ability to buy extensive air time, and potentially air false and misleading ads during that time (Nichols \& McChesney, 2013). This is censorship is via private, concentrated control of the media, and highlights the discrepancy in power between the capital holder and everyone else. Those without power find their views and interests underrepresented in mainstream media. Women and racial and ethnic minorities often fall into this category (Mosco, 2009b; C. Ryan, 1991; H. I. Schiller, 1989).

These characteristics are embedded in most mass media entities. Even those that define themselves as "local" are otherwise entrenched in a larger, often corporate, environment. Local television broadcast stations primarily broadcast network programming; even local newscasts repackage national stories with a local angle. Most 
News Work 37

local formats are modeled after national or network versions. Friedland (2001) argues this makes much of the local media experience not very local at all.

\section{Labor}

This study focuses on the labor aspects of working in commercial local television newsrooms in the United States and how this affects both newsroom workers and their journalistic output. Newsroom labor conditions are put into context within the larger picture of the political economy of the mass media. This context puts the pursuit of profits into sharp relief with the pursuit of public enlightenment, often at the labor expense of the newsroom workers involved.

Marx (1887) posited that maximization of profits is achieved through the labor of workers. Those who do not control the capital have no choice but to sell their labor to those who do. Profit comes from extracting as much surplus value from labor as possible, during both paid and unpaid labor time. In an information context, focusing on profits leads to a system that exploits its knowledge workers as well as its audiences, leaving them with little of useful non-commercial value in return. The commodity fetish draws the attention of the consumer to the finished product, while ignoring the social and economic conditions of exploitation that produced it (Garnham, 1990; Kellner, 1990; Marx, 1887; Mosco, 2009b).

Workers themselves are commodities that become cheaper as they produce more valuable commodities for sale. "The worker is related to the product of his labor as to an alien object” (Marx, 1959, p. 29, emphasis in the original). In capitalism, the objects produced do not belong to the worker, they belong to someone else. Additionally, the 
News Work 38

division of labor, which will be discussed in more detail below, takes much of the craft and pleasure out of work, depriving workers of fulfillment, all for the pursuit of profit. Limiting worker alienation through creative control plays a major role in worker happiness and the subsequent building of community and culture outside of the workplace. When workers have control over both the concept and production of a product, they have some discretion over their work and "real input" into decisions that affect them (Kalleberg, 2011, p. 7). The intrinsic rewards obtained from task performance allows workers to use their unique skill sets and abilities to do their jobs. Control over work pacing and scheduling can be similarly rewarding. Less-alienating working conditions have profound effects on how workers assimilate into their communities. While jobs with some sense of stability, autonomy, reasonable pay, and work/life balance help workers grow roots where they live, precarious jobs with low pay, no control, and no work/life flexibility prevent them from doing so (Kalleberg, 2011).

Labor process theory and the division of labor. Braverman's (1974) labor process theory explores methods of work under monopoly capitalism. Such work extracts as much surplus value from its sources of labor as it can. To achieve maximum profits, firms try to regulate and automate production process as much as possible. This effectively eliminates all vestiges of craft work, and results in the deskilling of workers as they lose control over their labor process to those in charge under the auspices of efficiency.

During craft work, workers control the tool. In automated or industrial production, technology is brought in to operate the tool. This separates the mental work from the 
News Work 39

physical, removing both elements from the craft of the job. A once-specialized skill set can be transformed into a singular repetitive piece of a working process, with different pieces distributed among multiple workers. The use of technology essentially reduces formerly craft-skill workers into lower-skilled, interchangeable laborers who need little training and can be paid a lower wage. This is often referred to as the division of labor (Braverman, 1974).

Such processes produce savings on wages, speed up production, and facilitate outcome predictability, allowing the capital holder to reap the benefits. The ultimate goal is to eliminate more expensive living labor in favor of the "dead labor" of machines that do not need sick days, health benefits, or days off. The technology speeds up the labor process and reduces labor costs through the reduction of externalities associated with human workers (Braverman, 1974; Marx, 1887; Örnebring, 2010).

This labor process can be seen in newsrooms today. Technology is implemented to increase the speed of journalistic output and has become a mainstay of competitive newsrooms. "Productivity" is equated with "more news faster" or "more news first" (Örnebring, 2010, p. 65). This need for speed has become naturalized in the workers and provides a template for how many understand the role of new technologies in a newsroom. At the same time, journalists are taking on more work previously done by others, but are often not being rewarded monetarily for their new skills (Örnebring, 2010).

Instead, journalists are expected to be "flexible laborers," able to meet the demands of the various media platforms a single newsroom outputs each day, covering 
News Work 40

everything from radio to television to print to the internet. Alternately, or often in conjunction with supplying content to more platforms, more previously-separate job descriptions are merged into one. Added work still occurs in the same amount of time the journalist used to have to report for one medium. Affected newsroom personnel are often expected to move content from one platform to another (for instance, television to web) without adequate training (Klinenberg, 2005; Tanner \& Smith, 2007). Journalists become disempowered as they watch their job descriptions change, their ranks shrink, and their ability to move elsewhere dwindle based on the continued conglomeration of media ownership (Gans, 2003).

Audience labor. Adding to paid staffing power, newsrooms also exploit labor from unpaid sources, including audience members. Audience labor comes in a variety of forms, from watching commercials to providing content. Former FCC economist Dallas Smythe (1994) argues that audience members themselves are treated as a commodity for sale to advertisers. All waking time is potentially appropriated as some form of work. The media teach workers to spend their income buying particular brands of goods during their leisure time, turning them into a consumer class for advertised commodities, thus making them instruments of advertisers. In exchange for their loyalty, these laborers are paid with programming. This all occurs while they are preparing for their next work day, breaking down the distinction between labor and leisure time.

Working from a different audience-as-labor angle, Jhally and Livant (1986) see programming as the "wage” audiences receive for watching commercials. Commercials mediate the production-consumption cycle by stimulating demand. In this model, 
capitalists pull value out of the audience without estranging it by providing programming, thereby maximizing surplus value watching time. Audiences are not working for the advertisers, per se, but instead for the programmers.

Audiences also provide direct free labor for media owners, particularly when it comes to website content, where anyone with an internet connection can post. While a site is populated by unpaid labor, any profit outcome of this work lands in the coffers of the media organizations (or, more specifically, their owners and stockholders) and not in those who performed the work. While such user-generated content has always been available via outlets such as letters to the editor, the extent of distribution to potential audiences today is greatly expanded via the internet (Napoli, 2010).

Napoli (2010) believes the gap between Smythe’s (1994) notion of audiences working for the advertisers and Jhally and Livant's (1986) that they work for the programmers is bridged in this online environment where audiences both produce and consume content. Websites such as YouTube and Facebook capitalize on advertising directed at those who publish on their pages. Comments generated on sites like Yelp and Amazon add value to those sites' content. Unpaid users provide this content while the commercial organizations benefit. Production for exchange is the definition of labor.

This project develops under this theoretical framework. The next chapter lays out how these theories are embodied in broadcast regulation in the United States. These regulations directly impact the state of the local television news business and its workers in communities across the country. The chapters following will outline the methods, 
News Work 42

findings, and discussions as newsroom staffers detail working under corporate profit expectations while attempting to keep their audiences informed. 
News Work 43

\section{Chapter 3: The State of the Local Television News Business in 2017, and How It Got to Be this Way}

The previous chapter detailed the theoretical importance of information in the community, and how the political economy of news work can impact the production of news. This chapter provides the regulatory background that prompted U.S. television station owners to apply concepts of commodification, spatialization, and structuration while growing their holdings. Together, these chapters provide the backdrop for the exploring how the political economic structures of local television news media affect newsroom workers, and subsequently, the information their audiences receive.

\section{Regulating in the Public Interest}

U.S. Congress and the Federal Communications Commission have passed and retracted guidelines over the years regulating how those with a license to broadcast over the public airwaves should behave. Regulations cover everything from how many media entities one company can own to how many minutes certain types of programming must be run by a station. Throughout the years, there has been one constant: having a license requires a local television station to broadcast in the public interest.

While never providing an explicit definition, the FCC has attempted to clarify what "the public interest” standard means on multiple occasions. For instance, monopoly ownership, which has been thought to stifle competition, is a recurring theme of regulating in the public interest. In 1940 and 1941, the FCC issued rulings that ultimately led to the divestiture of the Blue Network (now ABC Network) by the Red Network (now NBC), stating: "to the extent that the ownership and control of radio-broadcast stations 
falls into fewer and fewer hands, the free dissemination of ideas and information, upon which our democracy depends is threatened” (Federal Communications Commission, 1941). As will be discussed in the next section, however, attitudes governing concentrated ownership have dramatically changed over the course of the last 80 years.

The FCC targeted programming beginning in 1946 with its "Public Service Responsibility of Broadcast Licensees,” more widely known as the “Blue Book.” Arguably one of the most progressive regulatory steps in the history of the FCC, The Blue Book required certain public service standards for a broadcaster to maintain its license to operate on the public airwaves (Pickard, 2011). It also addressed marketplace media issues discussed throughout this paper, already showcased in the 1940s: increased commercialism, advertiser influence, sensationalistic programming, little minority representation, and media concentration. To combat these issues, stations were to concentrate on live, local program promotion and public affairs shows, air programming considered less commercially-viable, and remove “excess advertising” (Federal Communications Commission, 1946, p. 55). Not surprisingly, neither the industry nor Congress supported these demands, and they were eventually eliminated from legislation. Pickard (2011) argues that if such standards had been upheld, today’s mass media might look very different.

Around the same time, the Commission on Freedom of the Press, also known as the Hutchins Commission, similarly determined that while freedom of the press was essential to political liberty, the responsibilities that came along with this freedom were not being satisfied. Again, like the FCC in their Blue Book, the Hutchins Commission 
found too much concentration of media ownership, and news broadcast for profit instead of learning. To advocate for the public interest, media outlets needed to provide a truthful, comprehensive, and contextualized account of the day's events; be a forum for comment and criticism; host a representative image of society; clarify society's goals and values; and ensure the full access of news by all (Commission on Freedom of the Press, 1947).

In support of these goals, the FCC introduced the Fairness Doctrine in 1949 to "devote a reasonable percentage of broadcasting time to the discussion of public issues of interest in the community served by their stations," including opposing viewpoints (13 FCC 1246, as quoted in Pickard, 2015a, p. 116). Further strengthening public interest ideals, the FCC declared news and public affairs programming as key to meeting the needs of the community in 1960.

The FCC further tried to regulate the business of local television through the Financial and Syndication Rules (known as the fin-syn rules) in 1970. These rules prevented networks from owning prime time programming or running syndicated programming they had a financial interest in. The goal was to allow independent producers to flourish and keep the networks from monopolizing programming power. Instead, many believe it strengthened Hollywood studios instead of independent producers due to the production costs of innovative programming (Croteau \& Hoynes, 2006; McAllister, 2014). 
News Work 46

\section{Deregulating in the Business Interest}

In contrast to the 1940s, the 1980s ushered in an era of relaxed public interest regulation. By 1984, the FCC had eliminated license renewal requirements of 10 percent of airtime devoted to non-entertainment programming and 5 percent to public affairs. Stations were instead required to show "some" programming meeting community needs (Bishop \& Hakanen, 2002). By 1987, the Fairness Doctrine was also revoked (United States Court of Appeals, District of Columbia Circuit, 1989). While these moves left the public interest standard intact, they essentially eliminated any concrete guidelines for local television newsrooms and their owners to follow in how to meet that standard.

Deregulation continued into the 1990s. The Telecommunications Act of 1996 was considered the first major overhaul of federal telecommunications rules since 1934, and essentially opened the communications business in the United States to the free market by relaxing broadcast ownership requirements. The Act allowed, even encouraged, communications businesses to compete. When combined with the elimination of the Financial Interest and Syndication rules in 1995, the vertical integration possibilities of media corporations expanded immensely, permitting control of all levels of production, programming, and distribution under one broadcast owner, a structure never previously allowed. Additionally, the expansion of an owner's maximum allowed audience reach increased, up to $35 \%$ of the national audience from a previous limit of $25 \%$. This audience cap later expanded to 39\% in 2003, meaning a single corporate owner could reach a bigger, broader audience than ever before, yet still be compliant with standards of 
public interest (Bielby \& Moloney, 2008; Federal Communications Commission, 1996; R. Rice, 2008).

Multiple ownership rules also changed in favor of expanded corporate ownership in the 1990s. Prior to 1999, an owner could only run one television station in any local designated market area. Rules updated in 1999 and again in 2003 allowed ownership of two or even three stations within a market, depending on how many other television stations were broadcasting in the area (Federal Communications Commission, 1999, 2003a). By 2007, the FCC examined the 20 largest media markets case by case to determine if cross-ownership of daily newspapers, television, and radio stations by a single owner could be considered in the "public interest" (Federal Communications Commission, 2010).

In 2017, many of the remaining rules regulating local television broadcast production and ownership were rolled back by a politically-divided FCC. Broadcasters can own a print source in a news market of any size, and potentially two of the top four stations within a city. Radio and television stations are no longer required to have a studio in a local broadcast market. The FCC also restored the previously-eliminated UHF discount that only counts half of a station's actual reach for those positioned above channel 14. Combined, these structural changes set up the market for even greater local media ownership concentration, essentially delocalizing local stations and downsizing the local broadcast work force (Johnson, 2017a).

These moves coincided with the FCC's repeal of net neutrality, which can also impact local journalism. Small media companies do not have the financial backing and 
clout to compete with the bigger media players with resources to negotiate with internet service providers determining whose content receives favorable treatment (Ingram, 2017). As of early 2018, the inspector general was looking into potential coordination between FCC chair Ajit Pai and Sinclair Broadcast Group regarding many of these changes, which work in favor of a major business deal involving the merger of Sinclair and Tribune Broadcasting Company, which will be discussed more later in this chapter (Kang, 2018).

Competition + diversity + localism = public interest? In 2003, “competition,” “diversity,” and “localism” joined “public interest” in defining acceptable broadcast licensee parameters. While these additions were meant to clarify the public interest standard, there have been numerous ways to define each of these, and many suggestions as to how they should be incorporated into media policy. In spite of these additions, business interests often still take priority over the public’s interest and may have even been bolstered by them.

Competition. Congress drafted much of the ownership deregulation outlined above with "competition” in mind. Bipartisan approval of the Telecommunications Act of 1996 promoted competition by eliminating many ownership regulations. The goal was to “secure lower prices and higher quality services for American telecommunications consumers” (Federal Communications Commission, 1996, sec. preamble). The 2003 FCC Report and Order noted that in addition to lower prices, competition is:

the wellspring of greater innovation and improvements in the quality of service... we continue to have a public interest responsibility, distinct from our 
diversity and localism goals, to ensure that broadcasting markets remain competitive so that all the benefits of competition - including more innovation and improved service - are made available to the public. (2002 Biennial Regulatory Review, as quoted in Morse, 2004, p. 363)

Using a movie theater example, Croteau and Hoynes (2006) illustrate the effects of a marketplace setting on what is provided to an audience. A homogenized monopoly, depicted via one available movie theater showing one movie, is the least desirable outcome from a competition standpoint. Diversity grows as the one movie theater expands to a multi-plex (diverse monopoly), then to multiple theaters showing the same type of content (homogenized competition), and then into diverse competition via multiple independently-owned theaters showing a wide variety of films.

Keeping this illustration in mind, a deregulated "competitive” U.S. local media marketplace shuns the "multi-plex" path of diverse competition in favor of homogenized competition and homogenized monopoly. Domestic television ownership companies create "super groups," running dozens, if not hundreds, of stations across the country. Many use shell companies with "sidecar" agreements to expand beyond the legallyallowed ownership ceilings, which already permit an owner to have multiple television stations and/or other media holdings in the same city. Such measures boost the negotiating power of the parent company for network and syndicated programming and cable and satellite retransmission fees, while reducing the competition, diversity, and localism principles inherent to local broadcasting (Hagey, 2013; Malone, 2013). 
News Work 50

The 2017 spectrum auction also has the potential to reduce broadcast marketplace competition. For $\$ 10$ billion, one hundred and seventy-five stations auctioned off their share of the publicly-owned spectrum, ultimately affecting more than 1,000 stations that need to be reassigned within the remaining spectrum. Some stations will go off the air completely, while others will end up in sharing agreements (Pressman, 2017; Wang, 2017). Local newsrooms "sharing” content and production staff benefit the corporate owner more than the community at large, as monetary profits soar and content diversity and available local broadcasting jobs in the market decrease, as will be discussed in the next section (Hagey, 2013; Malone, 2014; Stearns \& Wright, 2011).

Diversity. The FCC (2003b) designated five categories of diversity for its media policy goals: viewpoint, program, outlet, source, and minority and female ownership. Viewpoint diversity is the availability of media content from a variety of perspectives "because the free flow of ideas under-girds and sustains our system of government" (Federal Communications Commission, 2003b, para. 32). Programming diversity is just that - diverse programming. Multiple independently-owned firms within a market fulfill outlet diversity. Source diversity provides for various content producers. Finally, promoting minority and female ownership is a continuing goal of the FCC, with the expectation of eliminating barriers for small business entry into the marketplace. ${ }^{2}$

The success of these guidelines in promoting diversity in local broadcasting is questionable. Sharing deals and other media mergers limit the diversity of content offered

\footnotetext{
${ }^{2}$ Together, these categories of diversity were used to devise a Diversity Index to determine whether media concentration in a certain market was suitably diverse. The index was struck down in 2004 as lacking a reasoned analysis for its weighting system and implementation (United States Courts of Appeals, Third Circuit, 2004).
} 
News Work 51

to the public in local markets though homogeneity of source. Fewer corporations control the images, information, and entertainment received by audiences. Television stations run as duopolies (two stations in the same market with the same owner) air less original local news content than those run independently. Stations in "sharing" agreements consolidate news staffs and often simulcast content on multiple stations. Add in standardized graphics throughout an ownership group and network-provided video, and diversity programming flattens not only within a broadcast market, but across the country as well (Alexander \& Cunningham, 2007; J. Rice, 2009; Stearns \& Wright, 2011; Yan \& Napoli, 2006; Yanich, 2010).

Programming standardization is prevalent in the United States. In 2016, 44\% of local television news stations had a cooperative agreement with another media outlet. The range of sharing ran from helicopters to information. A record number of newsrooms provided newscasts for other stations. Two hundred and eighty-six stations did not provide local news at all. Five companies owned 37\% of all full-power local television stations. These factors promote homogenous programming and content for audiences (Matsa, 2017a; Papper, 2017a, 2017b).

Journalistic routines limit viewpoints heard in the news. Limited staffing combined with constant deadlines mean resources are often concentrated around areas where significant news events happen. Therefore, community journalists interview the same people, often government or corporate officials, who appear credible, knowledgeable, and unbiased, but provide the same information to everyone (Bennett, 2012; Herman \& Chomsky, 2002; Schudson, 2008). 
News Work 52

Heavy use of officials makes it harder for non-mainstream sources to get their voices heard. Ryan (1991) urges community activists to become reliable newsroom sources to increase their chances of getting their positions on the air. Getting shut out of mainstream newsrooms prevents audience exposure to oppositional viewpoints, and limits how the public can construct their own alternatives.

Local newsrooms also tend to cover the same stories while chasing "the scoop" to be the first with new information on the air. News coverage is fragmented, taking events out of context to showcase the new or the dramatic instead of the important. Reports emphasize scandal to get audiences to tune in. Bourdieu (1998, p. 29) considers much of what is presented on television news to be "cultural fast food;” when everyone competes for the same story, the audience loses out on substance and diversity (see also Bennett, 2012).

Most mainstream news outlets also claim to provide an "objective” news experience. Codes of journalistic conduct by associations such as the Society of Professional Journalists and the Radio Television Digital News Association stress avoiding the appearance of conflicts of interest. This includes "political and other outside activities that may compromise integrity or impartiality” (Society of Professional Journalists, 2014) and warnings that "political activity and active advocacy can undercut the real or perceived independence of those who practice journalism” (Radio Television Digital News Association, 2015). Commercial newsroom workers, therefore, do not publicly participate in activities that could be perceived as opinion-enhancing (Bennett, 2012). Such avoidance can preclude opportunities to contribute to public debate and 
News Work 53

discussion, for fear of appearing to favor one view over another. This is in direct contrast to the goals of the public sphere: providing a well-versed, informed community electorate (Habermas, 1991).

Minority ownership of news outlets contributes to diversity of content and targets more programming to minority audiences. Yet in 2016, there were only 12 full-powered local television stations with black owners, up from zero ownership in 2013. Of more than 1,700 commercial broadcast television stations, less than $6 \%$ were owned by women, and less than 3\% were owned by minorities in 2014 (Flint, 2013; Pew Research Center, 2016). Lack of ownership diversity contributes to homogenized output, including local crime reports that focus on minority perpetrators and white victims, even if statistically this is not the norm (Bachen, Hammond IV, \& Sandoval, 2007). The Expanding Broadcast Ownership Opportunities Act of 2017 was introduced in the U.S. House of Representatives to bring back protections and incentives for minority owners. As of this writing, the bill has been referred to the Subcommittee on Communications and Technology (McKinney, 2017).

Localism. Focusing on localism preserves "unique cultural values and traditions" within a particular community, and facilitates the reduction of content homogenization (Napoli, 2001). In establishing the Corporation for Public Broadcasting in 1967, the Carnegie Commission stated: "television should serve more fully both the mass audience and the many separate audiences that constitute in their aggregate our American society” (as quoted in: Napoli, 2001, p. 208). But monetary and commercial incentives encourage corporate owners to seek out the largest audience, not the many separate ones. This runs 
News Work 54

contrary to the localism principles of serving the public interest by maximizing the ability of citizens to participate in decision-making processes. Congress legislatively ensured different geographic communities are effectively covered in local broadcast zones specifically to serve the many separate audiences in communities across the country (Braman, 2007; Napoli, 2001; D. K. Scott, Gobetz, \& Chanslor, 2008).

Croteau and Hoynes (2006) identify local control and local content as the two main elements of localism. Yet the local television environment in the United States allows corporate control to reside at a headquarters hundreds or thousands of miles away. Budget and other key decisions are often made by executives with little connection to the local community. Local media is generally controlled by the national corporate offices of the media giants.

Loss of local control equals loss of local content. Sinclair Broadcast Group, for example, assigns “must run” stories to its local stations, forcing newsrooms around the country to run the same, often slanted political content provided by the corporate office (see, for example, Ember, 2017a). The same group previously tried to centralize news and weather production across its stations in the mid-2000s, but shut down the effort when it failed to meet financial expectations (Bracht, 2006). Additionally, many stations work with affiliate services to provide non-local content, some of which comes from syndicated entertainment entities. The same trend can be seen on stations owned by the same company as local affiliates air stories from their "sister stations" from around the country (Farhi, 2012; Potter \& Matsa, 2014a). 
News Work 55

To boost localism, McDowell and Lee (2007) suggest the United States should follow Canada's lead. Instead of focusing on content, the characteristics of the production crew are examined. This encourages growth of the native production sector and cultural programming, fosters corporate growth, and strengthens the nation's television and film industries. This would be a positive force in bringing local production, with local jobs, back to the local broadcast community.

Equals public interest? The principles of competition, diversity, and localism are supposed to strengthen the public interest standard for community content provided by local television broadcast stations over the public airwaves. Yet even those who have worked in local broadcast regulation believe this standard is not being upheld by broadcasters in the United States. Former Democratic FCC Commissioner Michael Copps wrote in 2011:

I continue to believe that, in exchange for the free use of this country's valuable spectrum resources, broadcasters should have to demonstrate during their license renewal process what they have done to provide the news and information that informed civic engagement requires. After all, no business, no special interest, owns a hertz of spectrum in the United States of America. Spectrum belongs to the people. With something so valuable...it is curious that we tolerate such lax public interest oversight...the oversight has too often been reduced to placating the special interests who roam the corridors of power. (Copps, 2011) 
News Work 56

That same year, Steven Waldman, an advisor to the FCC, condemned both licensed mass media for not informing their communities and his agency for not doing its job to uphold its own standards:

The current system of public interest obligations for broadcasters is broken: TV stations are required to maintain programming records and other such paperwork, which FCC staff and members of the public rarely read...Licenses are routinely renewed, regardless of whether a station is investing huge sums in local reporting or doing no local programming at all. Over the FCC's 75-year existence, it has renewed more than 100,000 licenses. It has denied only four renewal applications due to the licensee's failure to meet its public interest programming obligation. No license renewals have been denied on those grounds in past 30 years. The current system operates neither as a free market nor as an effectively regulated one; and it does not achieve the public interest goals set out by Congress or the FCC. (Waldman, 2011, p. 25)

The public interest standard is not being met through the current system of broadcast regulation. Corporate conglomerates with broadcast interests successfully lobby the FCC to relax or eliminate regulations protecting what is left of public interest broadcasting. One of the arguments to promote deregulation is the false claim of online resource growth providing diverse local information for audiences. Not only is the web not filling local information holes created by disappearing legacy newsrooms, such as print newspapers, but it is also not expanding the amount of local news covered. Local news websites are overwhelmingly online postings of stories from print newspapers and 
News Work 57

television stations. Eighty-eight percent of Americans go directly to a news website for their online news (American Press Institute, 2014; George Washington University, 2011).

There have been few successful online local news websites. Those that exist are mainly newspapers that no longer print physical copies. A survey from 2015 shows that one out of every four news startups online has failed (Mutter, 2015). Therefore, it is still up to local television entities to responsibly provide content for their communities.

As discussed in chapter 2, community information has widespread benefits beyond its monetary value; it is a societal good, even if audience demand does not live up to its abundant supply. To bring a true public interest standard to the forefront, Pickard (2014, 2015b, 2015a) argues media should be considered a public good, as they differ from other commodities within capitalism. This is a point Entman (1989) also makes: most citizens do not seek out, for instance, high-quality political reporting. Under the market model, this reduces demand for this coverage, which then causes news organizations to provide fewer of these stories, thus creating a vicious cycle, and not contributing to the public good. Democracy requires that public-service journalism covers important policy issues at the local, state, national, and international levels. Therefore, the current marketplace structure needs to be dislodged. For Pickard (2015b), this involves public policy intervention.

Pickard is not alone in making such demands. Nichols and McChesney (2010) argue the press is a public good that needs a subsidy like education or the military. Market-driven journalism should not be running the "free" press. Bennett (2012) argues for more funding to allow public broadcasting to provide more programming from 
News Work 58

diverse points of view, as is promoted in many other democratic countries. These steps would bring U.S. media closer to its expected role as information provider for the public sphere.

\section{The Place of Journalism in the Marketplace}

There is an imbalance between the Federal Communications Commission's public interest standard and the deregulatory spree it has been pursuing since the 1980s. The community audience is the victim of these marketplace moves, as diversity of information decreases when newsrooms downsize, converge, and search for the largest, yet demographically specific, viewership to keep ratings, and therefore revenues, high. These regulatory moves illustrate the political economic impact of local broadcast ownership: those with capital have the ability to change or make the rules and therefore have power over those who work for them and ultimately those who receive their product.

The case of Sinclair. The growth of Sinclair Broadcast Group illustrates the outcomes of those with capital power combined with deregulation on local television ownership in the United States. In early 2018, Sinclair was the largest owner of local television news stations in the United States, with 193 stations in 89 markets (Sinclair Broadcasting Group, 2017). To further increase its audience reach and subsequent message power, in May 2017 the company announced it was buying Tribune Media Company for almost $\$ 4$ billion, pending FCC approval. This acquisition will add 42 local television stations to its portfolio, making it without rival the largest local television 
News Work 59

station owner in the country. Estimates are the new company will be able to reach $72 \%$ of the U.S. audience (Littleton, 2017).

As mentioned earlier in this chapter, Sinclair is known to be an openly conservative corporation that provides daily politically-motivated “must-run” stories for all of its local stations to air during their local newscasts. These include a "Terrorism Alert Desk” segment with stories that have included an anti-Hillary Clinton piece linking the Democratic party to slavery and another segment accusing the national media of publishing fake news stories. Additionally, stations must run 9 pieces of political commentary hosted by former Trump White House official Boris Epshteyn each week. Promotional materials echoing conservative media views read by local anchors and airing during news time are among the most recent content mandates made by the company (Ember, 2017a; Stelter, 2018a; Vogel, 2017).

Statements by President Trump’s son-in-law indicate that Trump’s campaign struck a deal with Sinclair for better media coverage during the election cycle (Dawsey \& Gold, 2016). Additionally, the company was fined in late 2017 for airing undisclosed paid advertising as news stories instead of focusing on community news (Johnson, 2017b). Combined, this influence of mega-owners over what is covered as news at the local levels is clear. While journalists at some of Sinclair's local stations, most notably KOMO in top 15 market Seattle and WJAR in mid-market Providence, Rhode Island, balk at the content of many corporate-mandated news stories, they can do little to push back beyond strategic airing at times of low viewership. Those at KOMO feel the segments damage their professionalism, while their owners say they do not dictate the 
local news segments of the station's content, keeping must-runs on national and international topics (Ember, 2017a; Shepardson, 2017; Vogel, 2017). Even with this caveat, ownership is still making key ideological editorial decisions aimed at local audiences in its pursuit of a more favorable business model.

This is not the first time Sinclair has filled news content during time slotted for local television newscasts. In the mid-2000s, Sinclair tried to hub much of its content from one main studio outside of Baltimore. Then, as in 2018, the audience was not told about the ownership's conservative agenda. Because of the dual-studio (local and hub) format, local anchors suddenly disappeared part way during a newscast to be replaced by the host from "News Central." Station competitors at the time were wary of the Sinclair model from both a community and a business standpoint. One executive from Viacom equated diversity of content with larger audiences, and, thus, higher earnings, discounting the one-size-fits-all approach to newscasting. Another, from now-defunct Belo, felt a newscast that reflected the community's interests would build loyal viewership better than a forced nationally-produced product, again leading to better business outcomes for the parent company (Rutenberg \& Maynard, 2003).

Sinclair ended its News Central productions in 2006 after not achieving expected financial savings, but is moving again in that direction (Bracht, 2006; Seifter, 2004). Should the Sinclair-Tribune merger be approved by the FCC, Sinclair's must-run programming will air across all market sizes, including the largest in the country, New York City. The company is also refusing to guarantee local news will continue on its stations; in January 2018, workers at the Portland, Oregon Sinclair station staged a picket 
to inform community members about the possibility of their owner ending local newscasts (NW Labor Press, 2018).

The local television news labor force in Sinclair's stations might also shrink. The company has a history of downsizing at the local level, laying off 54 across the country in 2017, including the entire investigative department of Seattle’s KOMO, and cutting 16 between KOMO and Portland’s KATU upon acquisition in 2013 (Duin, 2013; Lerman, 2017).

Taken together, this clearly shows how corporate ownership can take advantage of its power over not only its work force, but also the information presented to its community audiences. The elite and powerful get to broadcast their message to the masses, and, in this case, manipulate their own workers to be mouthpieces for the company line. They can limit what news and viewpoints are reported, and what gets left by the wayside. This is the antithesis of working in the interest of the public.

Positive outcomes of corporate ownership on local newsrooms. While the Sinclair case illustrates the downsides of mishandled corporate power on local television newsrooms, there can be positive aspects of such ownership for both the audience and the local broadcast journalism community, as well. When Hurricane Harvey devastated Houston, Texas, the fourth largest city and tenth largest media market in the country, one of the casualties was TEGNA-owned CBS station KHOU, which was inundated with 5 feet of water. Its newsroom, production control room, and set were destroyed. With the help of the "TEGNA Nation,” a group of 100 workers from stations across the company, KHOU was back on the air 4 days later in a newly configured station control room set up 
in Dallas. The Nation also helped with field reporting while Houston-based crews got back on their feet. Nation members were again deployed from stations around the country when production crews moved back to Houston 6 months later (personal correspondence, Facebook, \& Twitter posts, August 27-September 5, 2017, April 2018).

In times of disaster, having resources spread around the country can and does help keep vital life-saving information on the air and/or on the web for those in need. Scripps similarly drew from its nationwide pool when it evacuated its Cape Coral, Florida station during Hurricane Irma, and sent reinforcements to its other local Florida stations to cover the storm. While the station in southwest Florida was physically empty, the community was still receiving vital information from its journalists stationed in safer spaces around the area (Jessell, 2017).

This shows that large-scale corporate ownership can lead to stellar journalism and displays of public interest in the event of a local emergency by virtue of the extensive resource pool it can draw upon to enhance coverage. Locally mobilizing such forces during the day-to-day routine should be the goal, however, to ultimately serve the public interest all of the time. Instead, local news staffers are often caught between the pull of reporting in the public's best interest while also keeping their corporate owners satisfied. The next chapter explains the methods used in this project to get a deeper look into exactly how local television news works. 
News Work 63

\section{Chapter 4: Research Methodology}

A two-part qualitative approach answers the over-arching question of this project: How does the political economic structure of corporate-owned newsrooms affect how local television news workers do their jobs providing information to the community? This research seeks to gain both a broad overview of the affected population, as well as an indepth understanding of the more focused issues these workers face. It also pursues the experiences of newsroom employees who were not often targeted in the literature, such as "behind-the-scenes” workers and those in relatively new job descriptions within larger markets. Behind-the-scenes workers include producers, photojournalists, video editors, assignment desk workers, managers, engineers, and master control operators. Those with newer job descriptions in larger markets include Multi-Media Journalists (MMJs), automation directors, digital workers, and Producer-Editors. Those in more well-known television news jobs, such as anchors and reporters, are also included, particularly for their expertise on how the business of local television news has changed over time.

Because these changes are of interest, the population targeted is workers in local television newsrooms in the 25 largest U.S. media markets, as determined by Nielsen for 2014-2015. ${ }^{3}$ These markets represent nearly half of television viewing households in the United States (49.5\%), and each contain over a million households. The top 25 tend to be highly sought-after by experienced newsroom professionals looking to cover the largest metropolitan areas in the country. People who work in these markets usually have been in

\footnotetext{
3 These markets included New York City, Los Angeles, Chicago, Philadelphia, Dallas-Fort Worth, San Francisco, Boston, Washington, DC, Atlanta, Houston, Phoenix, Detroit, Tampa-St. Pete, Seattle-Tacoma, Minneapolis-St. Paul, Miami-Ft. Lauderdale, Denver, Orlando, Cleveland, Sacramento, St. Louis, Pittsburgh, Portland (OR), Charlotte, and Raleigh-Durham (Nielsen, 2014).
} 
the business for a number of years, a demographic preferred for research trying to determine circumstance change over time.

To delve further into the potential impacts on such workers, five subquestions are addressed:

1: How does changing ownership and station consolidation affect how newsroom workers are able to do their jobs?

2: How do budget pressures and commercial pressures affect how newsroom workers do their jobs?

3: What impact does the implementation of changing technology have on newsroom workflow?

4: What is the role of job stability in how newsroom personnel do their jobs?

5: What other conditions impact how newsroom workers perform their jobs?

\section{Data Collection}

In order to decrease the risk of limitations of a single method of data collection, this study uses both online surveys and in-depth interviews. Qualitative survey data searches for "empirical diversity in the properties of the members" (Jansen, 2010, para. 11). This is different than a quantitative survey, which generally seeks a numerical distribution of variables. The survey highlights the issues a broad variety of local television newsroom workers encounter in their day-to-day journalistic endeavors. The semi-structured interviews provide a richer understanding of what is behind those issues and how they impact the workers themselves as they gather and disseminate news to their 
communities (Roller \& Lavrakas, 2015). Table 2 provides a breakdown of study participants.

\begin{tabular}{lcc}
\hline Job Title & $\begin{array}{c}\text { \# of survey } \\
\text { Responses }\end{array}$ & $\begin{array}{c}\text { \# of interview } \\
\text { responses* }\end{array}$ \\
\hline Anchor & 4 & \\
Assignment Editor & 3 & 2 \\
Digital Team & 6 & 0 \\
Director & 10 & 1 \\
Editor & 2 & 3 \\
Engineer & 6 & 3 \\
Executive Producer & 3 & 0 \\
Master Control Operator & 0 & 3 \\
News Managers (not EP) & 3 & 1 \\
Photojournalist & 10 & 3 \\
Producer & 21 & 4 \\
Reporter or MMJ & 7 & 8 \\
Writer & 0 & 6 \\
Other & 6 & 4 \\
& & 2 \\
\hline
\end{tabular}

*Totals add up to more than 24 because multiple job descriptions were often discussed during interviews.

Table 2. Study participants for both surveys and interviews

Survey. The online qualitative survey sought a diversity of experiences within the population of newsroom workers. Raw numbers of people with certain characteristics within a population were not the focus; instead, the focus was on the characteristics themselves (Jansen, 2010). The sample, therefore, was not a probability sample, but was instead an attempt to reach a wide range of worker types, including many who were often un- or under-represented in newsroom studies (K. M. Ryan, 2009b). No statistical inferences of the population have been made from the data (American Association for Public Opinion Research, n.d.). The results are purely descriptive in nature. 
News Work 66

There were two rounds of survey distribution. The first round of began September 1, 2015 and ended on November 1, 2015. Round two began on May 25, 2016 and ended July 25, 2016. Every newsroom that aired a daily local television newscast in a top 25 market was targeted, including broadcast, cable, and community access stations. A breakdown of these stations is in Appendix A.

To increase confidentiality and openness of discussion, respondents’ names and affiliations were not asked. The survey allowed respondents to skip or report "prefer not to answer" to any question they wished, with the exceptions of current market and job title. These exceptions were adopted to keep track of over- or under-representation of certain groups of workers in the study. Most questions were multiple choice, with a few short open-ended responses requested. The survey was anticipated to take no more than 10 minutes of a respondent's time, and most finished in about 5 minutes. The survey can be found in Appendix B.

To expand the potential pool of interview subjects, the end of the survey contained a space to leave contact information for a respondent willing to participate in an in-depth interview. This contact information was not connected to survey answers, again to protect confidentiality.

Email distribution. Email distribution was originally targeted to the News Director of each individual newsroom. News Directors are the executives in charge of a station's news operation. They were asked to pass along the link to the web survey to all newsroom, photography, editing, and production personnel so as to gain as wide a labor pool as possible. This point of entry was chosen after asking a number of news managers 
their ideas for preferred method of initial distribution. If contact information for managers of photography, editing, and/or production departments was found, an email request was also sent to them to help flesh out distribution.

Emails were sent to all newsrooms within a market on the same day. Distribution originally began via Qualtrics, but it was soon discovered that some station groups were directing Qualtrics emails to spam folders, and surveys were therefore not hitting their intended targets. Survey distribution was then changed to an email link sent via the researcher's Portland State email address, with all introductory information remaining the same.

This method turned out to not be a robust way to gather data. Only 2 completed surveys were returned via this method, and 3 news directors emailed the researcher declining to participate. Therefore, this method was only used during the first round of survey distribution.

Social media. Beginning September 24, 2015, links were distributed via the Society of Professional Journalists Facebook page, the Radio Television Digital News Association's Facebook page, the personal Facebook page of the researcher, and the media-oriented Twitter account of the researcher.

There were two postings to the Society of Professional Journalists Facebook page (September 24, 2015 and October 13, 2015), and three postings to the Radio Television Digital News Association’s Facebook page (September 29, 2015, October 21, 2015, and May 29, 2016). There were three postings to Carey Higgins-Dobney’s personal Facebook page on September 25, 2015, October 5, 2015, and October 21, 2015, and numerous 
shares via friends from those. The link was also tweeted on the researcher's mediaoriented Twitter account at various dayparts throughout September and October 2015 and May, June, and July 2016 and passed along to others by followers there.

These methods proved more fruitful, resulting in a grand total of 94 newsroom workers consenting to participate, 81 providing usable answers to at least some of the questions, and 67 answering every question.

Interviews. The interview stage began June 5, 2016 and concluded on October 31, 2016. Twenty-four people participated. As in the survey, interviewees were top-25 U.S. media market newsroom personnel. They were found via the survey, social media postings, word-of-mouth, and direct and indirect (colleagues of colleagues) personal contacts of the researcher. Interviewees were provided with a recruitment letter and consent form that outlined the project, potential (minimal) risks, and researcher contact information. These documents can be found in Appendices C and D.

Interviews took approximately one hour, had audio digitally recorded, and did not include the respondents' names or stations. All interviewees were identified only by a generic job title that could describe a number of people in television news in their market (reporter, anchor, photographer, MMJ, editor, director, engineer, etc.). The format was similar to that used by Higgins-Dobney and Sussman (2013), with a pool of preliminary questions to begin and follow-ups based on responses. The researcher conducted all interviews. The preliminary list of questions is in Appendix E.

Because interviews involved workers from across the United States, 21 took place via Skype, Google Talk, or FaceTime video conferencing software. These programs have 
been shown to be useful for such endeavors and promote flexibility of scheduling for both interviewer and interviewee. Rapport has been shown to often be as easily established via video chat as in person (Deakin \& Wakefield, 2014). Because interviewees work in a digital video based medium, access to necessary (free) software and ease of use were not an issue. The interviewee was allowed to choose their preferred video chat method. The three remaining interviews took place in person.

There were a number of factors that contributed to the final interview count. Kvale (1996, p. 101) answered the "how many" question with "Interview as many subjects as necessary to find out what you need to know," with 15 +/- 10 as the standard starting point. With the varied character of newsrooms and job descriptions, and the number of media markets targeted, the possibility was left open for a higher count. However, answers among participants began to form a pattern after about 20 interviews, indicating saturation was nearing. Additionally, as time wore on, fewer people of varying job descriptions were willing to participate, with the majority of new volunteers having similar backgrounds and jobs as those already spoken to. Since one of the goals of this study was to gain a broader understanding of the experiences of many types of newsroom workers, as the job description pool narrowed, so did the need for additional responses.

\section{Author Background}

In an effort of transparency, it should be noted that I, Carey Higgins-Dobney, the author and researcher of this study, have been and am, as of this writing in early 2018, a worker in a local television newsroom in a Top 25 market. I have seen and personally experienced many of the issues discussed in this project; these were major factors in my 
interest in pursuing this line of research. I let the interview participants know of my affiliation with a local television newsroom, although this information was not included in the online survey. Many participants who were not used to being on the receiving end of interview questions were able to relate to my background, which potentially made conversations less stressful for all involved.

I recognize that my experiences over 20 years in local television newsrooms, including 17 in a top 25 market, may color interpretation of data. I have seen local television newsroom mergers and acquisitions that have resulted in worker downsizings, including the loss of full time work hours for me, and for my spouse. Dozens of friends and colleagues have lost jobs over the course of my career for similar reasons. Programming has been hubbed into facilities across the country at both stations I have worked at in Portland, Oregon; news control rooms are automated across the market. Multiple station mergers, acquisitions, and affiliation swaps have occurred, including the consolidation of two newsrooms into one at the Fox affiliate, and an ownership change at the NBC affiliate, both while I was an employee. MMJs are a common sight in our newsrooms, and part time schedules abound.

One of the driving factors behind this project was the question as to whether these were all "normal" occurrences for a top 25 market. Is Portland an outlier, or are these circumstances now standard operating procedure across the country? Professor Gerald Sussman and I (2013) examined the Portland case in 2012; this research was designed to expand beyond that specific market to find out how truly widespread job description 
convergence, automation, hubbing, and other news gathering and dissemination changes are.

The two-pronged approach of interviews and surveys, combined with an extensive review of the literature, and personal discussions with others who have done similarly-themed research have been undertaken to put these experiences into perspective within the current political economic framework of the local television news business.

\section{Considerations of Confidentiality}

In order to protect the confidentiality of those participating in this project and allow for more open and honest responses, at no time were survey or interview data linked to a respondent's name or station affiliation. Survey respondents were identified only through a self-described generic job title common to many in the field. Interview participants were assigned a generic job title based on their main job functions. Throughout the upcoming findings and analysis, participants will be identified only by these generic job titles and the number of years they had been in the local television news business at the time of participation. This will provide the reader with an idea of who responded and their level of experience while protecting the participant and their coworkers from any potential professional retaliation, up to and including job loss and exile from a particular station owner, for their answers.

Additionally, any potentially identifying information within an answer has been redacted, both in transcripts and in the following chapters. This includes obvious references to city locations, coworkers, or details specific to a particular person or location. As trained journalists, both the researcher and the participants understand the 
News Work 72

implications of being confidential sources. Therefore, confidentiality and confidence in the research process were of the utmost importance throughout this project. 
News Work 73

\section{Chapter 5: Corporate Power and Its Influence on News Construction}

Herman and Chomsky (2002) argue the profit desires of corporate ownership supersede the obligations of the media as public interest entities. Their propaganda model lays out how the inequality of power plays to the advantage of those with hegemonic power by suggesting “filters” are implemented in the gathering and reporting of most news coverage. These influence not only what is covered as news within a market, but also who is chosen as a source of information.

The mission statements of four of the five largest owners use language targeting the business aspects of broadcasting and digital production instead of the federallymandated public interest values. Only TEGNA's purpose statement “To serve the greater good of our communities” touches upon that cornerstone of the Communications Act of 1934. The rest focus on consumer purchasing, company assets, and connecting advertisers with audiences.

These latter values lead to precisely the types of coverage Herman and Chomsky describe in television newscasts. Brislin (2004) argues that journalist autonomy is the defining difference between propaganda and journalism; therefore, working under corporate capitalist (or other) influence blurs that line. Just as autonomy allows journalists to practice their profession, it also allows for the potential empowerment of the citizenry. As empowering communities is a goal of information dissemination, and a key function of journalism, the impact of the Propaganda Model can be devastating to civic participation while instead promoting consumerism (Adler \& Goggin, 2005;

Anderson et al., 1994; Norris, 2006). 
News Work 74

\section{Filter 1: Size, Ownership, and Profit}

Given the corporate-oriented mindset local television stations, Herman and Chomsky’s first filter is size, ownership, and profit orientation of the mass media. As mentioned earlier, in 2016, five companies owned over a third of the local television stations in the United States, and two of these were on course to combine in 2018. This is a long way from the forced divestiture of the Blue Network from the Red in 1941 to prevent monopoly ownership and lack of competition. Diversity of viewpoint is compressed and localism disappears as fewer owners run more stations across more markets, emphasizing profits over public interest (Alexander \& Cunningham, 2007; Matsa, 2017a; Yanich, 2010).

With the steady stream of television stations mergers and acquisitions that have occurred since the Great Recession, these business deals affect many working in local television newsrooms. Nearly half (11 of 24) of participating interviewees have been through a station ownership change. New owners often mean a complete overhaul of a station, generally accompanied by layoffs to save money. One worker survived three rounds of layoffs under one owner before his company was sold to another and job stability set in. Staff at another station has become numb to the changes of repeated sales: “The rumors about us being sold again - nothing changes at this point” (Video Editor, 18 years). Rapidly-growing smaller companies tend to have the worst reputations among workers when it comes to cutting staff as ownership grows: "It's all about the money. They let their best people go...And so the morale is just - it's in the toilet” (Photojournalist, 18 years). 
News Work 75

Profit orientation can mean the elimination of journalism resources that require more time and expense to develop stories. Investigative units, for instance, cost stations time, money, and personnel, which go against the quest for profits. Hence, they are often eliminated or the investigative staff is otherwise assigned to news stories known as "day turns.” Such stories are pitched in the morning and are on the air before the reporter's shift is over, severely limiting the amount of investigation on the subject matter.

Investigative team members are very proud of the work their units do for the community, yet are very cognizant of the financial considerations that go into having investigative teams at their stations: "I know that I've got this great job that allows me to make a difference in my community...And I want to make sure that my bosses know that there are those great stories out there” (Investigative Reporter, 34 years). An investigative photojournalist (33 years) notes his unit “could change laws. Put people behind bars. Do reports that really change people's lives and make a huge difference...We're committed to making our community better through our stories.” This latter statement speaks to the public interest standards stations are supposed to be providing for their audiences. At the same time, the photojournalist concedes: “Investigative units come and go. They're expensive. You pay more. You see less. So it is a real commitment to creating and sustaining an investigative unit.” This is a commitment many station owners are not prepared to make.

A producer who had worked closely with an investigative unit at one of his former stations believes such reporting is critical for keeping local stations relevant to their communities: "People get more out of those issues than covering an unfortunate fire, 
News Work 76

or a Go Fund Me page set up for a crash victim...I think people will be much more interested and we can engage them more and do more with a great, in-depth investigative team" (Producer, 8 years). This arguably is good for not only the public interest, but also the bottom line. More viewers equal bigger ratings, which equal more advertising money for the station. Previous studies have shown that quality, including investigative reporting, sells (Gottlieb \& Pertilla, 2001).

But many in newsrooms indicate they do not have a budget to accommodate reporting crews working on long-term stories while still filling their daily broadcast time. "We simply didn't have the staff and the resources available to have an investigative unit, so we didn't” (News Manager, 27 years). Beat reporters who specialize in specific locations or subject matters also often fall by the budgetary wayside in favor of general assignment reporters who can cover any breaking or spot news story as it happens. "We've cut staff over the years in the regular newsroom. So there's not as many people to go around” (Investigative Reporter, 34 years).

This squeeze on the labor force will be discussed further in Chapter 7.

\section{Filter 2: Advertising as a Primary Income Source}

As per the Murdock and Golding (1973) discussion in Chapter 2, corporate entities that own newsrooms often also have other goods, programs, or services to promote. These promotions are often integrated into the production of news, called plugola, filling news time with what is essentially a commercial for a sellable product somehow tied to the news company's owner or network. This means less original reporting time by paid crew is needed, and the parent company or network earns free 
publicity. Simultaneously, the public is denied access to more pressing community issues (Higgins \& Sussman, 2007; McAllister, 2002).

Advertising importance as a primary income source in the realm of broadcasting is Herman and Chomsky’s second filter. ${ }^{4}$ Advertisers essentially pay to keep local television news on the air by purchasing airtime. In return, stations agree to provide the proper audience for their sponsors. Each increase in ratings point equals more money for the station and more potential customers for the advertiser. Journalists and newsrooms are pressured to remove negative stories or add positive ones about their sponsors to achieve such ends (Herman \& Chomsky, 2002; D. Schiller, 2007).

Survey respondents were remarkedly candid about the widespread practice of this form of story selection: of those who make decisions about content, nearly half, $49 \%$, said they have been pressured to promote a positive story about an advertiser or other affiliated acquaintance. Forty-five percent have been pressured by news management to squash a story that might be financially detrimental to their station or owner. Nearly a third have experienced both types of content pressure. Figure 1 illustrates the comparison. A digital producer (3 years) experienced this firsthand at a previous job: "I almost got fired for writing something because it was an advertiser, even though it was true.” She notes that her current newsroom has allowed similar stories after being checked by a station lawyer before air.

\footnotetext{
${ }^{4}$ It should be noted that since this propaganda model was made, that advertising is no longer the sole source of local station income, although it remains the main source. In 2016, eighteen large station groups made $67.4 \%$ of their revenue from advertising, while $23.6 \%$ came from retransmission agreements made with cable and satellite providers. Digital media and "other" revenue comprised the rest of income (Friedman, 2016).
} 


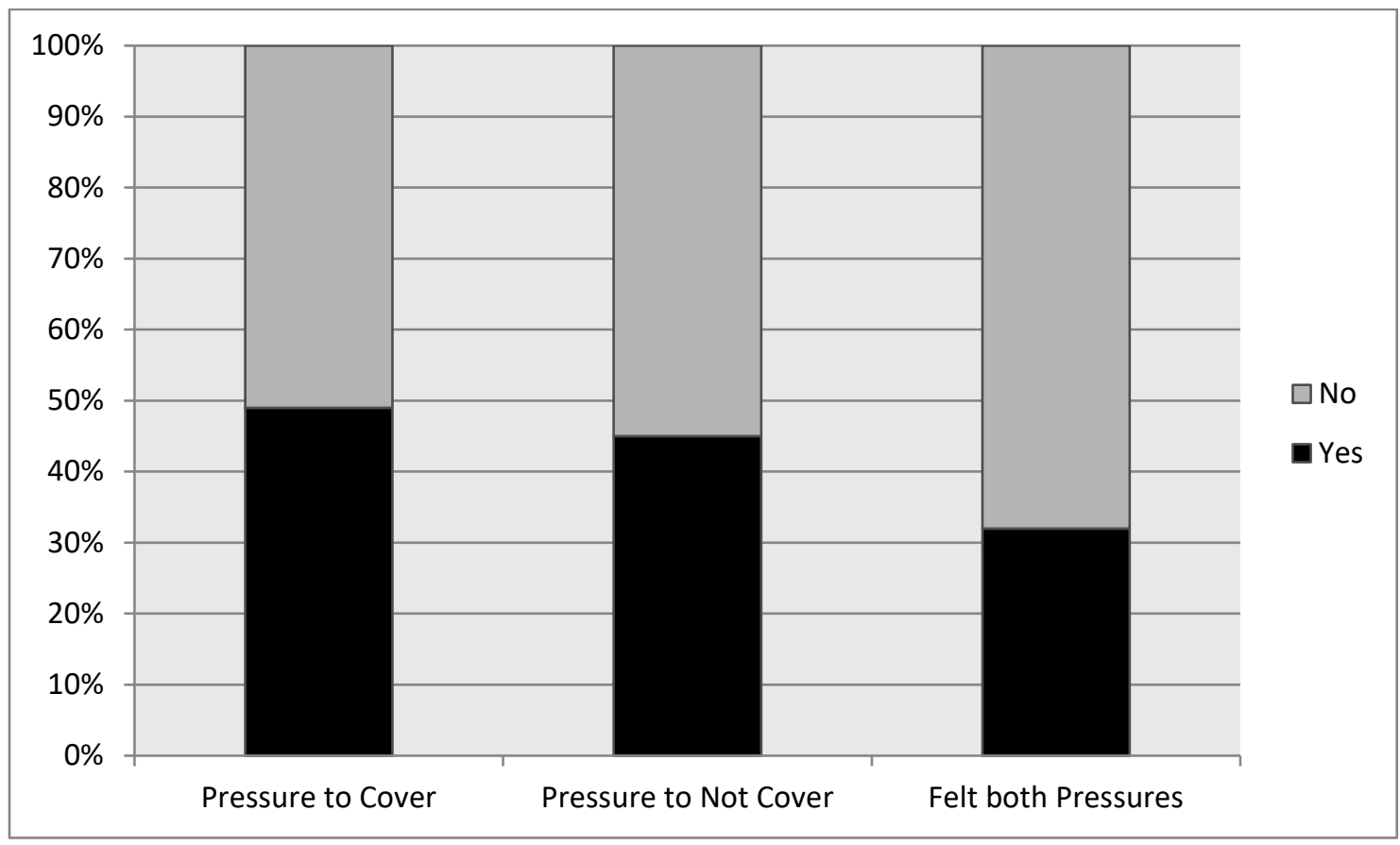

Figure 1. Percentage of relevant surveyed workers that felt pressure to cover or not cover a story for station financial gain.

Story coverage pressures fall on those working a wide range of job descriptions.

Of 21 producers who answered the survey, 7 (33\%) feel pressure to cover a story because it might be financially beneficial to either their station or the station's owner. Six (29\%) feel pressure to not cover a story for similar reasons. Four of these workers (19\%) have experienced both kinds of pressure. A producer addressed this issue during her interview: “You just cover it just because you're supposed to cover it, but that's really the end of why it’s newsworthy" (Producer/Editor, 5 years).

Of the 10 photojournalists who answered these survey questions, fully half feel pressure to cover a story for financially beneficial reasons. Four (40\%) feel similar pressure to not cover a story. Three of these workers (30\%) have experienced both kinds of pressure. While some stations avoid sending recognizable on-air reporters to cover 
things like “ribbon cuttings at a car dealership,” more inconspicuous photojournalists shoot such assignments instead (MMJ, 4 years). Reporters do not completely avoid this issue, however; three of seven (43\%) survey responses indicate they feel pressure to cover and two of seven (29\%) to not cover stories for station financial reasons.

What effect does this have on viewers? If an audience is denied a story for the sake of station budgetary considerations, they could be missing out on relevant health, safety, or community information. If a car dealership is ripping people off or there is a health violation at a local restaurant, withholding these stories because they involve newscast sponsors is not serving the public interest. Instead, the information being promoted or squashed is serving a commodity function for the station. Marketing the station for advertising trumps educating the public.

There are other forms of advertising dollars at work during local television broadcasts as well. Product placement during newscasts is a regular part of local morning news programs. One station owner welcomed branded cups of McDonald's coffee on set as a way to "shore up advertising revenue” in Las Vegas. Stations followed suit in Top15 markets Chicago and Seattle (Clifford, 2008). Upshaw, Tchernov, and Koranda (2007) found 750 instances of commercial influence on newscast content within 294 studied local newscasts.

Public relations videos, called VNRs (Video News Releases) also arrive at stations daily. These often air as part, or sometimes as the entirety, of a news story. When the materials are not labeled as promotional on air, they can be interpreted by an audience to be a locally-investigated report. Many are absorbed into a news station’s format to 
News Work 80

make them appear to be organically produced by that station, further blurring the line between news and advertising (Broaddus et al., 2011; Farsetta, 2006). This practice can originate beyond the local level; multiple government agencies under then-president George W. Bush provided pre-packaged stories about federal programs to local news stations, being careful to not indicate they were public relations materials (Barstow \& Stein, 2005).

In spite of the widespread availability of VNRs and other press release materials, news workers in this study were not terribly concerned about their use. While assignment desks receive many of them, often on a daily basis, most news personnel do not believe they are put on the air as delivered by the promoter. "The only time we do use those is if they're offering guests on a specific topic that's in the news... If they're pitching story ideas, not as much” (Producer, 15 years).

This might be platform-specific, however. News station digital teams appear to rely more heavily on press releases and other prepackaged news to provide content for a station's website. “They're churning out the daily news. So they are taking press releases that we get and they're rewriting them and they're posting AP [Associated Press] reports, and they're posting digital versions of what the tv reporters are doing. And then...they're pulling national stories and sharing them” (Digital Producer, 3 years). As stations become more involved in the digital realm, these promotional tie-ins, plugs, and advertiser-approved stories spread the advertiser bias from broadcast to other digital and mobile platforms. 


\section{Filter 3: Selection of Sources}

The third filter is the reliance on government, business, and other “experts” to explain the news for an audience. Sources with high social standing or authority have power to influence information output. These sources are generally seen as “objective,” accurate, are easy to find, and are reliable providers of information. This allows newsrooms to cover stories using fewer resources (Herman \& Chomsky, 2002). Shoemaker and Reese (1996, pp. 108-109) describe the job of newsgatherers as to “deliver, within time and space limitations, the most acceptable product to the consumer in the most efficient manner.” Relying on these sources helps fit that bill.

Those with limited time and resources tend to lean on these sources more heavily. Solo journalists working as MMJs rely on public relations professionals as sources more than their 2-person reporter-photographer crew counterparts in time-budgeting effort. Regularly using such sources gives these viewpoints more weight and airtime than others. (Blankenship, 2016)

In order to maintain the trust of these sources, relationships must remain cordial. Much like stories ignored or emphasized for commercial considerations, stories that do not air to keep the peace can also be a detriment to the public. For example, one top 25 newsroom avoided reporting some potentially negative local police force stories in an attempt to repair its strained relationship with the department. "That's where we ran into a lot trouble... Instead of just sticking to our guns and trying to do good journalism, we went on a full-on public relation campaign.” ${ }^{5}$ Another worker believes certain stories are

\footnotetext{
${ }^{5}$ Redacting identifying information for this worker, who was not authorized to speak about this topic publicly.
} 
News Work 82

covered to serve a personal interest at the station, with otherwise little news value for the audience. “It's kind of felt like this is clearly someone’s friend. This is ridiculous, why are we covering it?” (Producer, 5 years).

Many sources have a vested interest in what is reported. Public figures are trying to maintain their authority; elected officials are keeping their jobs and agendas intact. Business leaders often need public favor to push ahead with their plans. Even the journalist has a stake in their sources: their credibility. Creating "stable social arrangements” helps in the successful execution of this reporter-source dance (Berkowitz, 2009; Tuchman, 1973). Molotch and Lester (1974) refer to this as a relationship between “promoters” and “assemblers.” Promoters are generally assumed to have an agenda; assemblers walk a fine line between producing propaganda (with purpose) or producing news (to reflect reality). News dissemination should therefore be considered "purposive behavior," with the agendas of all parties in mind.

\section{Filter 4: Flak}

"Flak" is a method of media discipline often associated with advertisers and political entities, although at the local level, flak can also be found at the corporate owner and audience levels. A person or entity with power responds negatively to a report or program, causing fallout for the newsroom in question. One top 25 newsroom experienced flak after it aired an investigative piece that was not flattering to a local agency. “They were retaliatory, of course. They wouldn’t return phone calls. They would have press conferences and announce to everybody else but not tell us what was going on. They would never respond to our records requests... we did a hit for that. In terms of 
operationally" (Investigative Photojournalist, 33 years). Similarly, the station trying to repair its relationship with the local police force in the previous section was cut off from public information announcements until the rift was healed.

Advertisers use flak by threatening to withdraw ad money if they are associated with reports or programs that might challenge their image. This ties in with filter 2, using advertising as a primary income source. The ad agency that arranged the previouslydiscussed McDonald's product placement promotion expected stations to remove their brand from the set or risk "termination of an agreement" if a story would upset the sponsor (Clifford, 2008).

Under the Trump presidential administration, political flak is a common occurrence for many in the U.S. mainstream media. White House sources favor news outlets that promote their agendas while labeling those that do not as "fake news" in an attempt to discredit them (Massie, 2017). Such moves are aimed to hurt the financial well-being of the media source by driving audiences away, thus losing advertising dollars.

At a more local level, in 2017, stations owned by Sinclair Broadcasting and those pending acquisition by the company battled over editorial control in their newsrooms. The fallout resulted in backlash against station workers during union contract negotiations, punishing employees for opposition to corporate-related editorial and labor decisions (Kroman, 2017). Employees leaving the company are sharing tales of trouble from not airing all must-run stories or complying with broadcasting corporate-scripted promotional spots (Stelter, 2018b). Others feel trapped by contracts drawn up by the 
News Work 84

company that can prove financially and/or professionally devastating to break. Sinclair has shown it is willing to sue its employees to enforce contract "liquidation" clauses if an employee quits (Holman, Greenfield, \& Smith, 2018), taking flak to an individual extreme.

Flak even comes from the audience in an attempt to persuade news organizations to cover stories in the way they see fit. In this age of social media, direct communication to those in newsrooms is a tweet, post, or email away. A local news anchor in top 25 market Portland, Oregon took to Facebook to explain how many local television newsrooms cover stories, realizing that "too many people are looking for affirmation, instead of information” and use threatening language in an attempt to bully news organizations into agreeing with their personal leanings. The tone is set in the first lines of the post, illustrating the potentially explosive nature of audience interaction on the internet: "I don't mind being called names. It comes with the job. But the past week or so has been unlike anything I've seen in my career” (Joe Donlon (KGW-TV) Facebook post, November 17, 2016. Used with permission). Again, these same audience members drive the ratings that keep the news stations on the air. A drop in ratings equals a drop in station revenue, often squeezing newsroom budgets even tighter.

\section{Filter 5: Ideology as a Control Mechanism}

The final filter from Herman and Chomsky is ideology as a control mechanism. Media uses ideology to mobilize a populace against an enemy, particularly those that threaten property rights or support radicalism. Herman (2000, p. 109) termed this "an almost religious faith in the market," with non-market mechanisms deemed suspect. The 
News Work 85

media frame stories in dichotomies, often with an overtone of fear (Klaehn, 2009). This is especially prevalent in national and international news items. In Herman's (2017) last article published prior to his death in 2017, he outlined the historical and continuing use of media anti-communist, specifically anti-Russian, propaganda in such mainstream press as the New York Times.

Media coverage of the political climate of the 2010s, including accusations of Russian interference in the 2016 Presidential election, highlight the use of ideology as a filter. This has trickled down to the local news level with the quickly-expanding ownership of conservative-leaning Sinclair Broadcasting and its "must run” story policies. It is also found in protest coverage broadcast on local stations across the United States, as groups labeled “Antifa” or "anti-fascist” clash with those perceived to be far right-wing or white supremacist (Ember, 2017a; Queally, St. John, Oreskes, \& Zahniser, 2017).

The five filters of the Propaganda Model clearly demonstrate how wealthy corporate interests and powerful state players have the advantage of control over information flow, and therefore potential public manipulation through local television news broadcasts. While those with capital control get to broadcast their messages and publicly protect their brands, those with dissenting opinions and other more marginalized populations are often left without a voice in the mainstream media. The Sinclair case further illustrates that such gatekeeping and opposition is not limited solely to outside influences, but also impacts and attacks those already on the inside working at local 
News Work 86

television stations. This puts the profit motive at the forefront of broadcasting, at the expense of the public interest. 
News Work 87

\section{Chapter 6: Technology, the Division of Labor, and the Impact on Newsrooms}

In a capitalist society such as the United States, revenue maximization is the goal of most businesses. Local television stations hosting newsrooms are no exception. As per Marx (1887), profit comes from extracting as much surplus value from labor as possible. These laborers do not have the capital means to run their own operations, so they are limited to working for those who do. In the case of many local television news stations, this means laboring under the oversight of a large corporate conglomerate based in a city hundreds or thousands, of miles away.

To save on labor costs, these conglomerates often bring in new technologies to automate processes previously completed by the craft skill work of humans, replacing more expensive living labor with computerized labor. While the remaining workers often pick up new skills in learning to run the new machines, often referred to as "reskilling," many feel the stripping away of their craft leaves them more “deskilled,” or, as one production manager/director (13 years) lamented upon first encountering automated news production: "they took my paintbrush away," replacing it instead with inflexible buttons (Braverman, 1974; Örnebring, 2010).

This chapter examines how the implementation of technology impacts television newsroom workers in their day-to-day endeavors to provide audiences with the stories and information they need to know for successful engagement in their communities.

\section{Technology in Information Gathering and Dissemination}

Newsroom workers generally appreciate upgraded technology standards for making information gathering and dissemination a faster process. Computers and smart 
News Work 88

phones, in particular, allow journalists to have quick access to information for story research and status updates. Yet this increase in speed and access also means that newsroom managers push for more content faster, pressuring journalists to update stories more often and more quickly on more platforms. Thanks to the always-on connectivity of wi-fi and cellphone data, many staffers are expected to engage with audience members and upload new information to the web while still working on their reports for television.

Therefore, it is not surprising that $62 \%$ of survey respondents state technology has both helped and hindered how they go about their jobs. "It's helped in that better technology has made things easier and faster. But it's hurt in that easier and faster isn’t always the best for accuracy, accountability or responsibility” (Executive Producer Survey Participant, 20 years). The latter half of this statement explicitly contradicts working in the public interest of the audience at home. With trust and confidence in U.S. media institutions steadily declining to their lowest levels ever in Gallup poll history, such sentiments from those working in the business do not bode well for enlightening and empowering community members (Swift, 2016). Figure 2 depicts the breakdown of how survey participants feel about the use of technology in their newsrooms. That less than a third of respondents find technology to fall squarely on the "helpful" side of the spectrum, compared to nearly two-thirds finding a helpful yet hindering aspect reflects the idea that new technology is not being used solely for beneficial purposes within the newsroom. 


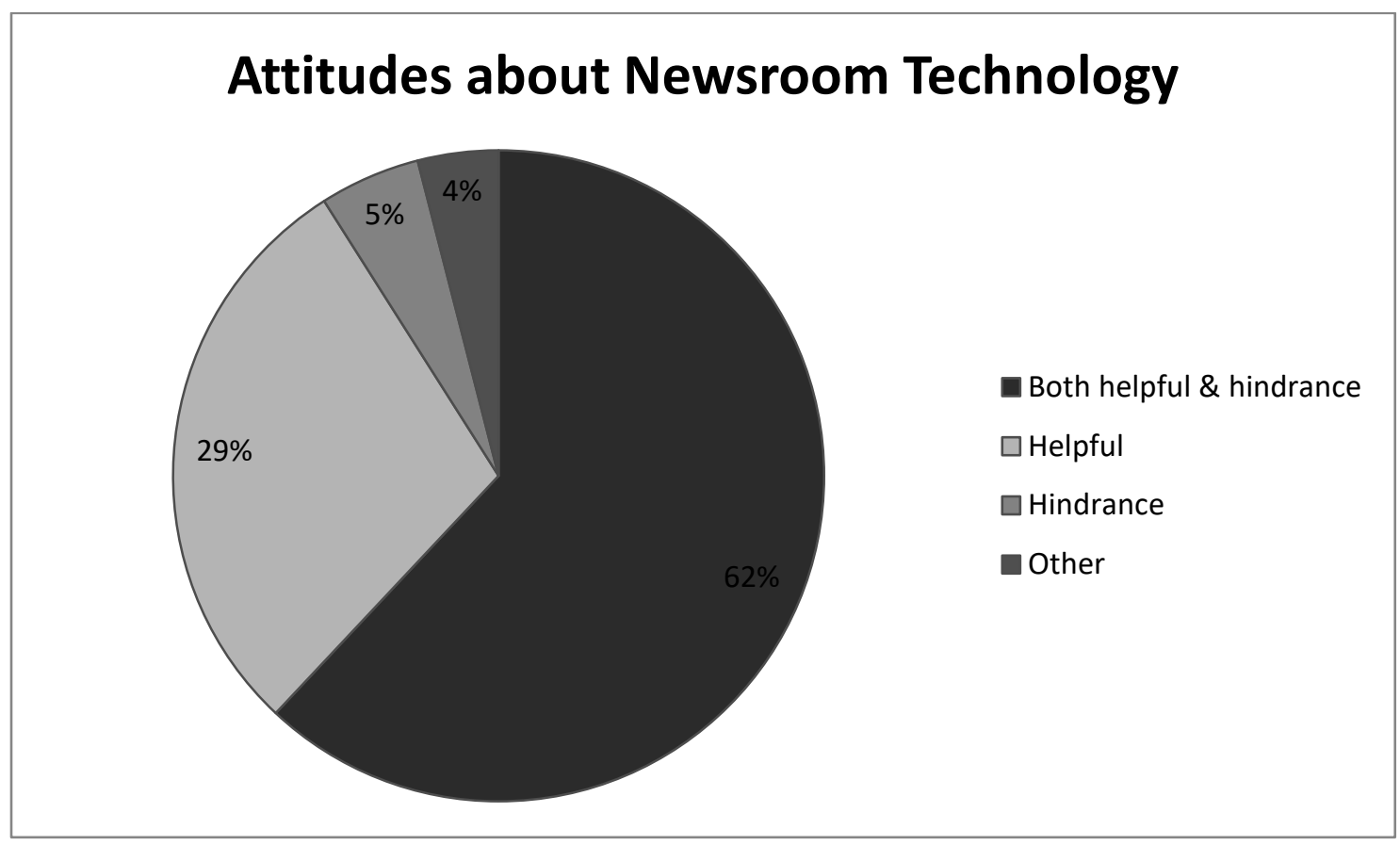

Figure 2. Worker attitudes about technology in their newsrooms.

In the station and out in the field. News gear for those reporting in the field is smaller and more manageable than in years past. Upgrades in cell phone technology allow greater live reporting capabilities from places that were previously inaccessible, including following stories in real time as the action moves. "The ease of getting remote images has been a great technology boost. We now have the ability to walk with protestors on the street or get to remote locations that a traditional microwave truck can't go” (Director Survey Participant, 36 years). Photojournalists and MMJs point out lighter cameras with higher storage capacity make field reporting less burdensome.

This downsizing of gear, however, also means that one person now has the physical ability to handle equipment that used to be assigned to two or three workers, 
thereby downsizing staff and consolidating job descriptions. This convergence allows newsrooms to eliminate positions, saving money while heaping extra work on those that remain:

Technology has allowed me to do my job more efficiently, and unfortunately other people's jobs as well. I can write my story and my chyrons ${ }^{6}$ directly into the computer that broadcasts it on TV...eliminating the writer from the newsroom. I can also shoot my own stuff thanks to smaller cameras, edit it on my laptop and email it right back to the station, eliminating the need for tape/film/image editors, transmission people and engineers to maintain all that stuff. (Reporter Survey Participant, 25 years)

Technological advances mean editing video is easier today than it was in years past. From a capitalist owner standpoint, this ease and swiftness of operation allows these job duties to be tacked onto other jobs they have never applied to before, saving money by consolidating labor. This includes "Multi-Media Journalists" or "MMJs" who shoot, report, and edit their own video for air, adding to their shift workloads and eliminating positions. The effects of this added work on journalists will be examined more in the next chapter.

This also means that specialist editors are becoming harder to find in many local television newsrooms. Newscast producers have picked up video editing duties to add to their already-busy schedules of writing reports, putting stories in order, and keeping track of live reporters: "I'll research the story, I'll write it, and I'll edit video for it"

\footnotetext{
${ }^{6}$ Chyron is a brand of graphic system used in many newsrooms. Graphics that run along the bottom of the screen during a newscast are often referred to as "chyrons."
} 
(Producer/Editor, 5 years). Such efficiencies further shrink the number of people contributing to the gathering and distribution of news, while also removing the time and skill available to apply creative touches to the newscasts, and the number of people available to check for mistakes. “Technology has made getting information and show elements easier. However, it has also allowed my company to downsize, asking more work out of me while others lose their job” (Producer Survey Participant, 14 years). In-studio work has also been affected by the implementation of technology. Many studios no longer have human camera operators stationed behind studio cameras, correcting shots and providing direction to those on-air. Instead, cameras are run either by a remote joystick, or, in ever-growing numbers, by production automation systems. “There’s nobody in the studio except the talent...we do more with fewer people, and that's in part a function of the technology that's available today” (Anchor, 40 years). Anchors often roll their own teleprompters while keeping up with changing scripts, updating breaking news, verifying information, and moving around a studio set. One anchor on a multi-hour morning news program decided the move to self-prompting was the beginning of the end of her career. In a Facebook post on her personal page, she detailed everything she felt was wrong with having anchors prompt for themselves:

Today we started running our own prompter on our morning show. Today I started reading cold and putting all my faith in our great producers to not write me a script that will get me fired. Today I started a countdown clock to my last day on the morning show. Today I stopped thinking about WHAT I was reading and spent my whole time worrying about WHERE the words were on the screen. 
News Work 92

Today I became a true talking head.

I don't see the copy before I say it. I don't interpret. I don't look for factual land mines, context, or errors.

I just read. And run my own prompter. (Facebook post, used with permission, September 13, 2016)

Such statements again point to concerns about the public interest function of local broadcast media. If journalists are no longer given the opportunity to find "factual landmines” or fill in missing context for viewers, then the journalism suffers. Using technology as an excuse to force job convergence so a parent company can eliminate paid positions, consolidate work flow, and keep costs down speaks more to a marketplace mindset than to a public interest one.

Television station owners also use technology to replace many of the people who work in production control rooms. Automated production control centers replace living specialist human labor with pre-coded computerized labor. In the process, workers who specialize in audio, video, graphics, and other previously-utilized production positions lose their jobs or have to compete for a spot as an automation director. "The directors...do just about everything now... I mean, they're responsible for having the cameras set up properly, for the audio, for everything” (Anchor, 40 years).

Having one person with a computer control numerous pieces of equipment leads to technical and informational mistakes on the air. One director (13 years) recounts a factual mistake on a graphic airing in three different newscasts before finally being caught: “A lot more stuff just falls through the cracks.” When combined with producers 
News Work 93

who are also editing their video, reporters shooting and editing their own stories, and anchors running their prompters, the portrait of newsroom job consolidation is clear: owners are using technology as a means to downsize their employment obligations. These moves are not improving the journalism provided to the audience; instead, they are decreasing the overhead a station owner pays for human workers, and increasing profit margins through the use of computers, gear, and technology. This is the embodiment of Braverman’s (1974) labor process: increasing surplus value by exploiting labor. While the technological tools available to journalists have the potential to be used in service to the public good, their ultimate context here is for financial benefit.

\section{Social Media and Digital Overload}

When talking about technology in the newsroom, many workers immediately think of social media. Keeping up on Facebook, Twitter, Instagram, Snap Chat, and other web functions is a big part of the job description for many working in local television news, with $72 \%$ of survey takers and $46 \%$ of interviewees indicating they are expected to engage in social media. While workers of all job descriptions contribute to their newsrooms' online discussions, those who are on air are nearly universally required to participate, and often have specific obligations for how often and sometimes even what to

post: “They’re required to do their things to grow their likes through the year...They have all kinds of social media requirements that they have to follow” (News Manager, 20 years).

In many newsrooms, large, automatically-updating monitors publicly display how everyone is doing in their social media audience reach: 
News Work 94

Share Rocket was just introduced into our newsroom...We call it the Hunger Games. Because every 10 minutes, the board refreshes and it shows you who’s top 10 in the newsroom social... And we get the email every morning at 6am. And it tells you who's doing what. (MMJ, 16 years)

Like attitudes towards the implementation of other newsroom technology, social media and online work fall into a "both helps and hinders" job performance category. While many like having so much information and a way to engage with the audience at their fingertips, newsroom expectations often tip the workload into nearly unmanageable territory. Television journalists are no longer solely working for television:

When I have to stop and tweet and do a Videolicious ${ }^{7}$ and these other things, it takes my focus away from the story, and puts it on generating more content. And I think that initially I think that my stories would suffer some from that.

(MMJ/Reporter, 35 years)

An investigative photojournalist (33 years) understands the importance of “digital clicks” for his stations' sales figures, but is concerned about the impact on the news product produced:

I wish sales people would take a couple of days in our shoes (laughs) that do all of that while covering a story and trying to get it right...you wind up with this kind of superficial coverage of a story and then you wind up missing something. There is a sense of urgency to provide content on multiple platforms. "Digital first” is a key phrase in many newsrooms, putting additional pressures on those gathering

\footnotetext{
${ }^{7}$ Videolicious is mobile software used to create short videos, complete with station branding.
} 
News Work 95

news in the field to post or update a story online before the competition, personifying Örnebring’s (2010, p. 65) “more news faster” and “more news first.” The line between television and digital is blurring by design, not only forcing newsroom staff to do more work, but also threatening their employment if they are not sufficiently speedy and proficient sharing digital content:

We're digital first, broadcast second. We break stories on the digital platforms. You have to be the first to break a story on Twitter. Get up your web story, picture, or video. So if you don't know how to do those things, you're not going to work. The social is everything. (MMJ, 16 years)

This also applies to those who are not on the air. As Facebook Lives, tweets, and web videos of events that have not been broadcast are expected from field crews, photojournalists feel pressure to post:

The push is to get it on the web as quick as possible. That's just where the viewers are. That's where the engagement is. And the quicker you get something on the web, the more interaction with the viewer you can have, which may develop the story later on in the newscast. (Photojournalist, 9 years)

This drive to be first is not new to newsrooms, but the immediacy of instant availability on the internet and social media means that journalists feel accuracy is sometimes sacrificed for speed when it comes to online postings. In a study of over 1,000 full-time U.S. journalists, three-quarters worried about accuracy, and half felt journalism quality suffered because of social media obligations (Weaver \& Willnat, 2016). Because there is a lack of posting oversight for journalists, these concerns are not surprising. An 
News Work 96

investigative journalist who has been in the business for 34 years finds the concept of unsupervised social media posting quite amazing: "It just boggles my mind that we're able to tweet and post as journalists without a second set of eyes reading our stuff...everybody says that's fine.” Yet concerns about quality, accuracy, and even libel on social media do not bode well for keeping the public well informed of its community surroundings, nor for the trustworthiness of the journalism outlet.

The impact of online media does not stop at the computer. Some newsrooms choose stories for broadcast based on how well they play on the web. A few television stations have even dropped broadcast Nielsen ratings for Share Rocket or other online audience metrics. A news manager describes it not as necessarily deciding to not air a story because of online trends, but more that "they make us rethink how we do something that we run on tv" (News Manager, 20 years). A producer sees the trend differently, however:

They're really focused on us being digital first, a digital first newsroom. And so, a lot of what we do is dictated by how is it going to play on the web...whatever's trending best for us, they always want them in the newscast in some form or fashion. (Producer, 15 years)

While tv crews are providing new content for the web, many web teams are focused on updating those stories and breaking news, as opposed to enterprising original content. A digital producer wants news outlets to broaden their horizons "because you need to be able to have great content that's not just regurgitating press releases," 
News Work 97

especially as digital and broadcast news boundaries continue to blur (Digital Producer, 3 years).

Those regurgitated press releases raise content questions discussed in the previous chapter. Press releases are provided to news outlets by organizations promoting something beneficial for themselves. If local television websites are focused on such releases, and television stations are relying on their websites for what to put on the air, then a vicious cycle of promotional materials is potentially being fed to viewers. While this is not the only material on the website, even the notion that this might be happening should make journalists and audiences question where their information is coming from.

On a positive note, local television news websites do provide space for "extras” that may not have a forum on broadcast television. TEGNA, one of the largest local television owners in the United States, has produced web-specific investigative reports on the opioid epidemic and the insurance consequences of veterans suffering from PostTraumatic Stress Disorder (see, for example, WXIA-TV, 2016). These reports were promoted heavily via social media and debuted in their entirety online. One received 4 million page views and 160,000 video plays within 6 days (Greeley, 2016).

Unlike posted press releases, this use of web space can cater to the public interest and reach a much wider audience than even a broadcast signal. Local stations need to provide their staffs with the resources to investigate, research, and produce such longerform pieces, however, for them to be beneficial to the community. As will be discussed more in the next chapter, such resources are often no longer available, as they are less 
News Work 98

cost effective and more time- and work-intensive than standard "day-turn" stories reported on during a shift and rarely returned to for follow up.

Station websites also post complete interviews that may not have time to air on television. One journalist interviewed then-President Obama and uploaded the full conversation to his station's website after only a portion was shared during newscasts. An investigative team member considers the website as both a type of legal protection and a method to showcase to the audience exactly how information is gathered:

We have the space to lay down the interview in its entirety, raw, with questions, answer, question, answer...an unedited version of what the interview was. And it covers us legally a lot then...I mean we picked the questions and the answers that you had for our story, but if you feel you were treated unfairly, we also put the raw interview on the web, and...we can prove or pull the analytics as to how many people viewed it, probably way more than people actually saw it on the air. It covers us. It's a good tool. (Investigative Photojournalist, 33 years) Those out in the field struggling to complete their workloads tend to not follow digital first mandates. Multi-media journalists who are already writing, reporting, shooting, and editing their own stories for air often leave their digital responsibilities for last. This is done mainly as a job-saving mechanism: if a story does not "make slot" when it is supposed to air on television, the reporter could be out of a job. Digital outputs, on the other hand, have no deadline: 
News Work 99

If you can’t make deadline, you can't work. So, no offense, there is no deadline on digital. There's no newscast per se. It's a touchy subject in our newsroom right now. A very touchy subject. (MMJ, 16 years)

Connecting with the social media. For many newsroom workers, social media offers tips and information about community happenings and provides a way to connect with audience members. Journalists appreciate these aspects of the online world. Opening a dialogue between news personnel and viewers at home allows journalists to know what is important to the viewing area community. An investigative reporter recalled a story he never would have known about had it not been for a viewer on Facebook: "I would not have gotten that tip I don’t think without social media. Without her being able to reach out” (Investigative Reporter, 34 years).

For some job descriptions, however, social media is one more information source to sift through each day. A photojournalist laughingly described the usefulness of social media as “another level of clutter you have to be involved with at all times," even after acknowledging its usefulness as an information source (Photojournalist, 9 years). Producing staff concurred:

Now it seems a lot of police departments, politicians, they don't email us, they'll just post statements on Facebook and Twitter. So if you don’t see it on your newsfeed, or you're too busy and you don't have time to go through your newsfeed, you might miss something. So again, I think it's helpful, but it's kind of another thing to keep track of. (Producer, 8 years) 
News Work 100

Social media is such an important aspect in newsrooms, hiring decisions are made based on how many posts and followers journalists have when they apply for a job: I mean all of my job interviews, they're like looking at my Twitter account, how many followers do you have? Do you engage with people?..How do you engage with people? Do you just post a link and just let it sit there or do you talk to people? You know, so. It’s very important. Huge. (MMJ, 16 years)

Another MMJ at a station not affiliated with one of the major broadcast networks has no social media requirements, but recognizes its importance in the business: "when I’ve gone to journalism job conferences, industry type things, everyone’s just talking about 'Oh I want to see how many followers you have on Twitter, how many likes you have on Facebook'” (MMJ/Host, 8 years). Social media engagement is a requirement not only on the job, but to even obtain a job.

This two-way conversation with the audience is important enough that those who teach the next generation of journalists at the college level have stressed its use with students. They emphasize the importance of taking their skills beyond the classroom and broadcast news boundaries:

What we try to teach our students now is the whole multi-platform idea that you guys are content producers, but it’s much more than just putting together your package for the newscast. We need you to be tweeting from the scene of a story. And your story's going to go out on our Twitter page and our Facebook page and plus our website, and on TV. So it's trying to get them to understand that it's more difficult, quite frankly...from the old days where you went and covered a 
News Work 101

fire, let's say, or an event, and you shot it and then you came back, and logged your video and put together a story. Now, you'd better be doing some tweets right when you get to the scene, and updating people, and then you come back and put your story together, and then it's gotta go out on TV and online and on Twitter and everything else. (News Manager, 27 years)

\section{Training and Equipment Selection}

With new media, new technology, and newly converged job descriptions in the newsroom work environment, workers anticipate training. However, those expectations are often not met. For some, it is seen as “classic newsroom sink or swim. We're going to throw it in there, give you a minimal explanation and hope it works” (Producer, 5 years). A reporter-turned-MMJ recalls being given an hour with a photographer to learn how to shoot video. "Every time I had a question, I had to track someone down... and then our photographers were very generous with their time.” He said at the beginning "there were days I would come back and barely have enough stuff to use” for his on-air stories because he did not know what footage he would need while he was out in the field, due to lack of training (MMJ, 35 years).

Another MMJ similarly felt like he had to lean heavily on fellow journalists to get his stories on the air when he was first starting out. "I had a woman who's been in the business for 20, 30 years, and she really helped me” (MMJ/Host, 18 years). Otherwise, his training was inadequate for the transition into solo journalism, especially for the larger-sized market he found himself in. 
News Work 102

Such tales highlight what can easily turn into an alienating labor experience: lack of creative control over the product being produced. When a worker does not know how to use the equipment provided and is still expected to produce a product in the same time frame as those who have been doing so for years, alienation sets in. Per Marx (1959), when workers are no longer in control of their actions but are instead directed by the economic outcomes of capitalism, they lose their ability to control their destiny. This is a set up for what Kalleberg (2011) calls “bad” jobs.

Alienation, a lack of management recognition, and the disconnect from the anticipated final product greatly influence the stress levels of the workers. In describing his less-than-adequate preparation for solo journalist life, an MMJ described it as:

It was the worst I ever went through. I wanted to cry. I wanted to quit...There were a lot of times when I really seriously thought if I just park this work car, leave the work phone, and just walk away and never come back, they'd never find me and I'd never have to be responsible for any of this ever again. It was horrible. In a lot of ways. Just the stress. (MMJ/Host, 18 years)

Stress has been shown to decrease productivity and increase burnout and employee turnover in information industries (see, for instance, Sethi, King, \& Quick, 2004). As local television news employees are handling more job duties with potentially inadequate training and arguably high stress levels as a result, the situation does not bode well for decreasing employee alienation, increasing community involvement, or even ultimately saving the employer financially in the long run. Replacing employees, even with cheaper hires, is a time-consuming and expensive prospect (Cappelli, 1995). Getting 
a journalist incorporated into a new community, understanding story context, and building the trust of sources, also takes time. Therefore, decreasing stress and alienation should be something newsroom corporate owners look at positively, including better job skills and equipment training.

This is not to say that everyone has negative training experiences. Most seem to believe, however, that much of the learning curve happens once the new tech is online or on the air. “Ultimately, you can't prepare for certain things and then you find out on-air that you can't. Now we know!” (Producer/Editor, 5 years). Finding out how equipment works while on the air also impacts the audience in ways that may detract from newsroom credibility and professionalism. At a time when both trust in local television news and audience tune-in are in sharp decline, such mistakes impact both the viewer and the station’s finances (Matsa, 2017b; Swift, 2016).

Not one person in this study has much of an influence in equipment decisions, and the level of frustration about this is high. Only one production manager has had a chance to test some lower-level equipment before purchase; but all other major equipment decisions are out of his hands:

There are certain things that they'll test at certain stations and they've come to me a few times and said hey we want to test this.... but the big stuff, like the switcher, and [automation], and [graphics], and audio boards, that's at a higher level than me. (Production Manager/Director, 13 years)

All of the behind-the-scenes technical personnel interviewed for this project have similar stories: those outside of their ranks make the major decisions, without their input. 
"There were rumors, and our senior director at the time was going on a lot of trips -secret trips. He was part of the nomination committee" for automation equipment that would replace human production workers (Director, 30 years). A Master Control operator and Video Editor similarly had limited to no input on the equipment they use daily for their craft.

Even on the digital side, web teams feel their hands are tied when it comes to how much influence they have on the platforms and equipment they work on: "They say we have input, but we don't. And I've asked for lots of things that I haven't gotten. I feel like I’m beating a dead horse every single time I ask” (Digital Producer, 3 years).

\section{Consequences of Forced Technology Implementation}

This disempowerment of journalists in choosing the tools of their trade contributes to workers leaving for better opportunities, breaking their community connections, and leaving audiences less informed and less empowered in the process. Those who feel alienated have a negative view of their business and are often still involved only because they get paid. "I look at it as a job. I go in, I do my time, I get out" (Photojournalist, 18 years).

One MMJ is using the time left in his contract to prepare for whatever new direction might come next, potentially outside of a local television newsroom. In the meantime, the company he works for has chosen him to train others on the specific corporate-chosen technology used by all of its stations. He is making the best of the situation: 
News Work 105

I have been forced to challenge myself, again with this training that I'm doing with other people, I really didn't want to be a part of, but how do you say no when the company asks you to do it?...At first it was like trying to force new gadgets into my routine that have now become a little more part of my routine...the technology has improved and made the job more fun and better. (MMJ/Host, 18 years)

Personal craftsmanship and newsroom trust in the ability of workers to do their jobs elicits passionate responses. A director/manager sees the frustrations of his peers, during what he terms "too much micromanaging" in his newsroom:

I would definitely check the manager resources and work that out. Because I think there's too many managers and not enough actual people involved. And I can see that in the producers and writers faces sometimes, when they come in the booth. (Director/Production Manager, 13 years)

The implementation of new technology is considered both a blessing and a curse by local television newsroom workers. While using new technology can lead to craft worker innovation and provide new spaces for unique and in-depth journalistic output, many workers view it more as a way for their parent companies to consolidate job descriptions distributed among as few workers as possible. The added workload, often with unfamiliar gear, no staff input, and little training, increases worker stress, decreases worker perceptions of news story quality and dissemination, and disempowers those who feel they have no say in the tools they use in their trade. Potential creativity is lost to time constraints levied by additional job duties, expected increases in content gathering and 
News Work 106

distribution, and a mindset described as "make slot not art” (Facebook post, April 16, 2018).

The digital realm puts the latest information at the fingertips of news workers and provides a new space for story tips, long-form content posting, and audience interaction. At the same time, it adds another multi-layer source journalists need to dig through for story data and provides multiple extra platforms for news staffers to fill with content. This content is expected to contribute to viewer "clicks" contributing to station ad revenues that are never seen by those providing the content.

Technological innovation provides opportunities for news staffers to share more relevant content, increase creative production value, and partake in two-way interaction with their audiences. But their workloads are such that many of these more creative and community-enhancing endeavors are nearly impossible to carry out in the course of a work shift. The overworked staffers participating here have demonstrated that ownership often adds technology to newsrooms not to generate better journalism or more creative content, but instead to consolidate employment and enhance revenue-generating opportunities. Fewer staffers grappling with more technical and content responsibilities are concerned about the quality of their final product not living up to acceptable journalistic standards. This is not serving in either the public's nor the workers' best interests.

The next chapter explores the consequences of this compressed labor force in more detail. 
News Work 107

\section{Chapter 7: Converging Job Descriptions in a Compressed Labor Force}

To keep profits perpetually high (and subsequently keep expenses low), companies seek cost minimization, predictability, and flexibility when organizing their work forces (Osterman, 1987). In the past, these goals were often achieved via an internal market structure, with workers climbing the job ladder within a company and remaining for their careers. This allowed both the firm and the employee to plan for the future, and for the employee to become an expert in firm-specific skills. Loyalty to the employee by the company was rewarded with loyalty to the company by the employee, or at least adequate job performance. Low turnover aids output predictability and potential performance flexibility, while fewer employee candidate searches and training sessions lower costs (Cappelli, 1995; Tilly \& Tilly, 1998).

\section{Downsizing for Economic Advantage}

As neoliberal policies took hold in the United States and around the globe, deregulation positioned businesses to seek higher profit margins often at the expense of their employees. In the 1980s, President Reagan linked economic competitiveness with the ability to eliminate workers from the work force to gain an edge. Now, lean investment markets tend to respond well to company downsizings (Cappelli, 1995). Layoffs have since become part of basic firm restructuring. Media markets are no exception. After the U.S. economy crashed in late 2007, the local television news industry shed over 1600 workers in 2008 and 2009, even as the number of news hours being produced grew (Papper, 2011). 
News Work 108

Numerous participants in this study took an economic hit during the recession. A producer was downsized and out of work for 8 or 9 months. A photographer took an unpaid furlough. Multiple workers under contract voluntarily took pay cuts or forwent raises “because you don’t want to be the only guy who says no” (Investigative reporter, 34 years). These were in addition to the $32 \%$ of surveyed workers who had experienced cut hours or had been downsized in the past. When the survey was conducted in 2016, fifty-three percent were still concerned about losing their jobs, and of those, nearly half (46\%) had experienced previous hours cut or complete job loss.

Beyond downsizings, what became known as "buyouts" were a regularlyrecurring theme during this project. TEGNA, one of the largest local television station owners, was offering early retirement packages to certain station employees over the age of 55 with more than 15 years of company tenure. Employees perceived this as a moneysaving measure; longer tenure at a station generally translates to larger paychecks. But the news veterans involved were also some of the most experienced personnel at the station. Their loss leaves big gaps in community reporting expertise.

Because of these buyouts, dozens of long-time news workers left the company in 2016. The long list includes 4 anchors and reporters at Seattle’s KING, who all retired on the same day, along with at least 11 more of their colleagues. One had been with the station for over 45 years. At least twelve staffers from WFAA in Dallas, once considered Belo's flagship station before being bought by TEGNA, also “retired,” including 3 photographers with over 85 years of combined experience at the station (Eck, 2016). 
News Work 109

Those working at other companies who were familiar with the buyouts wondered what it could potentially mean for their futures in the industry:

I would be afraid, shaking in my boots right now to try to get a job with TEGNA. Those guys, it’s like every 6 months or every quarter, depending on their profit scale, they're going to lay people off, and it's either off the top or off the bottom. (Investigative Photographer, 33 years).

The massive loss of experience at stations across the country does not speak well to serving the public interest. Those who have been in a market for years have strong community connections, a sense of story context, and an understanding of what the underlying issues of a community are, all characteristics reminiscent of those discussed in chapter 2 as necessary for community empowerment and democracy. Removing decades of experience from an area's journalism field in a span of days does not promote citizenship knowledge as much as cost savings. The value of long-time employees will be discussed more throughout this section.

Numerically flexible workers. Following downsizings, companies often hire outside workers and subcontractors to fill employment gaps without permanently adding employees, making firms more flexible to shifting economic conditions. These numerically flexible workers are hired on an as-needed, short-term temporary basis, and their skill sets may vary (Kalleberg, 2001). In the broadcast news business, these workers often receive "freelance," "contract," or "vacation relief” titles. Among these is a vacation-relief video editor who was supposed to be on a 9 month on, 2 month off work rotation, but found his off time lengthening while paid work time was decreasing: "I 
News Work 110

worked my 9 months. I was laid off for 4, and then I was only brought back for 4. Laid off for another 2, brought back for 2. And I want to say I was laid off for another 4 months after that" before the 9 months of continuous work actually began again (Video Editor, 18 years).

Of 78 workers who answered a related survey question about their job status, 9 were non-full-time, regular staffers. Six of these identified as part time (8\%), and 3 (4\%) as freelance or contract workers. Of 24 interviewees, 1 was a contracted freelancer, 1 was vacation relief, 1 had previously been vacation relief, and 1 was working on a per diem basis ( $4 \%$ each).

This is not to say that all non-standard scheduled workers are unhappy; some say they enjoy the freedom of their work schedules. Two of the freelancers indicated they were satisfied with that status. Ryan (2009b) found that freelancers are generally happy with their pay, which tends to be higher than that of more permanent staff. Florida (2003) sees these workers as part of the creative class: flexible, often project-oriented employees, who like to think for themselves for a living, and enjoy the cultural offerings of the cities they live in more than the community aspects. However, Ryan's freelancers were not as happy with the potential loss of future work and a lack of employment benefits, such as health insurance. This is an aspect of Florida's creative class that Scott (2006) sees as a downfall: the lack of a job structure luring these creative individuals to stay and work in a community. Indeed, permanent staff members in Ryan's analysis appreciated their less-precarious employment status. 
Participants here agreed: most of those who worked any schedule other than regular full time expressed displeasure at their situation. Only 1 of the 6 part-timers in the survey was happy with that status. One of the 3 surveyed freelancers was looking for a more permanent job. The interviewed vacation relief worker was happy to have full time hours with benefits but wished for a more regular and less life-disrupting schedule. The per diem worker wanted guaranteed hours. The interviewed freelancer was trying to get a full-time job before his 1-year contract ran out, which would cut his maximum allowed hours to half-time. The former vacation relief worker had given his bosses an ultimatum after receiving his fifth layoff notice and was finally rewarded with a permanent full-time job.

Even though many workers prefer standard full-time work arrangements, numerous large-market stations lean towards freelance or contract workers when hiring for job openings. For example, a long-time Top 5-market photojournalist called himself a “dinosaur” and predicted he would not be replaced with a full-time staffer when he retired. “They will replace me with a daily hire person. A freelancer” who would make the same pay per union contract, but would not receive paid sick days, vacation days, or a benefits package (Photojournalist, 40 years). This was a correct prediction; his replacement is indeed a freelancer, and not a permanent staff member.

Scheduling complications. The use of downsizing, contract employees, and nonstandard work schedules leads to riskier job prospects and community involvement for local workers. Precarious employment and unpredictable work conditions affect not only an employee’s work life, but also individual, family, and community endeavors 
(Kalleberg, 2009). Stability is considered necessary for “workers’ sanity, nurture, and happiness” (Storper \& Walker, 1983, p. 7).

Work-life balance turns into a challenge for newsroom employees who have irregular schedules. While news schedules are not known to be 9 to 5 jobs, some workers do not have consistent days, or even dayparts, off. One of the vacation relief workers is considered full time, but only has 2 permanent days of work per week, and those are on weekends. The rest of her hours are dependent on what position needs to be filled. This could include shifts on mornings, days, or nights. When we spoke, she was in the middle of a 17-day work stretch. When asked how she balanced her schedule with the rest of life, she revealed that her partner also worked in news, "so she understands the bullshit when I say, I gotta go to bed at 6 o'clock” (Director, 13 years). Another worker is on a per diem arrangement with his station, and never knows exactly what his schedule is going to look like: “I’m usually 4 to 5 days a week. Not always, but usually. Sometimes, I’ve had some where I've gone 14 days in a row” (Master Control, 41 years).

The number of participants with nonstandard work arrangements indicates that some stations have taken what Kalleberg (2011) calls the "low road” approach to filling workplace needs. These treat labor like other production resources and fill job holes on a “just-in-time” schedule. Those labeled vacation relief, freelance, per diem, and even some of the part time workers ride an employment wave based on market needs instead of skill and company loyalty. Longer work weeks, less worker autonomy, and higher stress levels are common. Both the per diem and the vacation relief worker want better work schedules. Providing them with such schedules, however, would require their 
companies to commit to their employment, instead of using them to fill holes in the schedule as needed. From a marketplace standpoint, this may not be the most financially prudent employment model, but instead might be one that protects the public interest by retaining news workers engaged in their communities.

It has been shown that good, stable jobs "provide a foundation for a high quality of life, healthier workers, and stronger families and communities” with workers “more likely to be able to put down roots in a community, conceive and raise children, buy a house, and invest in family lives and futures” (Kalleberg, 2011, p. 2). In precarious working situations, workers can neglect becoming socially engaged in their communities for fear of job loss and an imminent need to move elsewhere.

Since community connections have been shown to be essential to getting jobs, changing jobs, and getting promotions, avoiding such interactions affects both current and future community and labor prospects. These networks not only connect the worker to the employer, they also connect to many resources outside of the workplace, allowing for increased bargaining power and interactions within the shared culture of both the community and organization involved. The lack of such a network can easily become an economic disadvantage for both employer and employee (Tilly \& Tilly, 1998). It also can lead to a less stable community life outside of the workplace.

Newsroom tenure. Stations with high employee turnover, voluntary or otherwise, foster concerns about the quality of newsgathering and reporting to community. To stretch budgets, newsrooms often hire younger workers with less experience and often no connection to the area. This concerns working journalists: 
News Work 114

I think it's important that people stay in one market for years because you become familiar with the issues involved, and you become familiar with the people. Those who are new to the area, there’s a learning curve, without a doubt...the longer you stay here, the more invested you are in where you live. And I just think that's an advantage for the station. (Anchor, 40 years)

A producer who had recently moved into one of the largest U.S. markets noticed marked differences in reporting quality and the journalists' community connections, even compared to other markets in the top 25. Her sentiments illustrate the importance of news workers being well-connected to the communities they are covering:

People who are just starting their careers...they don't know what to get necessarily, what to collect. And here it's like they're just the utmost professionals. They have such great connections within the people in the city. The cops, the firefighters, the aldermen. It makes for really good journalism. It's honestly irreplaceable when they lose good reporters; it's really tough because they have such great connections. (Producer/Editor, 5 years) Meanwhile, producing staffs are notorious for high turnover, constantly putting newer, less-experienced people in charge of each daily news show. A producer in one of the 10 largest markets has only been at his station 3 years and is already one of its more senior producers. Morning show producers are often younger and less experienced than those working dayside and evening shifts, yet are putting together multiple hours of news for the community each day. A producer in his late 20s working the evening shift describes himself as the youngest producer on that shift, but a bit older than those on the 
morning. While age does not dictate ability, it does inform the amount of time one has lived in the community. Positions with high turnover leave newscasts vulnerable to potentially less-than-relevant community news coverage.

This is where mentoring can play a big role in the success of younger and newer staffers. It was exactly this type of mentorship that motivated a 35-year veteran of the business to get started in TV news, after changing course from pursuing a non-journalism degree:

I wanted to write so when I was working as a production assistant, instead of taking a dinner break, I would stay and write...I'd write one story for [the anchor] every day. And she'd go over it with me and we'd talk about writing...I got an audition tape out if it... and got my first on-air job. (MMJ/Reporter, 35 years) The desire for greater mentorship and journalistic growth is driving another MMJ to look for a new job. After 8 years at her non-affiliate station, she is the most senior person in her newsroom. “I could stay there, but I'm not going to grow. I don't get feedback on my writing as much as I'd like to...I'd like to be around other people that I could learn from.” These learning experiences influence journalists well into their careers. A video editor (18 years) calls a news director he worked with early in his career “still a hero of mine;” he thinks of that newsroom as "being where I learned how to work in a professional news environment.”

As station owners encourage those who have been around for decades to leave for budgetary reasons, the big question is who will guide the next generation coming into the newsroom, or the area, or the latest job description. The TEGNA early retirement buyouts 
News Work 116

were specifically aimed at workers who had the longest tenures at their respective stations.

I think the danger is, you're going to have that void in experience in leadership, that person in the newsroom, the go-to person, who you can say, 'well Jack's been here 35 years, Jack?’ Jack says ‘yeah I remember that, of course. We have film of that somewhere.' That sort of thing. And replacing people with very inexperienced, very cheap labor. I think there’s a big danger in that. (News Manager, 27 years)

The exodus of news veterans has many worried about the impact on news coverage. There is a noticeable gap between the news veterans and the less-experienced in some of the biggest newsrooms in the country, with the scale tipping greatly towards those newer to the business:

You can count in our newsroom the amount of people that have been around for 20-plus years on less than a hand. You can count how many people just have been in the business less than two years using both hands and...all of your toes. It's that big of a gap...that's not sustainable. You gotta have people who are going to come into the business and stay in the business and make a living out of it. And that's not happening right now. We're not headed in that direction. (Investigative Photojournalist, 33 years)

Those who teach the next generation of broadcast journalists at the university level have noticed a shift in the jobs students can now obtain right out of college. They start in markets much larger than in previous years, losing the ability to learn on the job 
in smaller markets like previous generations. A newer journalist already in a top 25 market acknowledged that building the necessary job skills and connections to dig into community happenings takes time. When she started, she admits “I didn’t really know what I was doing” (Digital Producer, 3 years). She took it upon herself to learn the key players for her role in the newsroom.

News managers, in particular, have noticed an increased need to mentor their new hires because they do not have the field experience like those in the past. Without spending time in smaller markets before moving into the top 25, “they’re not going to gather the right things that you need for your newscast” (News Manager, 20 years). This inexperience leads to missing crucial elements of stories or missed story angles. For instance, one news worker knows an MMJ who missed a local campaign story follow up thanks to being overwhelmed by the required multi-media job duties. ${ }^{8}$ Another news manager notes “These days it seems management's so much more involved in the direction of things. And I think part of that is because the experience level has really dropped in many of these positions," leading to more work for the managerial staff, as well (News Manager, 27 years).

The great variety of experience levels that can be found in large market newsrooms indicates that mentors with long tenure can provide an immeasurable resource to those still trying to get their bearings in their communities. They not only have the advantage of polished skill sets, but also the ability to share context and contacts

\footnotetext{
${ }^{8}$ Redacting identifying information to protect the discussed MMJ.
} 
News Work 118

with those newer to the area. The trend towards encouraging such newsroom veterans to leave is detrimental to reporting for the public interest.

\section{Audience Labor}

Audience members, usually unpaid, also play a role in providing content on air and online. Because every local television news station has a website, at least one Facebook page, and most have mobile apps, newsrooms exploit audience labor to keep these digital platforms filled. In 2014, 14\% of surveyed audience members using social networking sites contributed pictures and $12 \%$ contributed video to a news organization's web page (Matsa \& Mitchell, 2014). Smart phones and ubiquitous data connections mean that news organizations expect unpaid news tips and content from their audiences in an effort to fill time and digital space for maximizing station revenue (Higgins-Dobney \& Sussman, 2013).

Taking news audience labor to the next level was a service called Fresco News. Newsrooms could post mobile app requests for video or pictures to be provided by regular viewers for $\$ 60$. This viewer gig work supplied news footage for stations’ air and websites while saving the station costs of labor, equipment, and vehicle wear and tear. Fox Owned-and-Operated stations in 10 of the country's 25 largest markets had a partnership with the service (Baig, 2016). A smaller-market station in Anchorage, Alaska relied heavily on audience-provided video for its newscasts, to the point where the Fresco News website prominently displayed a video with the station’s Chief Operating Office touting how much money he saved by using this service in place of professional station photojournalists. The service ran into financial difficulties in 2017, however, and appears 
to have shut down. Chat and email inquiries have not been returned, and social media postings by former Fresco News video providers indicate they are not being paid nor having messages answered, taking labor exploitation to the extreme.

Even with services like Fresco News and the ease of posting video to the web, paid newsroom staff are not really concerned about audience-provided content. A photojournalist (18 years) estimates about 10 to 20 percent of his station's video originates from viewers. “To me, that's a very small amount.” User-generated content (UGC) is used by stations to get video or pictures on the air or online quickly, until a station worker can get to the scene. Once the professional video is ready, audienceprovided clip stops being used.

The exception to this is weather. Weather pictures and videos from viewers, aired with name or social media handle credit, are considered standard fare. These are not followed up with a professional visit, unless the situation is "really really bad" or “something more controversial” warranting a crew and further investigation (Producer, 5 years). Otherwise, weather UGC fills broadcast and web space without staff considering the implications of the practice.

In reality, the widespread use of user-generated content is a strike against the craftwork involved in professional news work. Pictures, stories, and video submitted by viewers are removing that skill from the professionals and putting it into the hands of cheap, often free, amateur labor that may not have the same journalistic skills as a trained news crew. The audience's unpaid labor provides content for the financial gain of 
commercial organizations, potentially at the expense of professionally-trained craft journalists.

\section{Increasing Workloads and Job Convergence}

For those paid workers remaining in local television newsrooms, the quantity of work that needs to be accomplished is growing, while the time to get it done remains the same. Eighty-three percent of survey respondents indicate they are providing content and/or technical support for more newscasts than in the past. Seventy-one percent of these employees who are doing more have not received a pay increase to do so. Only $12 \%$ received a raise, and $10 \%$ took a pay cut while doing more work. Figure 3 depicts the sharp contrast between those with increased workloads and those being compensated accordingly. Most believe workloads are only going to increase in the future. Sixty-six percent of survey respondents think their station’s local television news output is going to

\section{Compensation Versus Work Load}

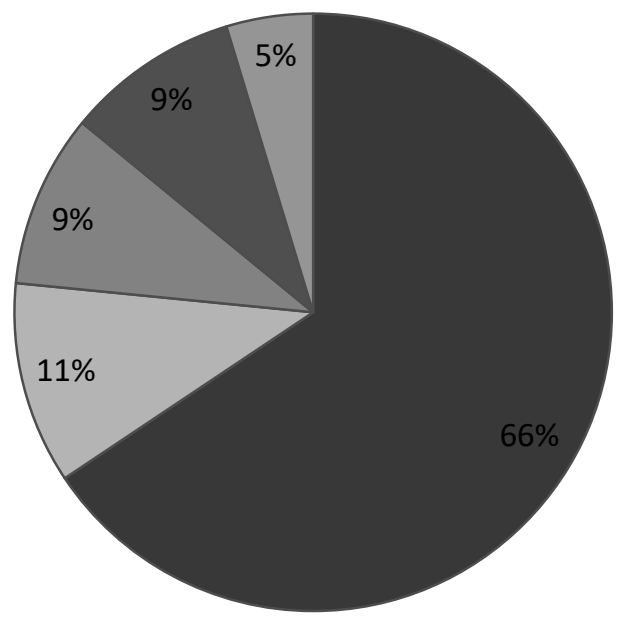

Increase work load, no pay change

$\square$ Increased work load, received raise

$\square$ Increased work load, took pay cut

Received raise with no change in work load

$\square$ No change in pay or work load

Figure 3. Pay changes for news workers versus work load. 
increase in the next 2 years, while a full 93\% think their station's web and/or mobile outputs will increase.

Interview discussions reiterate these claims. The numbers of news broadcasts, combined with ever-growing online duties, keep those working in local television newsrooms busy almost 24 hours a day. One worker characterized the news cycle as “constant. It never stops... we’re filling God knows how many hours a day now. It Just. Never. Stops. And you're always updating on social media” (Anchor, 40 years).

What did all of this extra work do to workers’ perceptions of their job performances? Nearly $40 \%$ of the surveyed workers who are providing for more newscasts believe the changes affected their job performance negatively. This is compared to $22 \%$ who thought their performance has improved. Figure 4 illustrates this pattern.

\section{Perception of Job Performance}

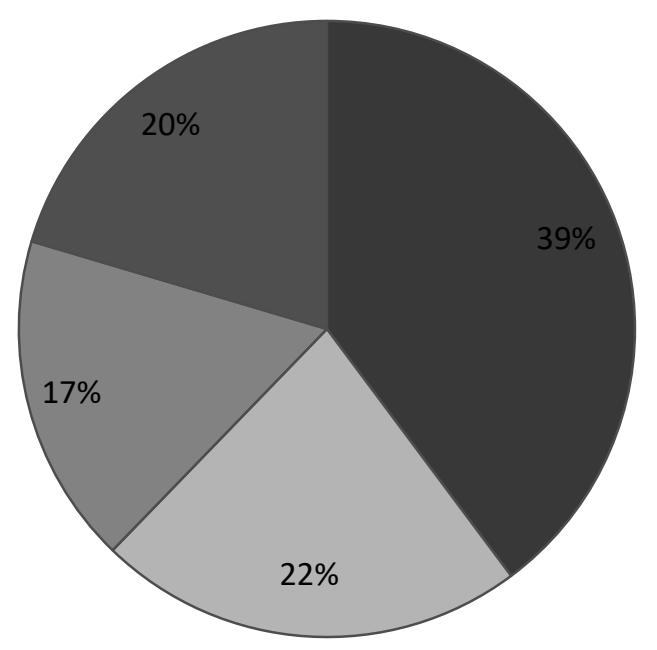

Affected Negatively $\square$ Affected Positively $\square$ No Effect

Not sure

Figure 4. Perceptions of job performance by workers with increased workloads. 
Surveyed workers are concerned not only with individual impact, but with the impact on the overall news product, as well. Those with increased workloads have slightly more negative outlooks on their output. Fifty-four percent of all respondents, and $60 \%$ of workers with increased workloads believe their news output has been negatively influenced. Only just over a quarter (28\% of all workers; $26 \%$ of those with increased workloads) feel the news product has been positively influenced. Figure 5 shows the complete breakdown.

This reaffirms previous studies regarding performance perceptions among news workers juggling heavier workloads. Reinardy and Bacon (2014) found that many reporters, anchors, and producers at local television stations across the United States felt they were sacrificing quality for time spent on digital platform endeavors. Time famine

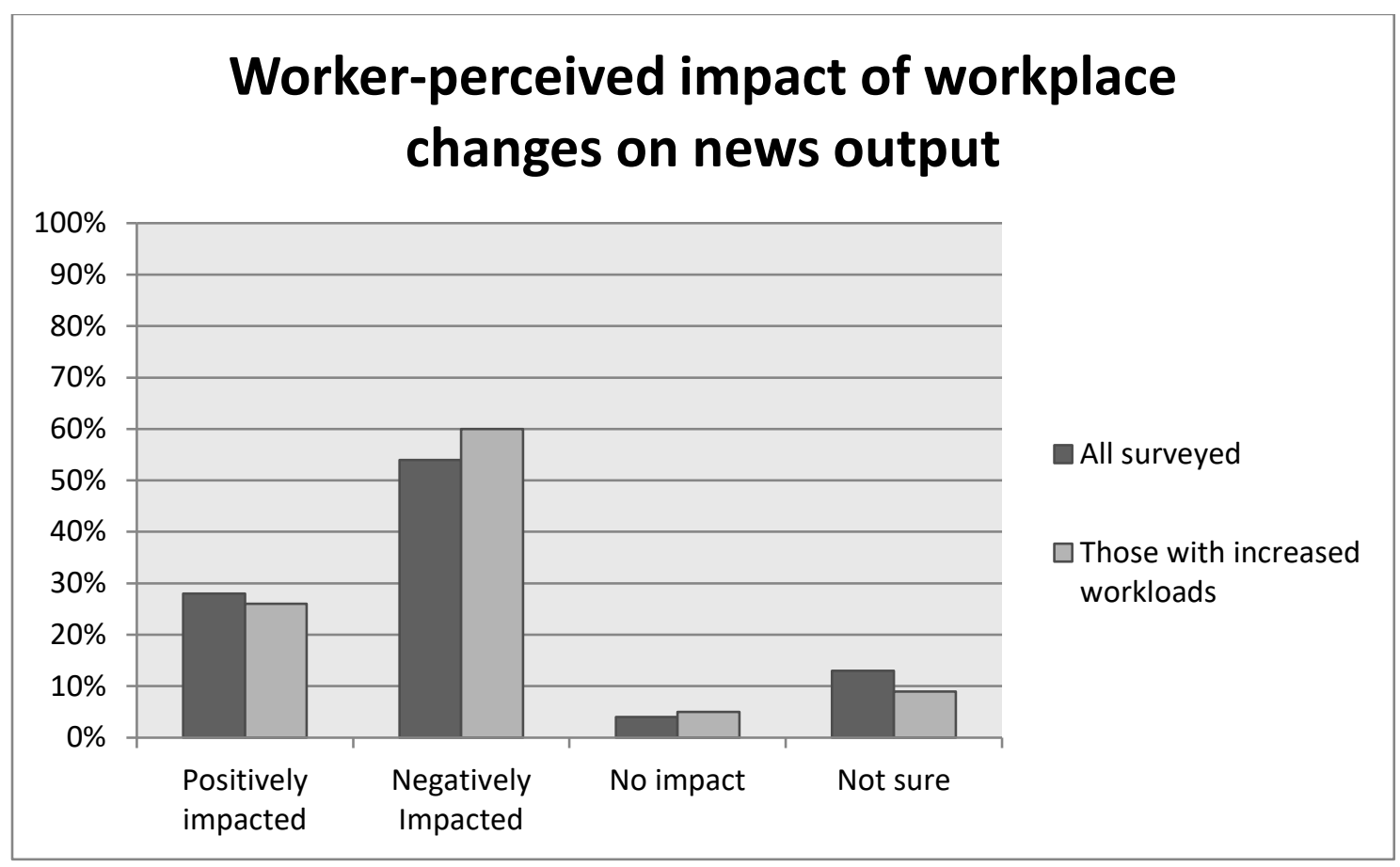

Figure 5. How surveyed workers think workplace changes have affected their news product. 
weighed heavily on these newsroom employees, with work overload depressing feelings of job satisfaction, work quality, and autonomy. A quarter of newsroom respondents felt similarly in Smith, Tanner, and Duhé's (2007) study; not only did the workers feel their work was suffering, they felt that their peers’ work was, as well.

MMJs. Staffers treated as multi-media journalists are growing at a rate of $2 \%$ to 3\% per year at local television news stations, forcing reporting, editing, and photography specialists to combine all three duties in the field (Papper, 2017c). One MMJ (8 years) feels the combination work detracts from the actual journalism work being done. "I can't really give them [interview subjects] 100\% attention. I have to be sure that they're in frame.”

This is a concern that has been expressed in multiple studies. Because MMJs are juggling more job descriptions individually than those working in reporter-photographer pairs, shortcuts become a way to make sure everything is completed on time for air and web. Blankenship (2016) found that multi-media journalists often feel their split attention reduces their job competence. They also worry more about unexpected occurrences because there is less leeway to recover. An MMJ (35 years) in this study concurs:

I'm concerned about the quality of what we're putting on the air... because the demands on our day are becoming so large that we're having to cut corners in order to get it all done. And I don't think that's a good service for the public. And as a long-time journalist, that concerns me.”

Perez and Cremedas (2014) found nearly $80 \%$ of their respondents agreed or strongly agreed with the statement that while carrying out multiple job duties, journalism 
News Work

quality suffers. Sixty-two percent believe job satisfaction suffers. Forty percent are rethinking their careers. One of the MMJs interviewed for this project embodies these perceptions. He is not certain he will stay in the business after his contract expires. As far as quality of work?

To this day, I would say I edit most of my pieces in 20 minutes. And that's not great work, no matter how good you are...time is being used better, but it still suffers just because I'm concerned about other things. My reputation will suffer less for bad video than inaccurate information. Or a missing element to a story. (MMJ, 18 years)

Many MMJs start their careers as reporters, and later add photographer and editor duties, although there are exceptions. In the case of one of the interviewees in this project, the transition from to MMJ occurred after 33 years as a specialist reporter/anchor. While embracing the idea, he finds balancing the multiple craft duties difficult:

In theory, I like the idea of controlling it all. From the finding the story and setting it up to going and doing the interview, to writing it, and then editing it. The problem for me is, the quality of the product that is the end result. It's just a better product when I have a photographer to work with. The pictures are better. They think visually, I think in words... when I have to turn around and get the pictures myself? I almost always come back and say 'oof.' I don’t have anything that’s good. It works, it’s serviceable, but it doesn’t look good. (MMJ, 35 years) 
News Work 125

Yet the consensus is that the MMJ model is here to stay and that their place in the newsroom is only going to grow, often for financial reasons. "It's just cheaper to do it that way...The stations need content. And MMJs are the content makers” (MMJ, 16 years). An investigative photojournalist (33 years) notes that a station in his market had tried to eliminate all reporter-photographer teams and all standalone editors. The experiment failed: “they figured out that's not sustainable. And they're now they're back to having photographers with reporters, and they have a couple of editors that they've hired...so that was the pendulum that swung a little too far and came back and bonked them in the head.”

Therefore, MMJs may not be the best approach for every journalistic situation. In fact, some stations refuse to send out one-person crews for safety reasons, especially for live reports. While reporters are often sent out solo to gather video and information, when it comes time to go live during a news broadcast, they often have a photographer join them. "There are parts of the city that are so dangerous, or sometimes live shots that are so complicated...that we'll send two photographers with one reporter” (Producer/Editor, 5 years). Some MMJs say they would refuse to do solo live shots even if they were allowed:

I would never work in a place that made me do that [MMJ a live shot]. Because you're just putting yourself in danger. The job is already dangerous when you're on these crime scenes by yourself in not-so-nice neighborhoods. I wouldn’t do it. I wouldn't do it. (MMJ, 16 years) 
News Work 126

Safety is a pressing issue for MMJs. Even when reporting and shooting during the day, one MMJ admits that not only does she feel unsafe, but it is something she feels often in the field:

All the time. (laughs) I wouldn’t say that I've ever been like threatened or a gun was ever pulled out on me, but you know when you get that feeling in the pit of your stomach like I need to get out of here? There are plenty of those situations...I was covering a drive by into a house, and the house ended up being drug house, and I was on the other side of the street. No other stations were out there, just me shooting video, and a guy drove by and he was like 'girl, you brave, you better get out of here!' And I was like, ok that's my cue. (MMJ, 4 years) Immediately following these remarks, however, the same journalist said she is generally more concerned about the gear she is carrying than her own personal safety: Most of the time, I'm not really worried about me, I'm more worried about my equipment. Which might be silly, but I've got thousands and thousands of dollars of equipment...if someone came and threatened me, I don’t have a way to fight back. I'm 5’2, 120 pounds. What am I going to do? (MMJ, 4 years)

These safety considerations are not limited to only a market or two; reporters working both solo and in teams encounter dangerous situations routinely. San Francisco field crews have had numerous encounters with robbers (Keys, 2013, 2014). In Virginia, a former television station employee shot and killed a reporter and a photographer live on the air in 2015 (Tribune Wire Reports, 2015). Another reporter was punched while reporting live in Philadelphia (Schaefer, 2016). Yet in the pursuit of smaller staffs and 
higher station revenues, consolidated field crews continue to grow (see, for instance, Papper, 2017c).

Automation. Reporting staffs are not the only area affected by job consolidation. Those working behind the scenes also find themselves doing the jobs of numerous others when stations introduce automated production systems into their work spaces. Braverman’s (1974) labor process is exemplified through the many combined formerly separate craft specialty positions now executed by one computer “operator.” In place of creativity and teamwork, most newscast production takes place solo in front of a computer screen prior to the live show hitting the airwaves.

As is the case with MMJs, the quality of the production is a concern for those tasked with running automation. One regular complaint is a lack of flexibility to cope with an ever-changing newscast. A longtime director (30 years) calls it: "consistent mediocrity. I mean it does a great job and...it makes all the shows look alike but if you want to make a little tweak or do this or that, you're stuck with what you're stuck with" (Director, 30 years). This leads to more mistakes on the air. A director describes herself as “doing 5 different things” and is not surprised when an inaccuracy airs multiple times before being fixed (Director, 13 years). These directors are also chasing microphones, camera shots, live reporter audio, video audio, and graphics while putting the proper video sources on the air.

The producers who write the newscasts that the directors put on the air also understand the limitations of automated news production. "I think when something goes wrong, it's harder to get back on track [than with manual production], or to just go to 
News Work 128

your backup plan... it’s so easy to overlook just one tiny little detail” (Producer, 8 years). Directors agree. A survey participant (Director, 31 years) points out that while "regular" news can be relatively easy to pull off, rapidly changing newscasts can quickly become complicated: “[Automation] makes fluid, breaking news much more difficult to execute cleanly and with as much production value as the 'old' technology.”

Much of this rigidity in production comes from one person controlling all equipment. Automated news production technology exacerbates the ability for station owners to cut staff. News workers are not surprised by its implementation for profit's sake:

I think the people that reap the most benefits from technology in newsrooms are the people who are signing the checks for the people in newsrooms. I don't think the viewer benefits more...jobs just kind of collapse in on other people's jobs...So there were different types of audio people, and chyron-checking people, and all those jobs have gone to the wayside. So who benefits from losing those people? Well, the people that no longer have to write those paychecks. But who doesn't benefit? Well, the producers get more discrepancies in their show because chyrons are misspelled, and viewers have to look at misspelled chyrons more, so it's that kind of stuff. (Producer/Editor, 5 years)

A station's use of automation also drives away those who do not wish to take over the duties of their colleagues. When first introduced to an automation system in 2010, one director "ran from it" and found work at a non-automated station. Now? "Well, it’s everywhere," and he currently directs and manages a production department that runs an 
News Work 129

automated news production system. He has had directors leave to work in non-automated control rooms at other stations (Production Manager/Director, 13 years).

Newscast production control rooms are not the only station areas being automated. The sector that keeps the programming on the air, traditionally called "Master Control," is not only automated but is also often hubbed in an office outside of the local station. Programming and commercials might originate hundreds or thousands of miles away from the local station for air. A Master Control operator was running a total of 9 stations out of his control room, including one in another television market, and always anticipated more outputs around the corner. This included switching commercials for live news programs in multiple cities, the main revenue-generator for television stations and their owners.

But as automation spreads, so do layoffs. A few months after his interview, the Master Control operator's station was automated further, and he and multiple others lost their jobs. The parent company decided to hub his stations through another station, thousands of miles away. That hub now controls programming for similarly-owned stations around the country.

\section{The Role of Unions}

For those that remain in local television stations, some turn to collective negotiation through unions to help improve labor conditions. Union membership is on a downward trend, however, weakening the power of the workers and their surrounding institutional protections (Cappelli, 1995; Kalleberg, 2009). As overall union membership fell to its lowest rate ever in 2016 at 10.7 percent, membership for those in "radio and 
television broadcasting and cable subscription programming” was an even lower 5.9 percent, dropping from 6.7 percent the year before (Bureau of Labor Statistics, 2017c, 2017a).

This is even as union membership generally has financial incentives for those who join. Overall, full-time nonunion workers made only 80 percent of the median weekly wage of union workers in 2016. For those working in information industries, union workers had a median weekly wage of $\$ 1238$ in 2016 versus $\$ 1133$ for nonunion workers $^{9}$ (Bureau of Labor Statistics, 2017b, 2017c).

The local news workers participating in this study realize the impact of unions; a full $29 \%$ of interviewees and $32 \%$ of survey respondents are union members. Another $13 \%$ of interviewees and $32 \%$ of survey respondents have been members in the past. Unions represent workers in each job status: full time, part time (with and without benefits), and contract/freelance.

Union membership varies greatly by job description. Only one of the 22 producers participating in this study is a union member. Compare this to 9 out of 12 directors who are unionized, and 5 of 11 photojournalists. A producer describes a previous position where almost newsroom worker position except producer was unionized as "we were getting screwed” (Producer, 5 years). Figure 6 illustrates these stark differences in union membership based on job title.

\footnotetext{
${ }^{9}$ While union wage is not available for radio and television broadcasting workers, the nonunion weekly wage is \$1020, lower than the average nonunion information worker (Bureau of Labor Statistics, 2017b).
} 


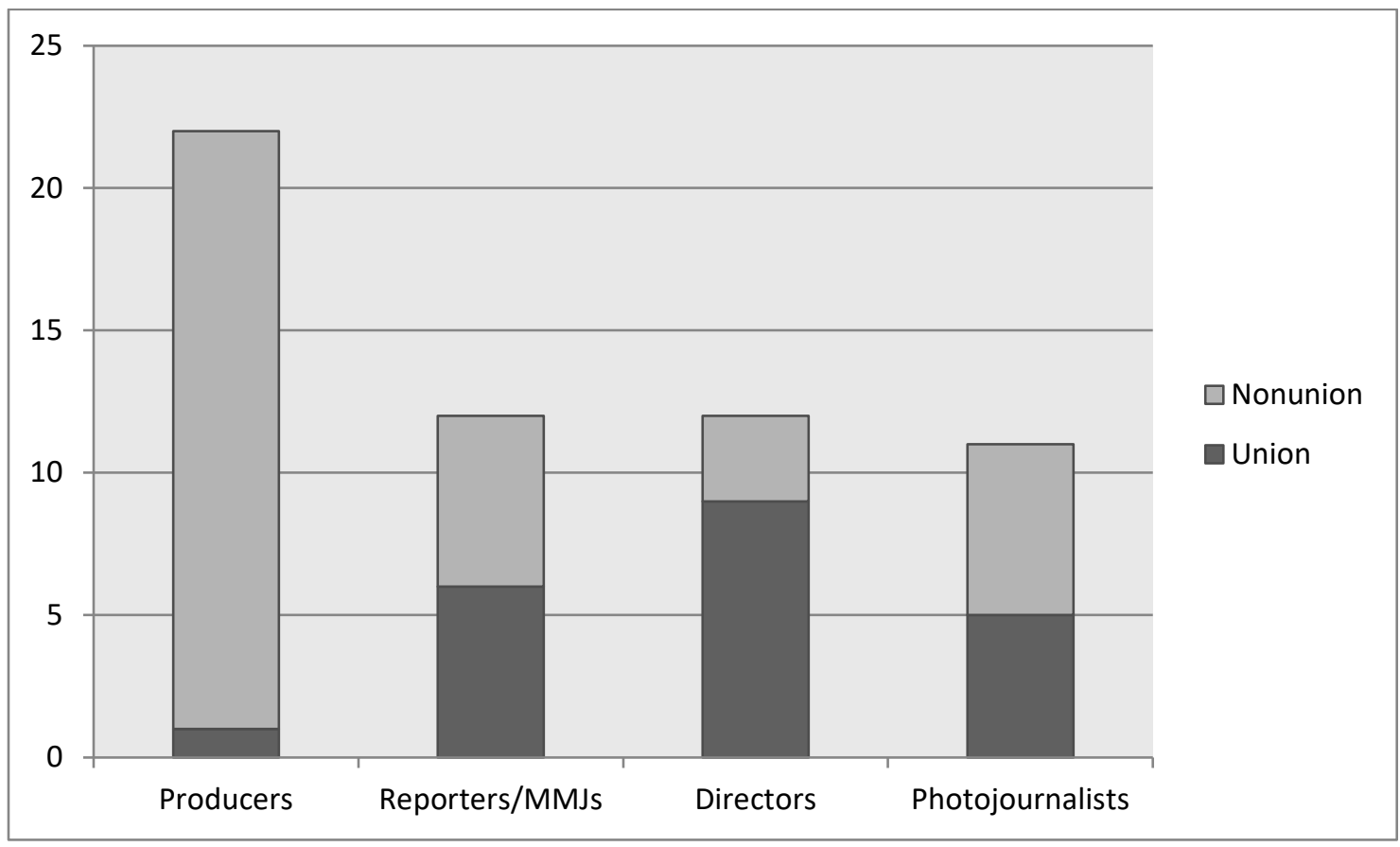

Figure 6. Comparison of union versus nonunion workers by job description.

Union members appreciate the support of their unions. Until a job required membership, two interviewees never wanted to join, but now say they would never work someplace without a one. "What I’ve learned is, unions, especially in our business, exist where they're needed" (Video Editor, 18 years). Much of that incentive is based on getting fair pay for work done:

I love the union...This is my first union job. I can assure you that until...I make six figures, I will never work in a non-union shop again...My last two jobs were salary, and I was just abused. No one gave me comp time. I would ask to be paid, you know, and given what I was due, cuz, I worked 60 hours this week! Oh, thanks kid...It's just wrong. (MMJ, 16 years)

A photojournalist who had been in a union at a previous station but is not at his current station recognizes the union guarantees each worker is getting his or her due: 
News Work 132

What I liked about it was you knew you weren’t getting...underpaid compared to somebody else. There was a scale. You got paid according to how much time you had at the company. So you knew exactly how much the other person next to you was making as well. Here, you have no idea if you're underpaid, overpaid. You just don’t have any idea. (Photojournalist, 18 years)

Based on those participating in this study, there is also a career length advantage for union employees. Those who are union members average 22.7 years in the news business (mean), compared to 16.0 years for nonunion members. If managers are removed from the mix, the nonunion average is 15.9 years ${ }^{10}$. Most managers are ineligible for union membership.

Because higher wages can impact a station's bottom line, many station owners are hostile to unionization attempts at their properties, and actively try to dismantle those already in place. Two stations in Peoria, Illinois had not one, but two contentious contract negotiation rounds under different owners. In both 2011 and 2016, AFTRA talks broke down over outsourcing requests, wages, and healthcare. The 2011 version nearly brought on a strike, while 2016 saw a public demonstration by workers outside of the station (Tarter, 2016).

Contract negotiations were similarly tense in Portland, Oregon between KGW-TV and new owner TEGNA in 2016-2017. The company demanded elimination of union “jurisdiction” rules from all three KGW unions to allow nonunion workers to do the same

\footnotetext{
${ }^{10}$ For the purposes of this calculation, anyone identifying as a News Director (not a director or newscast director), Executive Producer, Platform Manager, Production Manager, News Manager, Creative Services Director, or generic Manager fell into this category.
} 
work as union workers but under different terms. Workers held a public rally in downtown Portland to bring community attention to the issue, and members from all three unions attended the others' contract negotiation sessions in a show of solidarity. In the end, the jurisdiction elimination clause was dropped, but not without a significant fight by union workers and representatives. A similar union fight against the company was had simultaneously by the TEGNA-owned station in Seattle, KING-TV (McIntosh, 2016; Mcintosh, 2017; NW Labor Press, 2016).

Vincent Mosco has been a supporter of trade unions working together to support knowledge and communications workers in their quest for stable employment (see, for example, Mosco, 2009a; Mosco \& McKercher, 2009). The Screen Actors Guild and the American Federation of Television and Radio Artists combined forces into one union (SAG-AFTRA) in 2012 to better negotiate for their members (Finke, 2012). The coalition fight at KGW-TV by members of IBEW, SAG-AFTRA, and IATSE similarly demonstrated successful solidarity by union workers.

\section{Proposed Solutions}

The working conditions discussed here do not lend support to the public interest standards of local television reporting, but instead highlight the impact of market-driven journalism and the political economy of the news. Participants in both the surveys and the interviews are concerned with the quality of the product and information being put on the air in their communities. As the number of on-air newscasts and digital platforms continues to grow, so does the workload for television journalists. At the same time, fewer people are juggling more job duties formerly performed by specialized craft 
workers, demonstrating a focus on getting greater levels of surplus value out of employees.

Instead of concentrating on providing empowering information for their communities, news staffs are “cutting corners” and focusing on making broadcast deadlines and digital quotas. Not only does this lead to a lower perceived quality of journalism by the news workers themselves, it also potentially compromises their ability to assimilate into their communities. As the community is the backbone of the stories being told, the source of much of the information being gathered, and the recipient of the final broadcast and digital products, losing such grounding is a negative outcome for all involved. The emphasis of profit over public interest is clearly felt by those working in commercial newsrooms. As deregulation encourages the growth of ever-larger station owners, news workers believe the situation will continue to decline.

As the people in the trenches each day, the newsroom workers participating in this study have some very strong opinions as to how to improve their journalistic output for their communities. The first is simply adding more staff. By adding more news gatherers and disseminators to the mix, workers would not be as rushed and could concentrate more on the job at hand:

I would add more writers, because if you have more writers, they have less stories, and they can focus on writing better stories, editing better video. I would add more producers because they -- producers don't have to worry about producing an entire hour, which is a daunting task. I would add more technical staff because then things get on air better. More well-trained people would be the 
News Work 135

only thing that I would have changed in every single market I worked at. (Producer/Editor, 5 years)

This added staffing would allow journalists to gather stories more in line with public interest and public sphere standards. The education of the audience, keeping the powerful in check, mobilizing the electorate, and contextualizing complicated community events could become more prominent during local news broadcasts. More staffing would also allow for fewer consolidated job descriptions within the newsroom. Instead, the political economy of the typical local television broadcast newsroom dictates that most specialists are eliminated or reassigned to MMJ “general assignment” duties to boost station value and save on employee costs. Stories therefore generally stay short, with little research or air time to provide context for the audience (Anderson et al., 1994; Bennett, 2012; Habermas, 1991; Kovach \& Rosenstiel, 2001; Schudson, 2008).

Station managers argue that flexible labor allows for more "boots on the ground" as more people are trained to do more things. In practice, however, there is not enough staff to go around, multi-skilled or otherwise. One producer (8 years) has been trained as an MMJ, but never goes out in the field because “we don't really have enough producing staff to do that.” What is happening at some stations is not an influx of news gatherers, but instead of news managers:

We're losing reporters; they're filling them with freelancers. We're losing photographers, and they're not replacing the photographers. We're losing editors; they're not replacing editors. But, when you walk by the giant news conference room...it's amazing how many managers we have... and every single one of 
News Work 136

those layers is a layer between the photographers on the street, the editors in the booth, the reporters on the street and top management... they'll just question why it's not getting done. The reason it's not getting done is because you have fewer soldiers out on the field. (Investigative Photojournalist, 33 years)

The issue then becomes micromanagement and an increasing risk of alienation, as workers are no longer able to focus on their strengths or creativity. Staff members need to be trusted to do their jobs. This allows employees to pursue what they believe is important news for their communities, staving off alienation and unhappiness:

Let your people do what they're best at...find a way to let them shine versus just sort of crank out content. Everyone at your station has something to give, you know. Something they're good at. Something they're passionate about. (Producer/Editor, 14 years)

If, as per Marx, the maximization of profits comes through the labor of workers, however, having fewer "soldiers" completing more tasks is the goal. While the call for more specialists lines up with public interest concerns, the more realistic lack thereof leads to less diverse content, fewer investigative reports, and more superficial community coverage (Bennett, 2012; Croteau \& Hoynes, 2006; Matsa, 2017a). Therefore, in addition to adding staff, news workers would also like to see additional in-depth investigative reporting at their stations.

News staffs firmly believe that audiences not only will watch longer stories but will embrace the issues presented. "I think people will be much more interested and we can engage them more and do more with a great, in-depth investigative team” (Producer, 
News Work 137

8 years). Indeed, even when browsing on their cell phones, audiences are open to longerform, more in-depth stories than many of those currently shown during a local television newscast (Mitchell, Stocking, \& Matsa, 2016). One photojournalist even suggested minidocumentaries as a way to share important local news stories, “a better told story than 1:20 of news will get you” on a typical local television news broadcast (Photojournalist, 9 years).

In spite of the potentially added cost, some large-market stations are already experimenting with different methods of delivering local content. A producer describes such content as “edgier,” and more along the lines of Last Week Tonight with John Oliver or The Daily Show, minus the satire and catered to the city being covered. One show already on the air in Denver fits the bill:

The way they put it, they don't want fires, they don't want shootings, they don’t want the spot news of the day. They kind of want to delve into the issues. And sometimes it can be fun stuff, sometimes it can be -- sometimes it can be political stuff. It's kind of a good mix. So I think that is going to be the next push. (Producer, 8 years)

Again, this requires a staffing and resource commitment to happen. Communities and their citizens will always need someone to gather and report the happenings affecting their lives. News workers need time and resources to find, investigate, report, and disseminate the stories community members need to hear to be fully functioning citizens. With more workers, individual responsibilities can be shared, relieving some of the time 
News Work 138

pressures currently leading to a work environment described as "a grind" as flexible labor expectations grow (Producer, 5 years).

Directors believe multiple-person production crews are more likely to catch mistakes prior to air, keeping journalistic integrity in check. Producers without editing burdens can write their shows without video worries or technical concerns, which are handled by those with more expertise. Reporters and photographers working together have time to more deeply investigate important local issues, gather information, shoot quality video, and edit the final product than those working solo. More available time and staff would also allow creativity to shine, relieving some aspects of worker stress and alienation, as the final product could go beyond what one photographer (18 years) calls "meat and potatoes." This would bring some of the craft work back to the craft of producing local television news.

Similarly, not eliminating the staffers with the most experience keeps important community connections, context, and mentoring abilities intact in local television newsrooms. These senior journalists know the market and newsroom practices best and help newcomers adapt to their communities and grow in their journalistic abilities. At a time when trust in the media is low, those with strong positive market recognition should be seen as journalistic assets and not financial liabilities.

Treating all staff as if they are station assets instead of financial liabilities would make employees happier and help them better engage in community life outside of the workplace. The vacation relief worker who issued an ultimatum to station management for a more permanent job was ready to move from his community if an offer did not 
News Work 139

happen. One MMJ is contemplating leaving the business at the end of his contract with hopes for a better work-life balance elsewhere. The freelance producer is making plans to relocate to another city if he cannot get a permanent contract before his temporary post expires. Even though news output relies on all of their expertise to fill newscasts and web space, newsroom staffers are often seen similarly to the equipment they use to gather the news, interchangeable and easily replaceable, echoing Braverman's (1974) description of the division of labor.

Station owners downsizing staffing numbers for the sake of boosting bottom lines is not the way to fulfill the station's public interest obligations. Instead, by combining multiple job skills into one job description while adding more platforms and news time to fill with content, ownership is exploiting their workers and, in the process, putting the quality of information distributed to the community at risk for incompleteness and errors. The political economic structure of corporate local television ownership is failing both its workers and its communities when it comes to public interest commitments. 


\section{Chapter 8: Serving in the Public or the Market Interest?}

\section{Conclusions, Limitations, and Future Research Directions}

This project began by asking: How does the political economic structure of corporate-owned newsrooms affect how local television news workers do their jobs providing information to the community? The reflections of 81 survey respondents and 24 interviewees from large market stations around the United States paint a pretty clear picture: as a whole, corporate ownership profit expectations negatively impact the staffing, content, and resources available to newsrooms for broadcasting in the public interest. Most newsroom employees realize the importance of the jobs they perform, however the amount and types of work they are being asked to accomplish are compromising their abilities to provide their communities with the quality of stories and information they wish to deliver. Reports are blatantly killed (or covered) because of corporate or advertiser demands. Photojournalists rely on “meat and potatoes” style shooting and editing skills to crank out multiple versions of the same story for air and web for growing numbers of newscasts. Producer-Editors and their Automation Directors miss graphical inaccuracies and make technical mistakes while trying to do too many things at once. Every newsroom employee faces the challenges of combined job descriptions, multiple information platforms, and time and/or resource constraints due to corporate bottom line considerations.

In a liberal democracy that relies on its news media for political and community information, corporate profit desires should not be a professional concern of the most seasoned news veterans in the country. Ownership expansion means fewer companies 
News Work 141

control rapidly growing numbers of local television stations around the United States. As these companies grow, they encourage further loosening of the rules governing ownership by claiming their business model is in the public's best interest.

At the same time, any definition of what is meant by "public interest" has been lost in the regulatory language. The Fairness Doctrine, which required broadcasters to air contrasting viewpoints on issues of public importance and subsequently bringing diverse information to audiences, was eliminated in 1987. Required time parameters for news and public affairs programming also disappeared in the 1980s (Bishop \& Hakanen, 2002; United States Court of Appeals, District of Columbia Circuit, 1989). What is left are vague notions of public interest spelled out by the Federal Communications Commission in 2003, focusing on competition, diversity, and localism.

But the expansion of ownership is squashing even these pieces of the public interest puzzle. The proposed Sinclair-Tribune merger highlights these inconsistencies. By reaching $72 \%$ of the country, there is much less competition within the ownership sector. Because Sinclair dictates increasing amounts of its station programming with must-run segments for local newscasts, diversity of information is flattening in cities around the country. Corporate ownership and segments being produced out of one studio for the entire country eliminates much localism. This model, therefore, does not operate in the public interest.

The proposition of Tribune's acquisition by Sinclair has received much backlash and flak from liberal and conservative media interests, citizen groups, and even the FCC itself (see, for example, Carty, 2017; Ember, 2017b; Kang, 2018; Vogel, 2017). The final 
News Work

outcome will dictate what the future of the broadcast business and local television news will look like in markets large and small. A profits-based marketplace model of broadcast journalism overshadows its public sphere, public service, and public interest functions. Job consolidation, cheaper hires, precarious employment, and computerized labor all point to corporate owners putting more emphasis on the bottom line than on the public interest principles their broadcast license requirements dictate.

The sentiments expressed by news workers throughout this manuscript do not mean that larger owners cannot serve in the public interest. What it does say is that on a day-to-day basis, they choose to not do so, and instead focus on how much money can be made for stockholders and other corporate interests. As was seen around the time of Hurricanes Harvey and Irma, large ownership companies have the capacity to produce vital life-saving information for their communities when they put their minds to it. The resources that TEGNA and Scripps poured into their coverage, and the safety nets they provided for their staffs, demonstrate that there can be positives found in the largercorporate owner model. On an average news day, however, this does not appear to be put to use. Instead, journalistic resources are stretched thin, overwhelmed staffs let details fall through the cracks, and ultimately the audience loses out.

This affects local communities on multiple levels. From a television worker standpoint, there is a loss of the community connection that comes from job insecurity. Stable jobs increase quality of life and contribute to stronger families and communities (Kalleberg, 2011, p. 2). Precariously-employed workers are more likely to neglect to engage as strongly in their communities. Additionally, the time-saving measure of relying 
on official spokespeople as sources instead of community members leads to a community disconnect as these official sources have agendas and tend to provide all news crews with the same information. This does not improve community learning, nor does it provide much in the way of community insight for either the journalist or the audience (Blankenship, 2016; Herman \& Chomsky, 2002; Molotch \& Lester, 1974; Shoemaker \& Reese, 1996).

Audience members rely on reporting by local news organizations to better understand the underlying cultures, issues, and resource availability within their communities. Having this knowledge empowers them to shape and strengthen their communities through more active participation (Adler \& Goggin, 2005, p. 241; Kretzmann \& McKnight, 1993; Perkins \& Zimmerman, 1995). Providing what is needed for citizen discussion, involvement, and empowerment is a major step in broadcasting in the public’s best interest. Yet oftentimes, news workers feel this is not their news organizations’ main focus.

The real-world experiences of large-market local broadcast television news workers explored here, combined with an examination of sped-up FCC deregulation and previous research on the broadcast industry, highlight the disconnect between the public interest requirements for U.S. broadcasters and their corporate ownership profit goals. The eyes of the people who work in the newsrooms in the largest metropolitan areas of the country, serving nearly half of the population, provide the insiders' view of news work in a corporate ownership environment. The voices of those behind-the-scenes workers who are often left out of news work studies, such as photojournalists, digital 
specialists, and producers, get their say. Those in consolidated job descriptions that are relatively new to the nation's largest markets, the multi-media journalists, producereditors, and automated directors, have their turn in the spotlight.

Returning to the original question of this project: How does the political economic structure of corporate-owned newsrooms affect how local television news workers do their jobs providing information to the community? The deregulated neoliberal business model of local television news focuses more on the money-making aspects of station ownership than on the local news product itself. Advertising is king; as news workers here disclose, stories are promoted or eliminated based on financial factors and advertiser satisfaction. Technology is brought in to consolidate job functions, which not only does not advance reporting in the public's interest but may instead be degrading the quality of news product the audience is receiving. Instead of treating news workers as important players in community, civic engagement, and democracy, they are treated like any other equipment: scheduled on a just-in-time basis, often with little job security or work-life balance, and able to be discarded from the company when economic conditions warrant. Yet these are the people bringing their communities the news they need to act as functioning citizens. The changes many of them have seen over their careers have them concerned about the future of broadcast journalism. Local television newscasts are still the go-to source for community news in the United States; It is imperative that those trained to gather and disseminate information keeping the powerful in check and the citizens informed are able to do their jobs without the pressure of the corporate pocketbook. 
News Work 145

To help in this matter, the business of local television news needs to be regulated for its contribution to the community. What constitutes "the public interest" needs to be more explicitly defined, and broadcasters need to uphold those standards. It is significant that the largest and fastest-growing local news ownership corporation will not even promise one of its local affiliates that it will continue to produce local news for the community (NW Labor Press, 2018). This is not the move of a company intent on the public interest aspects of owning local broadcast stations.

The consolidation of ownership will continue to grow and its relationship with its newsroom workers will continue to deteriorate without regulatory intervention. How much farther can owners push their news staffs into more converged job descriptions? How many more tasks can a journalist juggle while still providing verified information? How will this affect those venturing into the local television news business, and their ability to supply the public with the stories necessary for good citizenship and strong community?

Ownership expansion as promoted by FCC deregulation is not promoting public interest broadcasting at the local level. Instead, local television news stations act as offshoots of their corporate ownership and network affiliations, and pawns of their sponsoring advertisers, filling air time and web space with what sells over what informs. To truly work in the public interest, the focus would be on the diversity of culture and citizenship in the communities being served, providing stories empowering the people and revealing the issues that need to be addressed. Deregulation is not moving the business in that direction. Instead, it is bogging down those in local newsrooms through 
undersized staffing and oversized workload expectations. The community is the biggest loser, as a major source of information neglects to perform in its interest.

Without journalists focusing on the needs of their audiences, the powerful are free to run amok. During times of crisis, the safety of the viewership will be in peril. And in times of community building, lack of information disempowers members and discourages them from participating. It is the duty of those in charge of regulation to make sure that does not happen, just like it is the duty of those in the newsroom to keep their audiences informed when it does. The current system does nothing to curb the corporate misappropriation of the public airwaves and is therefore committing a supreme disservice to the community at large.

\section{Limitations}

Like all studies, this project has its limitations. This qualitative study is not intended to be representative of everyone who works in the local television news business. However, it does give insight into news staffers' concerns as they march into the ever-changing future of their business. The previous chapters have provided a look into what is on the minds of many news workers in the largest metropolitan areas of the country.

One limitation, particularly for the survey, is the lack of a total population of news workers that may have been included in this study. Therefore, there is really no way to discern what the response rate may have been. Those who participated here found the survey through their newsrooms, word of mouth, or on social media, opted in, and perhaps passed it along to others. The statistics throughout this piece are solely 
descriptive in nature. However, as the survey is to provide a broad overview of some of the issues to be addressed, it serves its purpose.

The surveys did have a Portland sample bias (see Table 3). This was somewhat expected, given the researcher has worked in the market for over 17 years. The only characteristic that stands out as somewhat different of Portland is a higher level of parttime employees than is reported from other markets. That said, the freelance employees are mostly concentrated in Los Angeles. A more in-depth investigation into the work forces of specific communities would be necessary to determine whether that is a trend of location, ownership, the business, or something else entirely.

In hindsight, a few added survey questions could have broadened insight into the business. For example, prompting open-ended responses to further explain issues of time and resource availability would have provided a deeper understanding of those particular issues. A question asking whether non-union members wanted to be a part of a union could have better discerned collective bargaining attitudes.

For the interviews, a missing piece is the experience of workers from Sinclair stations. When interviews were conducted in 2015 and 2016, there were not a large number of Sinclair newsrooms in the top 25, and the potential merger was not announced until 2017. Many of the propaganda accusations did not come to light until just before the election of 2016, after the interview collection time concluded. Future studies will want 
News Work 148

\begin{tabular}{|l|l|l|l|}
\hline $\begin{array}{l}\text { Market } \\
\text { Rank }\end{array}$ & Market & $\begin{array}{l}\text { Number of } \\
\text { survey } \\
\text { responses - at } \\
\text { response time }\end{array}$ & $\begin{array}{l}\text { Number of } \\
\text { interviewees } \\
- \text { over career }\end{array}$ \\
\hline 1 & New York City & 2 & 2 \\
\hline 2 & Los Angeles & 11 & 2 \\
\hline 3 & Chicago & 0 & 1 \\
\hline 4 & Philadelphia & 0 & 1 \\
\hline 5 & Dallas-Fort Worth & 3 & 2 \\
\hline 6 & San Francisco-Oakland-San Jose & 4 & 1 \\
\hline 7 & Boston (Manchester) & 2 & 1 \\
\hline 8 & Washington, D.C. (Hagerstown) & 1 & 0 \\
\hline 9 & Atlanta & 4 & 4 \\
\hline 10 & Houston & 1 & 1 \\
\hline 11 & Phoenix (Prescott) & 3 & 1 \\
\hline 12 & Detroit & 0 & 1 \\
\hline 13 & Tampa-St. Pete (Sarasota) & 2 & 3 \\
\hline 14 & Seattle-Tacoma & 4 & 3 \\
\hline 15 & Minneapolis-St. Paul & 11 & 2 \\
\hline 16 & Miami-Ft. Lauderdale & 1 & 0 \\
\hline 17 & Denver & 2 & 3 \\
\hline 18 & Orlando-Daytona Beach-Melbourne & 3 & 3 \\
\hline 19 & Cleveland-Akron (Canton) & 2 & 3 \\
\hline 20 & Sacramento-Stockton-Modesto & 0 & 1 \\
\hline 21 & St. Louis & 2 & 2 \\
\hline 22 & Pittsburgh & 0 & 0 \\
\hline 23 & Portland, OR & 30 & 5 \\
\hline 24 & Charlotte & 1 & 1 \\
\hline 25 & Raleigh-Durham (Fayetteville) & 1 & 1 \\
\hline & & & \\
\hline
\end{tabular}

Table 3. Number of respondents from each targeted market. Most interviewees discussed more than one market.

to include those working for that company, and any other mega-conglomerates that might appear.

Numerous people also turned down interview opportunities because they were hesitant to talk on the record, even given the parameters of confidentiality laid out for this study. Most of these were on-air talent, and quite a few worked for network Owned and 
Operated (O\&O) stations. One told me his network was "uber tense” about anything said about it, and he could not take that risk, even after thanking me for all of the protections in place (personal communication, August 2016).

Along the same lines, a news director at one of the O\&Os told me it was her network’s policy to "not participate in surveys and questionnaires” (personal communication, September 2015). The combination of these factors prompts questions about how many others opted out because of station or owner policy. A lack of participation from some owners could have impacted the results.

Interestingly enough, digital workers, those who spend their days on social media and the web, were the hardest job description to get a response from. As these workers appear to be the future of the business and are an ever-growing newsroom staple, a larger sample would have been nice to have.

\section{Future Studies}

Throughout this manuscript, numerous opportunities for future research present themselves. Many of the questions here might have different results if asked of medium and smaller market newsrooms. Smaller markets often have smaller budgets, less seasoned staffs, and higher turnover as staffers move on to larger markets. These factors might lead to different newsroom challenges than those found in the larger newsrooms examined here. Therefore, running a similar project across various sized markets might yield important insights into how those news workers are performing as well.

The question of shared newscast content across an owner's stations is also one worth examining in future studies. Smaller market stations are known to often share 
News Work 150

content, or even simulcast newscasts, on multiple stations within a market. With the reputation that Sinclair has built up requiring its stations to air "must run" content, this could be an important area of study across all sized markets if the proposed merger with Tribune moves forward.

The Sinclair merger and its consequences are worth future study, no matter its outcome. The regulatory changes that have been pushed through, the idea of centralized content on local stations, and the fights journalists are having with their owners over editorial control are all worthy of more in-depth investigation. Should the merger occur, a study similar to this one following up with those from both sides of the acquisition could provide important insight to the state of public interest reporting as deregulation of the business continues.

Additionally, the tenure of those working in local television newsrooms is an area to watch. The trend towards encouraging the older, more experienced, and therefore generally more expensive, members of the newsroom staff to leave so their positions can be filled with younger, cheaper multi-taskers speaks to the priorities of local television stations. Whether this trend can and does continue will have an impact on the expertise available within newsrooms about community happenings.

It is also worth looking beyond the newsroom to those who have made the transition to academia to see what their focus is. Some of the most insightful comments in this project came from those who have worked on both the academic and the professional sides of the journalism business. How practitioners, researchers, and instructors go about 
training the next generation of journalists says a lot about where they believe the business is heading.

\section{Final Thoughts}

The issues brought up by the information gatherers and disseminators in this project are not going away, nor is the transformation of the business to a market-driven model slowing. If anything, the cycle of technological, regulatory, and ownership changes is speeding up. In another decade, newsroom workers could be experiencing a completely different model of newscasting and journalism. But the community need for information will never cease. How that information is provided and who is providing it can be pivotal, as the business of broadcasting moves away from a public interest model and closer to relying on the market to decide what information is important for community and democracy.

This project brings the experiences of seasoned local television newsroom personnel to the forefront. The inclusion of those who do not often get a voice in newsroom studies helps pull back the curtain on the entire local broadcast newsgathering and dissemination process. This study provides a good base for diving more deeply into the political economic impact of the local television news ownership structure on local news distribution in the United States. 
News Work 152

\section{References}

Adler, R. P., \& Goggin, J. (2005). What do we mean by “civic engagement”? Journal of Transformative Education, 3(3), 236-253. https://doi.org/10.1177/1541344605276792

Alexander, P. J., \& Cunningham, B. M. (2007). Public and private decision making: The value of diversity in news. In P. M. Napoli (Ed.), Media diversity and localism: Meaning and metrics (pp. 79-96). Mahwah, N.J.: Lawrence Erlbaum Associates.

Ali, C. (2017). Media localism: The policies of place (First edition edition). Urbana: University of Illinois Press.

American Association for Public Opinion Research. (n.d.). Opt-in surveys and margin of error. Retrieved March 23, 2014, from http://www.aapor.org/Opt_In_Surveys_and_Margin_of_Error/1903.htm

American Press Institute. (2014, March 17). How Americans get their news. Retrieved January 16, 2018, from https://www.americanpressinstitute.org/publications/reports/survey-research/howamericans-get-news/

Anderson, R., Dardenne, R., \& Killenberg, G. M. (1994). The conversation of journalism: Communication, community, and news. Westport, Conn.: Praeger.

Armstrong, D. (1981). A trumpet to arms: Alternative media in America. Boston: South End Press.

Bachen, C. M., Hammond IV, A. S., \& Sandoval, C. J. K. (2007). Serving the public interest: Broadcast news, public affairs programming, and the case for minority 
News Work 153

ownership. In P. M. Napoli (Ed.), Media diversity and localism: meaning and metrics (pp. 269-306). Mahwah, N.J.: Lawrence Erlbaum Associates.

Baig, E. C. (2016, March 10). Shoot video for the local news, get paid. USA TODAY. Retrieved from https://www.usatoday.com/story/tech/columnist/baig/2016/03/10/shoot-videolocal-news-get-paid/81562956/

Bark, E. (2016, February 18). TEGNA's “early retirement” offer is its latest move to cut expenses, entice older personnel (3rd update). Retrieved March 23, 2016, from http://unclebarky.com/dfw_files/4aba1865f384269fac28e1ec3415552a-3591.html

Barstow, D., \& Stein, R. (2005, March 13). Under Bush, a new age of prepackaged tv news. The New York Times. Retrieved from https://www.nytimes.com/2005/03/13/politics/under-bush-a-new-age-ofprepackaged-tv-news.html

Barthel, M., Holcomb, J., Mahone, J., \& Mitchell, A. (2016, November 3). Civic engagement strongly tied to local news habits. Retrieved July 22, 2017, from http://www.journalism.org/2016/11/03/civic-engagement-strongly-tied-to-localnews-habits/

Belt, T. L., \& Just, M. R. (2008). The local news story: Is quality a choice? Political Communication, 25(2), 194-215.

Bennett, W. L. (2012). News: The politics of illusion (Ninth ed). Boston, Massachusetts: Longman. 
News Work 154

Bennett, W. L., Lawrence, R. G., \& Livingston, S. (2007). When the press fails: Political power and the news media from Iraq to Katrina. Chicago: University of Chicago Press.

Berkowitz, D. A. (2009). Reporters and their sources. In K. Wahl-Jorgensen \& T. Hanitzsch (Eds.), The Handbook of Journalism Studies (1 edition, pp. 102-115). New York: Routledge.

Berry, C. R., \& Glaeser, E. L. (2005). The divergence of human capital levels across cities. Papers in Regional Science, 84(3), 407-444. https://doi.org/10.1111/j.1435-5957.2005.00047.x

Bhattacharyya, J. (1995). Solidarity and agency: Rethinking community development. Human Organization, 54(1), 60-69.

Bhattacharyya, J. (2004). Theorizing community development. Community Development Society. Journal, 34(2), 5-34. https://doi.org/10.1080/15575330409490110

Bielby, D. D., \& Moloney, M. (2008). Considering global media: Sociological contributions. In R. Rice (Ed.), Media ownership : Research and regulation (pp. 269-300). Cresskill NJ: Hampton Press.

Bishop, R., \& Hakanen, E. A. (2002). In the public interest? The state of local television programming fifteen years after deregulation. Journal of Communication Inquiry, 26(3), 261-276. https://doi.org/10.1177/0196859902026003002

Blanchard, M. A., \& Association for Education in Journalism. (1977). The Hutchins Commission, the press and the responsibility concept. Journalism Monographs, 49. Retrieved from 
http://stats.lib.pdx.edu/proxy.php?url=http://search.ebscohost.com/login.aspx?dire $\mathrm{ct}=$ true \&db=eric\&AN=ED139017\&site=ehost-live

Blankenship, J. C. (2016). Losing their “mojo”? Journalism Practice, 10(8), 1055-1071. https://doi.org/10.1080/17512786.2015.1063080

Bourdieu, P. (1986). The forms of capital. In J. Richardson (Ed.), Handbook of theory and research for the sociology of education (pp. 241-258). New York, New York: Greenwood Press. Retrieved from http://www.marxists.org/reference/subject/philosophy/works/fr/bourdieu-formscapital.htm

Bourdieu, P. (1998). On television. New York: New Press.

Bracht, M. (2006, March 17). KOKH-25 to expand local staff; “News Central” to end. Retrieved January 20, 2014, from http://newsok.com/mediabrkokh-25-to-expandlocal-staff-news-central-to-end/article/2935747

Braman, S. (2007). The ideal v. the real in media localism: Regulatory implications. Communication Law and Policy, 12(3), 231-278. https://doi.org/10.1080/10811680701338532

Braverman, H. (1974). Labor and monopoly capital: The degradation of work in the twentieth century. New York, New York: Monthly Review Press.

Brislin, T. (2004). Empowerment as a universal ethic in global journalism. Journal of Mass Media Ethics, 19(2), 130-137. 
Broaddus, M., Harmon, M. D., \& Mounts, K. F. (2011). VNRs: Is the news audience deceived? Journal of Mass Media Ethics, 26(4), 283-296. https://doi.org/10.1080/08900523.2011.581978

Bureau of Labor Statistics. (2017a, January 26). Table 3. Union affiliation of employed wage and salary workers by occupation and industry. Retrieved July 8, 2017, from https://www.bls.gov/news.release/union2.t03.htm

Bureau of Labor Statistics. (2017b, January 26). Table 4. Median weekly earnings of fulltime wage and salary workers by union affiliation, occupation, and industry. Retrieved July 8, 2017, from https://www.bls.gov/news.release/union2.t04.htm Bureau of Labor Statistics. (2017c, January 26). Union members summary. Retrieved July 8, 2017, from https://www.bls.gov/news.release/union2.nr0.htm

Cappelli, P. (1995). Rethinking employment. British Journal of Industrial Relations, 33(4), 563-602.

Carey, J. W. (1988). Communication as culture: Essays on media and society. New York: Routledge.

Carty, K. (2017, November 24). Sinclair's vast media merger threatens democratic ideals. Congress must fight it. The Guardian. Retrieved from http://www.theguardian.com/commentisfree/2017/nov/24/sinclair-tribune-mediamerger-free-speech

Clifford, S. (2008, July 22). A product's place is on the set. The New York Times. Retrieved from http://www.nytimes.com/2008/07/22/business/media/22adco.html 
Coleman, J. S. (1988). Social capital in the creation of human capital. American Journal of Sociology, 94, S95-S120. https://doi.org/10.2307/2780243

Commission on Freedom of the Press. (1947). A free and responsible press: A general report on mass communication : Newspapers, radio, motion pictures, magazines, and books. Chicago, Ill.: University of Chicago Press.

Copps, M. J. (2011). What about the news? An interest in the public. In R. W. McChesney \& V. Pickard (Eds.), Will the Last Reporter Please Turn out the Lights: The Collapse of Journalism and What Can Be Done To Fix It (pp. 289298). New York: The New Press.

Croteau, D., \& Hoynes, W. (2006). The business of media: Corporate media and the public interest. Thousand Oaks, Calif.: Pine Forge Press.

Dawsey, J., \& Gold, H. (2016, December 16). Kushner: We struck deal with Sinclair for straighter coverage. Retrieved July 10, 2017, from http://politi.co/2ht6nw1

Deakin, H., \& Wakefield, K. (2014). Skype interviewing: Reflections of two PhD researchers. Qualitative Research, 14(5), 603-616. https://doi.org/10.1177/1468794113488126

DeFilippis, J., \& Saegert, S. (2012). Communities develop: The question is, how? In J. DeFilippis \& S. Saegert (Eds.), The Community Development Reader (2nd edition, pp. 1-7). New York, New York: Routledge.

Deuze, M., \& Fortunati, L. (2011). Atypical newswork, atypical media management. In Managing Media Work (pp. 111-120). SAGE. 
Driskell, R. B., \& Lyon, L. (2002). Are virtual communities true communities? Examining the environments and elements of community. City \& Community, 1(4), 373-390. https://doi.org/10.1111/1540-6040.00031

Duin, S. (2013, October 22). New owners swing the ax at KATU and KOMO. The Oregonian. Retrieved from http://www.oregonlive.com/news/oregonian/steve_duin/index.ssf/2013/10/steve_ duin_new_owners_swing_th.html

Eck, K. (2016, April 25). Here's the rundown of TEGNA buyouts so far [April 25, 2016]. Retrieved March 19, 2017, from http://adweek.it/1SVXKC3

Eck, K. (2017, January 5). Sinclair restructuring, cuts at Seattle’s KOMO. Retrieved December 17, 2017, from http://adweek.it/2hVVnsw

Ember, S. (2017a, May 12). Sinclair requires tv stations to air segments that tilt to the right. The New York Times. Retrieved from https://www.nytimes.com/2017/05/12/business/media/sinclair-broadcast-komoconservative-media.html

Ember, S. (2017b, August 8). Sinclair deal draws unlikely opponent: Conservative news media. The New York Times. Retrieved from https://www.nytimes.com/2017/08/08/business/media/sinclair-bid-to-acquiretribune-media-draws-opposition.html

Entman, R. (1989). The dilemma of journalism: Democracy without citizens. In Democracy without citizens: Media and the decay of American politics (pp. 1729). New York, New York: Oxford University Press. 
Farhi, P. (2012, November 27). A local TV trend: And now, the identical news. Retrieved July 16, 2017, from https://www.washingtonpost.com/lifestyle/style/a-local-tvtrend-and-now-the-identical-news/2012/11/27/9369a308-38bd-11e2-8a97363b0f9a0ab3_story.html

Farhi, P. (2017, January 9). Longtime D.C. TV anchor Maureen Bunyan is latest casualty of Sinclair's cuts. Washington Post. Retrieved from https://www.washingtonpost.com/lifestyle/style/veteran-dc-tv-anchor-maureenbunyan-out-at-wjla-possibly-ending-her-career/2017/01/08/8877aae8-d522-11e69cb0-54ab630851e8_story.html

Farsetta, D. (2006, March 27). Fake TV news: Recommendations. Retrieved November 3, 2011, from http://www.prwatch.org/fakenews/recommendations

Federal Communications Commission. (1941). Report on chain broadcasting. Washington, D.C. Retrieved from http://hdl.handle.net/2027/mdp.39015026285083

Federal Communications Commission. (1946). Public service responsibility of broadcast licenses: Report. Washington: Washington.

Federal Communications Commission. (1996). Telecommunications Act of 1996 (No. Pub. LA. No. 104-104, 110 Stat. 56). Retrieved from http://www.fcc.gov/telecom.html

Federal Communications Commission. (1999, August 5). FCC 99-208. Retrieved July 23, 2017, from https://transition.fcc.gov/Bureaus/Mass_Media/Orders/1999/fcc99208.pdf 
News Work 160

Federal Communications Commission. (2003a, June 2). FCC sets limits on media concentration. Retrieved July 23, 2017, from https://apps.fcc.gov/edocs_public/attachmatch/DOC-235047A1.pdf

Federal Communications Commission. (2003b, July 2). 2002 Biennial review, FCC 03127. Retrieved from https://apps.fcc.gov/edocs_public/attachmatch/FCC-03127A1.pdf

Federal Communications Commission. (2010). 2010 Review of Media Ownership Rules. Retrieved November 12, 2009, from http://www.fcc.gov/ownership/

Federal Election Commission. (2010). Speechnow.org v. FEC. Retrieved April 27, 2014, from http://www.fec.gov/law/litigation/speechnow.shtml

Finke, N. (2012, March 30). SAG-AFTRA merger approved. Retrieved September 18, 2017, from http://deadline.com/2012/03/sag-aftra-merger-approved-screen-actorsguild-american-federation-television-radio-arts-251114/

Flint, J. (2013, December 23). Black ownership of commercial TV stations nonexistent, watchdog says. Los Angeles Times. Retrieved from http://articles.latimes.com/2013/dec/23/entertainment/la-et-ct-black-owned-tvstations-20131223

Florida, R. (2002). The rise of the creative class: And how it's transforming work, leisure, community and everyday life. New York, New York: Basic Books. Retrieved from https://www.amazon.com/Rise-Creative-Class-Transforming2002-0501/dp/B01JQGZ60C/ref=tmm_hrd_swatch_0?_encoding=UTF8\&qid=\&sr= 
Florida, R. (2003). Cities and the creative class. City \& Community, 2(1), 3-19. https://doi.org/10.1111/1540-6040.00034

Forde, S. (2011). Challenging the news : The journalism of alternative and community media. Houndmills, Basingstoke, Hampshire; New York: Palgrave Macmillan.

Friedland, L. A. (2001). Communication, community, and democracy: Toward a theory of the communicatively integrated community. Communication Research, 28(4), 358-391. https://doi.org/10.1177/009365001028004002

Friedman, W. (2016, November 7). Local tv spot ads pull in most revenue, major tv groups dominate. Retrieved August 1, 2017, from https://www.mediapost.com/publications/article/288535/local-tv-spot-ads-pull-inmost-revenue-major-tv-g.html

Gans, H. J. (2003). Democracy and the news. Oxford: Oxford University Press.

Garnham, N. (1990). Capitalism and communication: Global culture and the economics of information. London ; Newbury Park: Sage Publications.

George Washington University. (2011, June 16). Online local news does not replace traditional newsroom sources, study shows. Retrieved January 16, 2018, from https://phys.org/news/2011-06-online-local-news-traditional-newsroom.html

Gil de Zúñiga, H. (2009). Blogs, journalism, and political participation. In Z. Papacharissi (Ed.), Journalism and citizenship : New agendas in communication (pp. 108-122). New York: Routledge.

Gottlieb, C., \& Pertilla, A. (2001, November 1). Quality sells. Retrieved January 15, 2018, from http://www.journalism.org/2001/11/01/quality-sells/ 
News Work 162

Grass Valley. (n.d.). Ignite and HDC automated production systems. Retrieved January 19, 2014, from http://www.grassvalley.com/products/ips

Greeley, P. (2016, March 7). WXIA leads TEGNA's shakeup of local news formula. Retrieved February 7, 2018, from http://www.tvnewscheck.com/marketshare/2016/03/07/wxia-leads-tegnasshakeup-of-local-news-formula/

Guensburg, C. (2008). Nonprofit news. American Journalism Review, 30(1), 26-33.

Habermas, J. (1979). The public sphere. In A. Mattelart \& S. Siegelaub (Eds.), Communication and class struggle: Capitalism, imperialism (Vol. 1, pp. 198201). New York, NY: International General.

Habermas, J. (1991). The structural transformation of the public sphere: An inquiry into a category of bourgeois society. Cambridge Massachusetts: The MIT Press.

Hagey, K. (2013, October 21). Sinclair draws scrutiny over growth tactic; TV-station king uses “sidecars” to skirt ownership limits. Wall Street Journal (Online), p. n/a.

Hardy, J. (2014). Critical Political Economy of the Media: An Introduction (1 edition). London; New York: Routledge.

Harvey, D. (2003). The right to the city. International Journal of Urban and Regional Research, 27(4), 939-941. https://doi.org/10.1111/j.0309-1317.2003.00492.x

Herman, E. S. (2000). The Propaganda Model: A retrospective. Journalism Studies, 1(1), 101-112. https://doi.org/10.1080/146167000361195 
Herman, E. S. (2017). Fake news on Russia and other official enemies: The New York Times, 1917-2017. Montly Review: An Independent Socialist Magazine, 69(3), $98-123$.

Herman, E. S., \& Chomsky, N. (2002). Manufacturing consent: The political economy of the mass media. New York: Pantheon Books.

Higgins, C. L., \& Sussman, G. (2007). Plugola: News for profit, entertainment, and network consolidation. In T. A. Gibson \& M. Lowes (Eds.), Urban Communication: Production, Text, Context (pp. 141-162). Lanham, Maryland: Rowman \& Littlefield.

Higgins-Dobney, C. L., \& Sussman, G. (2013). The growth of TV news, the demise of the journalism profession. Media, Culture \& Society, 35(7), 847-863. https://doi.org/10.1177/0163443713495078

Holman, J., Greenfield, R., \& Smith, G. (2018, April 3). Sinclair employees say their contracts make it too expensive to quit. Bloomberg.Com. Retrieved from https://www.bloomberg.com/news/articles/2018-04-03/sinclair-employees-saytheir-contracts-make-it-too-expensive-to-quit

Hoynes, W. (2003). Branding public service the "new PBS" and the privatization of public television. Television \& New Media, 4(2), 117-130. https://doi.org/10.1177/1527476402250672

Ingram, M. (2017, December 13). The media today: The loss of net neutrality threatens local journalism. Retrieved February 24, 2018, from https://www.cjr.org/the_media_today/net-neutrality-local-news.php 
News Work 164

Jankowski, N. W. (2003). Community media research : A quest for theoreticallygrounded models, 10, 5-14. https://doi.org/urn:nbn:nl:ui:22-2066/62961

Jansen, H. (2010). The logic of qualitative survey research and its position in the field of social research methods. Forum Qualitative Sozialforschung / Forum: Qualitative Social Research, 11(2). Retrieved from http://www.qualitativeresearch.net/index.php/fqs/article/view/1450

Jessell, H. A. (2017, September 26). WFTX goes far to supply local Irma news. Retrieved September 27, 2017, from http://www.tvnewscheck.com/article/107594/wftxgoes-far-to-supply-local-irmanews?utm_source=Listrak\&utm_medium=Email\&utm_term=WFTX+Goes+Far + To+Supply+Local+Irma+News\&utm_campaign=WFTX+Goes+Far+To+Supply+ Local+Irma+News

Jhally, S., \& Livant, B. (1986). Watching as working: The valorization of audience consciousness. Journal of Communication, 36(3), 124-143.

Johnson, T. (2017a, November 16). FCC relaxes media ownership rules in contentious vote. Retrieved November 24, 2017, from http://variety.com/2017/politics/news/fcc-media-ownership-rules-sinclairbroadcasting-1202616424/

Johnson, T. (2017b, December 21). FCC fines Sinclair Broadcast Group \$13.4 million for running sponsored content as news. Retrieved December 31, 2017, from http://variety.com/2017/politics/news/sinclair-fcc-fine-sponsor-violation$1202647175 /$ 
Kalleberg, A. L. (2001). Organizing flexibility: The flexible firm in a new century. British Journal of Industrial Relations, 39(4), 479-504.

Kalleberg, A. L. (2009). Precarious work, insecure workers: Employment relations in transition. American Sociological Review, 74(1), 1-22. https://doi.org/10.1177/000312240907400101

Kalleberg, A. L. (2011). Good jobs, bad jobs : The rise of polarized and precarious employment systems in the United States, 1970s to 2000s. New York: Russell Sage Foundation.

Kang, C. (2018, February 15). F.C.C. watchdog looks into changes that benefited Sinclair. The New York Times. Retrieved from https://www.nytimes.com/2018/02/15/technology/fcc-sinclair-ajit-pai.html

Kellner, D. (1990). Television and the crisis of democracy. Boulder, Colo.: Westview Press.

Kellner, D. (2000). Habermas, the Public Sphere, and Democracy: A critical intervention. Retrieved April 21, 2014, from http://pages.gseis.ucla.edu/faculty/kellner/papers/habermas.htm

Keys, M. (2013, September 28). San Francisco TV news crew caught in shootout. Retrieved January 8, 2018, from http://thedesk.matthewkeys.net/2013/09/sanfrancisco-tv-news-crew-caught-in-shootout/

Keys, M. (2014, September 3). San Francisco television reporter robbed at gunpoint. Retrieved October 25, 2016, from http://thedesk.matthewkeys.net/2014/09/sanfrancisco-television-reporter-robbed-at-gunpoint/ 
Klaehn, J. (2009). The Propaganda Model: Theoretical and methodological considerations. Westminster Papers in Communication \& Culture, 6(2), 43-58.

Klinenberg, E. (2003). Heat wave: A social autopsy of disaster in Chicago. University Of Chicago Press.

Klinenberg, E. (2005). Convergence: News production in a digital age. Annals of the American Academy of Political and Social Science, 597, 48-64.

Kovach, B., \& Rosenstiel, T. (2001). The elements of journalism: What newspeople should know and the public should expect. Crown/Archetype.

Kretzmann, J. P., \& McKnight, J. (1993). Building communities from the inside out: A path toward finding and mobilizing a community's assets. Evanston, Ill.; Chicago, IL: The Asset-Based Community Development Institute, Institute for Policy Research, Northwestern University; Distributed by ACTA Publications.

Kroman, D. (2017, July 7). John Oliver’s Sinclair rant: There’s more to the story. Retrieved August 1, 2017, from http://crosscut.com/2017/07/john-oliver-sinclairkomo-q13/

Kvale, S. (1996). Interviews : An introduction to qualitative research interviewing. Thousand Oaks Calif.: Sage Publications.

Lerman, R. (2017, January 5). KOMO cuts positions in newsroom. Retrieved February 20, 2018, from https://www.seattletimes.com/business/technology/komo-cutspositions-in-newsroom/ 
Littleton, C. (2017, August 7). Sinclair-Tribune merger opponents warn of 'excessive, unbalanced market power.' Retrieved August 8, 2017, from http://variety.com/2017/tv/news/sinclair-tribune-merger-opponents-1202517399/

Lowrey, W., Brozana, A., \& Mackay, J. B. (2008). Toward a measure of community journalism. Mass Communication \& Society, 11(3), 275-299.

Lutz, A. (2012, June 14). These 6 corporations control 90\% of the media in America. Retrieved February 16, 2014, from http:/www.businessinsider.com/these-6corporations-control-90-of-the-media-in-america-2012-6

Lynch, J. (2016, August 26). Nielsen has increased its U.S.. TV homes estimate for the first time in 2 years. Retrieved November 5, 2017, from http://www.adweek.com/tv-video/nielsen-has-increased-its-us-tv-homes-estimatefirst-time-2-years-173157/

Malone, M. (2013, February 4). The rise of the station super-groups. Broadcasting \& Cable. Retrieved from http://www.broadcastingcable.com/news/local-tv/risestation-super-groups/43886

Malone, M. (2014, January 21). Study: \$8 billion in station sales in ’13. Retrieved February 17, 2014, from http://www.broadcastingcable.com/news/currency/study8-billion-station-sales-13/128630

Marx, K. (1887). Capital: A critique of political economy. Volume I, Book One: The process of production of capital. (F. Engels, Ed., S. Moore \& E. Aveling, Trans.) (Vol. 1). Moscow, USSR: Progress Publishers. Retrieved from https://www.marxists.org/archive/marx/works/1867-c1/ 
News Work 168

Marx, K. (1959). Economic and philosophic manuscripts of 1844. (M. Milligan \& D. J. Struik, Trans.). Moscow: Progress Publishers. Retrieved from https://www.marxists.org/archive/marx/works/download/pdf/EconomicPhilosophic-Manuscripts-1844.pdf

Massie, C. (2017, February 7). WH official: We'll say “fake news” until media realizes attitude of attacking the President is wrong. Retrieved from http://www.cnn.com/2017/02/07/politics/kfile-gorka-on-fake-news/index.html

Matsa, K. E. (2017a, May 11). Buying spree brings more local TV stations to fewer big companies. Retrieved May 12, 2017, from http://www.pewresearch.org/facttank/2017/05/11/buying-spree-brings-more-local-tv-stations-to-fewer-bigcompanies/

Matsa, K. E. (2017b, July 13). Local TV news fact sheet. Retrieved July 13, 2017, from http://www.journalism.org/fact-sheet/local-tv-news/

Matsa, K. E., \& Mitchell, A. (2014). 8 key takeaways about social media and news. Retrieved January 18, 2015, from http://www.journalism.org/2014/03/26/8-keytakeaways-about-social-media-and-news/

McAllister, M. (2002). Television news plugola and the last episode of Seinfeld. Journal of Communication, 52(2), 383.

McAllister, M. (2014). Financial Interest and Syndication Rules. Retrieved April 6, 2014, from http://www.museum.tv/eotv/financialint.htm

McChesney, R. W., \& Nichols, J. (2010). The death and life of American journalism: The media revolution that will begin the world again (1st ed.). Nation Books. 
McDowell, S. D., \& Lee, J. (2007). Tracking “localism” in television broadcasting: Utilizing and structuring public information. In P. M. Napoli (Ed.), Media diversity and localism: meaning and metrics (pp. 177-191). Mahwah, N.J.: Lawrence Erlbaum Associates.

McIntosh, D. (2016, July 7). At KGW-TV, unions take stand against “Uberization” of news. Retrieved July 8, 2017, from https://nwlaborpress.org/2016/07/at-kgw-tvunions-take-stand-against-uberization-of-news/

Mcintosh, D. (2017, March 24). KGW returns to labor peace. Retrieved July 8, 2017, from https://nwlaborpress.org/2017/03/kgw-returns-to-labor-peace/

McKercher, C. (2002). Newsworkers unite: Labor, convergence, and North American newspapers. Lanham, Md.: Rowman \& Littlefield.

McKercher, C. (2014). Precarious times, precarious work: A feminist political economy of freelance journalists in Canada and the United States. In C. Fuchs \& M. Sandoval (Eds.), Critique, social media and the information society (pp. 219230). New York: Routledge/Taylor \& Francis Group.

McKinney, J. (2017, April 20). New bill aims to boost diversity and black broadcast station ownership. Retrieved July 13, 2017, from http://www.blackenterprise.com/news/politics/bill-aims-black-broadcast-stationownership/

Merritt, D. (2010). What citizen journalism can learn from public journalism. In J. Rosenberry \& B. St. John III (Eds.), Public journalism 2.0: The promise and reality of a citizen-engaged press (pp. 21-31). New York: Routledge. 
News Work 170

Mitchell, A., Gottfried, J., Barthel, M., \& Shearer, E. (2016, July 7). 1. Pathways to news. Retrieved August 8, 2017, from http://www.journalism.org/2016/07/07/pathwaysto-news/

Mitchell, A., Jurkowitz, M., Holcomb, J., Enda, J., \& Anderson, M. (2013, June 10). Nonprofit journalism: A growing but fragile part of the U.S. news system. Retrieved June 10, 2013, from http://www.journalism.org/analysis_report/nonprofit_journalism

Mitchell, A., Stocking, G., \& Matsa, K. E. (2016, May 5). Long-form reading shows signs of life in our mobile news world. Retrieved February 21, 2018, from http://www.journalism.org/2016/05/05/long-form-reading-shows-signs-of-life-inour-mobile-news-world/

Molotch, H., \& Lester, M. (1974). News as purposive behavior: On the strategic use of routine events, accidents, and scandals. American Sociological Review, 39(1), 101-112. https://doi.org/10.2307/2094279

Morse, K. (2004). Relaxing the rules of media ownership: Localism and competition and diversity, oh my-the frightening road of deregulation. J. Nat'l Ass'n Admin. L. Judges, 24, 351.

Mosco, V. (2009a). The future of journalism. Journalism, 10(3), 350-352. https://doi.org/10.1177/1464884909102595

Mosco, V. (2009b). The political economy of communication (2nd ed.). Los Angeles: Sage Publications. 
Mosco, V., \& McKercher, C. (2009). The laboring of communication: Will knowledge workers of the world unite? Lexington Books.

Murdock, G., \& Golding, P. (1973). For a political economy of mass communications. Socialist Register, 10(10), 205-234.

Murdock, G., \& Golding, P. (2016). Political economy and media production: A reply to Dwyer. Media, Culture \& Society, 38(5), 763-769. https://doi.org/10.1177/0163443716655094

Mutter, A. D. (2015, June 25). Why online news sites keep failing. Los Angeles Times. Retrieved from http://www.latimes.com/opinion/op-ed/la-oe-0625-mutter-newsstartups-20150625-story.html

Napoli, P. M. (2001). Foundations of communications policy: Principles and process in the regulation of electronic media. Cresskill, N.J.: Hampton Press.

Napoli, P. M. (2010). Revisiting ‘mass communication' and the 'work' of the audience in the new media environment. Media, Culture \& Society, 32(3), 505-516. https://doi.org/10.1177/0163443710361658

Nichols, J., \& McChesney, R. W. (2013). Dollarocracy: How the money-and-media election complex is destroying America.

Nielsen. (2014, September 27). Local television market universe estimates: Estimates as of January 1, 2015 and used throughout the 2014-2015 television season. Retrieved October 11, 2014, from http://www.tvb.org/media/file/Nielsen_20142015_DMA_Ranks.pdf 
Nielsen. (n.d.-a). Nielsen DMA Maps. Retrieved November 19, 2017, from http://www.nielsen.com/intl-campaigns/us/dma-maps.html

Nielsen. (n.d.-b). Television measurement. Retrieved March 28, 2018, from http://www.nielsen.com/us/en/solutions/measurement/television

Norris, P. (2006). The role of the free press in promoting democratization, good governance and human development. Presented at the Midwest Political Science Association. Retrieved from http://www.academia.edu/download/30897054/10.1.1.128.4598.pdf\#page=67

NW Labor Press. (2016, March 15). KGW-TV on trial for labor violation. Retrieved July 8, 2017, from https://nwlaborpress.org/2016/03/kgw-tv-on-trial-for-laborviolation/

NW Labor Press. (2018, January 16). Portland’s KATU-TV will face a union picket. Retrieved February 20, 2018, from https://nwlaborpress.org/2018/01/portlandskatu-tv-will-face-a-union-picket/

Örnebring, H. (2010). Technology and journalism-as-labour: Historical perspectives. Journalism, 11(1), 57-74. https://doi.org/10.1177/1464884909350644

Osterman, P. (1987). Choice of employment systems in internal labor markets. Industrial Relations, 26(1), 46-67.

Papper, B. (2008a, 2017). Salaries. Retrieved August 10, 2017, from http://rtdna.org/ Papper, B. (2008b, 2017). Staffing and profitability. Retrieved August 10, 2017, from http://rtdna.org/ 
News Work 173

Papper, B. (2009). TV and radio staffing and news profitability survey 2009. Retrieved from https://www.rtdna.org/uploads/files/09survey.pdf

Papper, B. (2011). Radio Television Digital News Association: Staffing and profitability. Retrieved from http://www.rtdna.org/article/2011_tv_and_radio_news_staffing_and_profitability _survey

Papper, B. (2017a, May 8). RTDNA Research: The business of TV news. Retrieved July 2, 2017, from https://www.rtdna.org/article/rtdna_research_the_business_of_tv_news_2017

Papper, B. (2017b, June 5). RTDNA research: Local news by the numbers. Retrieved July 2, 2017, from https://www.rtdna.org/article/rtdna_research_local_news_by_the_numbers_2017

Papper, B. (2017c, June 19). RTDNA Research: Newsroom staffing. Retrieved July 2, 2017, from https://www.rtdna.org/article/rtdna_research_newsroom_staffing_2017

Papper, B. (2017d, July 17). RTDNA Research: Salary survey. Retrieved August 7, 2017, from https://www.rtdna.org/article/rtdna_research_salary_survey_2017

Perez, S., \& Cremedas, M. (2014). The multimedia journalist in large-market television newsrooms: Can old dogs learn new tricks? Do they want to? Electronic News, 8(3), 159-176. https://doi.org/10.1177/1931243114557597 
Perkins, D. D., \& Zimmerman, M. A. (1995). Empowerment theory, research, and application. American Journal of Community Psychology, 23(5), 569-579. https://doi.org/10.1007/BF02506982

Pew Research Center. (2016, June 15). African American news media: Number of blackowned TV stations. Retrieved July 13, 2017, from http://www.journalism.org/media-indicators/african-american-news-medianumber-of-black-owned-tv-stations/

Pew Research Center: Journalism and Media Staff. (2015, March 5). Local news in a digital age. Retrieved April 17, 2018, from http://www.journalism.org/2015/03/05/local-news-in-a-digital-age/

Pickard, V. (2011). The battle over the FCC Blue Book: determining the role of broadcast media in a democratic society, 1945-8. Media, Culture \& Society, 33(2), 171-191. https://doi.org/10.1177/0163443710385504

Pickard, V. (2014). The great evasion: Confronting market failure in American media policy. Critical Studies in Media Communication, 31(2), 153-159. https://doi.org/10.1080/15295036.2014.919404

Pickard, V. (2015a). America's battle for media democracy: The triumph of corporate libertarianism and the future of media reform. New York, NY: Cambridge University Press.

Pickard, V. (2015b). The return of the nervous liberals: Market fundamentalism, policy failure, and recurring journalism crises. The Communication Review, 18(2), 8297. https://doi.org/10.1080/10714421.2015.1031995 
Potter, D., \& Matsa, K. E. (2014a, March 26). Groupwide news sharing. Retrieved July 16, 2017, from http://www.journalism.org/2014/03/26/groupwide-news-sharing/

Potter, D., \& Matsa, M. (2014b, March 26). A boom in acquisitions and content sharing shapes local TV news in 2013. Retrieved March 26, 2014, from http://www.journalism.org/2014/03/26/a-boom-in-acquisitions-and-contentsharing-shapes-local-tv-news-in-2013/

Pressman, A. (2017, April 19). Almost 1,000 tv stations are about to shift channels. Retrieved July 27, 2017, from http://fortune.com/2017/04/19/tv-stations-channelsfaq/

Project for Excellence in Journalism. (2013). State of the media 2013. Retrieved March 17, 2013, from http://stateofthemedia.org/2013/local-tv-audience-declines-asrevenue-bounces-back/

Putnam, R. D. (2000). Bowling alone: The collapse and revival of American community. New York, New York: Simon \& Schuster.

Queally, J., St. John, P., Oreskes, B., \& Zahniser, D. (2017, August 28). Violence by farleft protesters in Berkeley sparks alarm. Retrieved February 18, 2018, from http://www.latimes.com/local/lanow/la-me-ln-berkeley-protests-20170827story.html

Radio Television Digital News Association. (2015). RTDNA code of ethics. Retrieved July 22, 2017, from http://rtdna.org/ 
Reinardy, S., \& Bacon, C. (2014). Feast and famine? Local television news workers expand the offerings but say they are hungry for quality journalism. Journal of Media Practice, 15(2), 133-145. https://doi.org/10.1080/14682753.2014.960766

Rice, J. (2009, July 9). Centralized graphics: Look good, save \$\$. Retrieved November 14, 2013, from http://www.tvnewscheck.com/article/33724/centralized-graphicslook-good-save-/page/2

Rice, R. (Ed.). (2008). Media ownership : Research and regulation. Cresskill NJ: Hampton Press.

Rich, M. A. (2013). "From coal to cool”: The creative class, social capital, and the revitalization of Scranton. Journal of Urban Affairs, 35(3), 365-384. https://doi.org/10.1111/j.1467-9906.2012.00639.x

Roller, M. R., \& Lavrakas, P. J. (Eds.). (2015). Applied qualitative research design: A total quality framework approach (1 edition). New York: The Guilford Press.

Rosenberry, J., \& St. John III, B. (2010). Introduction: Public journalism value in an age of media fragmentation. In J. Rosenberry \& B. St. John III (Eds.), Public journalism 2.0: The promise and reality of a citizen-engaged press (pp. 1-7). New York: Routledge.

Ross Video. (n.d.). OverDrive: Key benefits. Retrieved January 19, 2014, from http://www.rossvideo.com/control-systems/overdrive/key-benefits.html Rutenberg, J., \& Maynard, M. (2003, June 2). Tv news that looks local, even if it’s not. The New York Times. Retrieved from 
https://www.nytimes.com/2003/06/02/business/tv-news-that-looks-local-even-ifit-s-not.html

Ryan, C. (1991). Prime time activism: Media strategies for grassroots organizing. Boston, MA: South End Press.

Ryan, K. M. (2009a). Temporary resistance: Strategies of freelance workers in American network television news. In R. Sickels (Ed.), The Business of Entertainment (Vol. 3-Television, pp. 125-142). Praeger Publishers.

Ryan, K. M. (2009b). The performative journalist. Journalism, 10(5), 647-664. https://doi.org/10.1177/1464884909106537

Ryfe, D. M., \& Mensing, D. (2010). Citizen journalism in a historical frame. In J. Rosenberry \& B. St. John III (Eds.), Public journalism 2.0: The promise and reality of a citizen-engaged press (pp. 32-44). New York: Routledge.

Saegert, S. (2012). Building civic capacity in urban neighborhoods: An empirically grounded anatomy. In J. DeFilippis \& S. Saegert (Eds.), The Community Development Reader (2nd edition, pp. 220-227). New York, New York: Routledge.

Saltzis, K., \& Dickinson, R. (2008). Inside the changing newsroom: Journalists' responses to media convergence. Aslib Proceedings, 60(3), 216-228. https://doi.org/10.1108/00012530810879097

Sampson, R. J. (2012). What community supplies. In J. DeFilippis \& S. Saegert (Eds.), The Community Development Reader (2nd edition, pp. 308-318). New York, New York: Routledge. 
sbgi.net. (2017). | The largest and most diversified television broadcasting company in the country today. Retrieved December 17, 2017, from http://sbgi.net/

Schaefer, M. A. (2016, June 10). Arrest made after Telemundo reporter attacked during live shot. Retrieved January 8, 2018, from http://www.philly.com/philly/news/20160611_Telemundo_reporter_attacked_duri ng_live_shot_near_City_Hall.html

Schiller, D. (2007). How to think about information. Urbana: University of Illinois Press.

Schiller, H. I. (1989). Culture, Inc.: The corporate takeover of public expression. New York: Oxford University Press.

Schiller, H. I. (1992). Mass communications and American empire. Boulder: Westview Press.

Schudson, M. (2008). Why democracies need an unlovable press (1st ed.). Cambridge [England]; Malden, Massachusetts: Polity.

Scott, A. J. (2006). Creative cities: Conceptual issues and policy questions. Journal of Urban Affairs, 28(1), 1-17. https://doi.org/10.1111/j.0735-2166.2006.00256.x

Scott, D. K., Gobetz, R. H., \& Chanslor, M. (2008). Chain versus independent television station ownership: Toward an investment model of commitment to local news quality. Communication Studies, 59(1), 84-98.

Seifter, A. (2004, November 18). Sinclair's News Central provides steady diet of proBush, anti-progressive news items. Retrieved January 26, 2014, from http://mediamatters.org/research/2004/11/18/sinclairs-news-central-providessteady-diet-of/132312 
Sethi, V., King, R. C., \& Quick, J. C. (2004). What causes stress in information systems professionals? Communications of the ACM, 47(3), 99-102.

Shepardson, D. (2017, December 15). Exclusive: FCC plans to fine Sinclair \$13.3 million over undisclosed c. Reuters. Retrieved from https://www.reuters.com/article/ussinclair-fcc-exclusive/exclusive-fcc-plans-to-fine-sinclair-13-3-million-overundisclosed-commercials-idUSKBN1E92C7

Shoemaker, P., \& Reese, S. D. (1996). Mediating the message: Theories of influences on mass media content (2nd ed.). White Plains N.Y.: Longman.

Sinclair Broadcasting Group. (2017). About. Retrieved July 10, 2017, from http://sbgi.net/\#About

Sirianni, C., \& Friedland, L. A. (2001). Civic innovation in America: Community empowerment, public policy, and the movement for civic renewal. Berkeley: University of California Press.

Smith, L. K., Tanner, A. H., \& Duhé, S. F. (2007). Convergence concerns in local television: Conflicting views from the newsroom. Journal of Broadcasting \& Electronic Media, 51(4), 555-574. https://doi.org/10.1080/08838150701626354

Smythe, D. W. (1994). Communications: Blindspot of Western Marxism. In T. H. Guback (Ed.), Counterclockwise: Perspectives on communication (pp. 266-291). Boulder: Westview Press.

Society of Professional Journalists. (2014). SPJ Code of Ethics. Retrieved July 22, 2017, from https://www.spj.org/ethicscode.asp 
News Work 180

Squires, G. D., \& Kubrin, C. E. (2012). Privileged places: Race, opportunity, and uneven development in urban America. In J. DeFilippis \& S. Saegert (Eds.), The Community Development Reader (2nd edition, pp. 347-352). New York, New York: Routledge.

Stearns, J., \& Wright, C. (2011). Outsourcing the news. Free Press, 11, 1-16.

Stelter, B. (2018a, March 7). Sinclair’s new media-bashing promos rankle local anchors. Retrieved March 8, 2018, from http://money.cnn.com/2018/03/07/media/sinclairbroadcasting-promos-media-bashing/index.html

Stelter, B. (2018b, April 4). Sinclair producer in Nebraska resigns to protest "obvious bias.” Retrieved April 4, 2018, from http://money.cnn.com/2018/04/04/media/sinclair-producer-resignsprotest/index.html

Storper, M., \& Walker, R. (1983). The theory of labour and the theory of location. International Journal of Urban and Regional Research, 7(1).

Swift, A. (2016, September 14). Americans' trust in mass media sinks to new low. Retrieved March 12, 2018, from http://news.gallup.com/poll/195542/americanstrust-mass-media-sinks-new-low.aspx

Tanner, A., \& Smith, L. (2007). Training tomorrow’s television journalists: In the trenches with media convergence. Electronic News, 1(4), 211-225.

Tarter, S. (2016, July 15). Contract talks continue with news personnel at WEEK, WHOI. Retrieved July 20, 2017, from http://www.pjstar.com/news/20160715/contracttalks-continue-with-news-personnel-at-week-whoi 
The Public Interest Standard in Television Broadcasting. (n.d.). Retrieved March 5, 2018, from http://govinfo.library.unt.edu/piac/novmtg/pubint.htm

Tilly, C., \& Tilly, C. (1998). Work under capitalism. Westview Press.

Tönnies, F. (1957). Community \& society (Gemeinschaft und Gesellschaft). (C. Loomis, Trans.). East Lansing, Michigan: The Michigan State University Press.

Traynor, B. (2012). Community building: Limitations and promise. In J. DeFilippis \& S. Saegert (Eds.), The Community Development Reader (2nd edition, pp. 209-219). New York, New York: Routledge.

Tribune Wire Reports. (2015, August 26). Reporter, photographer shot to death on air in Virginia; suspect dies at hospital - Chicago Tribune. Chicago Tribune. Retrieved from http://www.chicagotribune.com/news/nationworld/ct-virginia-tv-crewshooting-20150826-story.html

Tsoflias, S. (2017, September 13). Floridians looked to local news first for Hurricane Irma info. Retrieved December 2, 2017, from http://adweek.it/2wqaehi

Tuchman, G. (1973). Making news by doing work: Routinizing the unexpected. American Journal of Sociology, 79(1), 110-131.

TVB. (2017a). TVB $>$ Public $>$ Research $>$ TVB Analyses $>$ Hurricane Harvey. Retrieved December 2, 2017, from https://www.tvb.org/Public/Research/TVBAnalyses/HurricaneHarvey.aspx TVB. (2017b, August 30). Study reveals Texas communities impacted by Hurricane Harvey choose local broadcast television news coverage over all other media. Retrieved December 2, 2017, from 
News Work 182

https://www.tvb.org/DetailsPage/tabid/1569/ArticleID/2966/Study-RevealsTexas-Communities-Impacted-By-Hurricane-Harvey-Choose-Local-BroadcastTelevision-News-Coverage-Over-All-Other-Media.aspx

UNESCO. (2014). Free media contribute to good governance, empowerment and eradicating poverty. Retrieved March 20, 2018, from http://www.unesco.org/new/en/unesco/events/prizes-andcelebrations/celebrations/international-days/world-press-freedom-day/2014themes/free-media-contribute-to-good-governance-empowerment-anderadicating-poverty/

United States Court of Appeals, District of Columbia Circuit. 867 F2d 654 Syracuse Peace Council v. Federal Communications Commission (February 10, 1989). Retrieved from http://openjurist.org/867/f2d/654/syracuse-peace-council-vfederal-communications-commission

United States Courts of Appeals, Third Circuit. 373 F3d 372 Prometheus Radio Project v. Federal Communications Commission (June 24, 2004). Retrieved from http://openjurist.org/373/f3d/372/prometheus-radio-project-v-federalcommunications-commission

Upshaw, J., Chernov, G., \& Koranda, D. (2007). Telling more than news: Commercial influence in local television stations. Electronic News, 1(2), 67-87. https://doi.org/10.1080/19312430709336909

U.S. Congress. (1934). Communications Act of 1934: As amended by Telecom Act of 1996. 
U.S. Supreme Court. (2010). 130 S. Ct. 876 Supreme Court of the United States CITIZENS UNITED, Appellant, v. FEDERAL ELECTION COMMISSION.

Vogel, P. (2017, September 19). Sinclair insiders are sounding the alarm about its plans to transform local news. Retrieved December 31, 2017, from https://www.mediamatters.org/research/2017/09/19/sinclair-insiders-aresounding-alarm-about-its-plans-transform-local-news/217973

Waldman, S. (2011). The information needs of communities: The changing media landscape in a broadband age. Retrieved from http://www.fcc.gov/info-needscommunities\#download

Wang, S. (2017, April 14). The FCC spectrum auction is sending \$10 billion to broadcasters. Where will that money go? Retrieved June 20, 2017, from http://www.niemanlab.org/2017/04/the-fcc-spectrum-auction-is-sending-10billion-to-broadcasters-where-will-that-money-go/

Wasko, J. (2014). The study of the political economy of the media in the twenty-first century. International Journal of Media \& Cultural Politics, 10(3), 259-271. https://doi.org/10.1386/macp.10.3.259_1

Weaver, D. H., \& Willnat, L. (2016). Changes in U.S. journalism. Journalism Practice, 10(7), 844-855. https://doi.org/10.1080/17512786.2016.1171162

Williams, R. (2009). Advertising: The magic system. In S. Thornham, C. Bassett, \& P. Marris (Eds.), Media studies: A reader (pp. 730-735). New York: New York University Press. 
WXIA-TV. (2016). The Triangle: All 5 episodes. Retrieved February 5, 2018, from http://www.11alive.com/video/news/investigations/triangle/the-triangle-all-5episodes/85-2026006

Yan, M. Z., \& Napoli, P. M. (2006). Market competition, station ownership, and local public affairs programming on broadcast television. Journal of Communication, 56(4), 795-812.

Yanich, D. (2010). Does ownership matter? Localism, content, and the Federal Communications Commission. Journal of Media Economics, 23(2), 51-67. https://doi.org/10.1080/08997764.2010.485537

Zimmerman, J. (2008). From brew town to cool town: Neoliberalism and the creative city development strategy in Milwaukee. Cities, 25(4), 230-242.

https://doi.org/10.1016/j.cities.2008.04.006 


\section{Appendix A}

\section{Stations with Local Television Newscasts in Targeted Markets}

\begin{tabular}{|c|c|c|c|c|}
\hline Size & Market & $\begin{array}{l}\text { Targeted } \\
\text { Stations }\end{array}$ & Affiliation & Owner \\
\hline 1 & $\begin{array}{l}\text { New York } \\
\text { City }\end{array}$ & $\begin{array}{l}\text { NY1 } \\
\text { WCBS } \\
\text { WLNY } \\
\text { WABC } \\
\text { WNBC } \\
\text { WNYW } \\
\text { WPIX } \\
\text { NJTV } \\
\text { WMBC } \\
\text { WRNN }\end{array}$ & $\begin{array}{l}\text { Cable } \\
\text { CBS } \\
\text { Independent } \\
\text { ABC } \\
\text { NBC } \\
\text { Fox } \\
\text { CW } \\
\text { PBS } \\
\text { Independent } \\
\text { Cable }\end{array}$ & $\begin{array}{l}\text { Time Warner Cable } \\
\text { CBS Television Stations } \\
\text { CBS Television Stations } \\
\text { ABC Owned Television } \\
\text { Stations } \\
\text { NBC Owned Television } \\
\text { Stations } \\
\text { Fox Television Stations, Inc. } \\
\text { Tribune Media Company } \\
\text { NJ Public Broadcasting } \\
\text { Authority } \\
\text { Mountain Broadcasting Corp. } \\
\text { WRNN License Company, } \\
\text { Inc. }\end{array}$ \\
\hline 2 & Los Angeles & $\begin{array}{l}\text { KABC } \\
\text { KCAL } \\
\text { KCBS } \\
\text { KNBC } \\
\text { KTLA } \\
\text { KTTV } \\
\text { KDOC }\end{array}$ & $\begin{array}{l}\text { ABC } \\
\text { Independent } \\
\text { CBS } \\
\text { NBC } \\
\text { CW } \\
\text { Fox } \\
\text { Independent }\end{array}$ & $\begin{array}{l}\text { ABC Owned Television } \\
\text { Stations } \\
\text { CBS Television Stations } \\
\text { CBS Television Stations } \\
\text { NBC Owned Television } \\
\text { Stations } \\
\text { Tribune Media Company } \\
\text { Fox Television Stations, Inc. } \\
\text { Ellis Communications } \\
\end{array}$ \\
\hline 3 & Chicago & $\begin{array}{l}\text { WBBM } \\
\text { WFLD } \\
\text { WGN } \\
\text { WLS } \\
\text { WMAQ } \\
\text { WCIU } \\
\text { WTTW }\end{array}$ & $\begin{array}{l}\text { CBS } \\
\text { Fox } \\
\text { CW } \\
\text { ABC } \\
\text { NBC } \\
\text { Independent } \\
\text { PBS }\end{array}$ & $\begin{array}{l}\text { CBS Television Stations } \\
\text { Fox Television Stations, Inc. } \\
\text { Tribune Media Company } \\
\text { ABC Owned Television } \\
\text { Stations } \\
\text { NBC Owned Television } \\
\text { Stations } \\
\text { Weigel Broadcasting } \\
\text { Window to the World } \\
\text { Communications, Inc. }\end{array}$ \\
\hline
\end{tabular}




\begin{tabular}{|c|c|c|c|c|}
\hline 4 & Philadelphia & $\begin{array}{l}\text { KYW } \\
\text { WCAU } \\
\text { WFMZ } \\
\text { WPVI } \\
\text { WTXF }\end{array}$ & $\begin{array}{l}\text { CBS } \\
\text { NBC } \\
\text { Independent } \\
\text { ABC } \\
\text { Fox }\end{array}$ & $\begin{array}{l}\text { CBS Television Stations } \\
\text { NBC Owned Television } \\
\text { Stations } \\
\text { Allentown Marantha } \\
\text { Broadcasting Co, Inc. } \\
\text { ABC Owned Television } \\
\text { Stations } \\
\text { Fox Television Stations, Inc. }\end{array}$ \\
\hline 5 & $\begin{array}{l}\text { Dallas - } \\
\text { Fort Worth }\end{array}$ & $\begin{array}{l}\text { KDAF } \\
\text { KDFW } \\
\text { KTVT } \\
\text { KXAS } \\
\text { WFAA }\end{array}$ & $\begin{array}{l}\text { CW } \\
\text { Fox } \\
\text { CBS } \\
\text { NBC } \\
\text { ABC }\end{array}$ & $\begin{array}{l}\text { Tribune Media Company } \\
\text { Fox Television Stations, Inc. } \\
\text { CBS Television Stations } \\
\text { NBC Owned Television } \\
\text { Stations } \\
\text { TEGNA Inc. }\end{array}$ \\
\hline 6 & $\begin{array}{l}\text { San Francisco - } \\
\text { Oakland - } \\
\text { San Jose }\end{array}$ & $\begin{array}{l}\text { KGO } \\
\text { KNTV } \\
\text { KPIX } \\
\text { KRON } \\
\text { KTVU } \\
\text { KOFY }\end{array}$ & $\begin{array}{l}\text { ABC } \\
\text { NBC } \\
\text { CBS } \\
\text { MyNetworkTV } \\
\text { Fox } \\
\text { Independent }\end{array}$ & $\begin{array}{l}\text { ABC Owned Television } \\
\text { Stations } \\
\text { NBC Owned Television } \\
\text { Stations } \\
\text { CBS Television Stations } \\
\text { Media General, Inc. } \\
\text { Fox Television Stations, Inc. } \\
\text { Granite Broadcasting } \\
\text { Corporation }\end{array}$ \\
\hline 7 & $\begin{array}{l}\text { Boston } \\
\text { (Manchester) }\end{array}$ & $\begin{array}{l}\text { NECN } \\
\text { WBZ } \\
\text { WCVB } \\
\text { WFXT } \\
\text { WHDH } \\
\text { WMUR } \\
\text { BNN } \\
\text { WGBH }\end{array}$ & $\begin{array}{l}\text { Cable } \\
\text { CBS } \\
\text { ABC } \\
\text { Fox } \\
\text { NBC } \\
\text { ABC } \\
\text { Community } \\
\text { PBS }\end{array}$ & $\begin{array}{l}\text { NBC Owned Television } \\
\text { Stations } \\
\text { CBS Television Stations } \\
\text { Hearst Television } \\
\text { Cox Media Group } \\
\text { Sunbeam Television } \\
\text { Corporation } \\
\text { Hearst Television } \\
\text { Boston Neighborhood } \\
\text { Network, Inc. } \\
\text { WGBH Educational } \\
\text { Foundation }\end{array}$ \\
\hline 8 & $\begin{array}{l}\text { Washington, DC } \\
\text { (Hagerstown) }\end{array}$ & $\begin{array}{l}\text { WJLA } \\
\text { WHAG } \\
\text { WRC } \\
\text { WTTG } \\
\text { WUSA }\end{array}$ & $\begin{array}{l}\text { ABC } \\
\text { NBC } \\
\text { NBC } \\
\text { Fox } \\
\text { CBS }\end{array}$ & $\begin{array}{l}\text { Sinclair Broadcast Group } \\
\text { Nexstar Broadcasting Group } \\
\text { Inc } \\
\text { NBC Owned Television } \\
\text { Stations } \\
\text { Fox Television Stations, Inc. } \\
\text { TEGNA Inc. }\end{array}$ \\
\hline
\end{tabular}




\begin{tabular}{|c|c|c|c|c|}
\hline 9 & Atlanta & $\begin{array}{l}\text { WAGA } \\
\text { WGCL } \\
\text { WSB } \\
\text { WXIA }\end{array}$ & $\begin{array}{l}\text { Fox } \\
\text { CBS } \\
\text { ABC } \\
\text { NBC }\end{array}$ & $\begin{array}{l}\text { Fox Television Stations, Inc. } \\
\text { Meredith Corporation } \\
\text { Cox Media Group } \\
\text { TEGNA Inc. }\end{array}$ \\
\hline 10 & Houston & $\begin{array}{l}\text { KHOU } \\
\text { KIAH } \\
\text { KPRC } \\
\text { KRIV } \\
\text { KTRK }\end{array}$ & $\begin{array}{l}\text { CBS } \\
\text { CW } \\
\text { NBC } \\
\text { Fox } \\
\text { ABC }\end{array}$ & $\begin{array}{l}\text { TEGNA Inc. } \\
\text { Tribune Media Company } \\
\text { Graham Media Group } \\
\text { Fox Television Stations, Inc. } \\
\text { ABC Owned Television } \\
\text { Stations }\end{array}$ \\
\hline 11 & $\begin{array}{l}\text { Phoenix } \\
\text { (Prescott) }\end{array}$ & $\begin{array}{l}\text { KNXV } \\
\text { KPHO } \\
\text { KTVK } \\
\text { KPNX } \\
\text { KSAZ } \\
\text { KLHU } \\
\text { KAZT } \\
\text { KBAQ }\end{array}$ & $\begin{array}{l}\text { ABC } \\
\text { CBS } \\
\text { Independent } \\
\text { NBC } \\
\text { Fox } \\
\text { Independent } \\
\text { Independent } \\
\text { PBS }\end{array}$ & $\begin{array}{l}\text { E.W. Scripps Company } \\
\text { Meredith Corporation } \\
\text { Meredith Corporation } \\
\text { TEGNA Inc. } \\
\text { Fox Television Stations, Inc. } \\
\text { Jensen Media Group } \\
\text { Londen Media Group } \\
\text { Arizona State University }\end{array}$ \\
\hline 12 & Detroit & $\begin{array}{l}\text { WDIV } \\
\text { WJBK } \\
\text { WXYZ }\end{array}$ & $\begin{array}{l}\text { NBC } \\
\text { Fox } \\
\text { ABC }\end{array}$ & $\begin{array}{l}\text { Graham Media Group } \\
\text { Fox Television Stations, Inc. } \\
\text { E.W. Scripps Company }\end{array}$ \\
\hline 13 & $\begin{array}{l}\text { Tampa - } \\
\text { St. Petersburg } \\
\text { (Sarasota) }\end{array}$ & $\begin{array}{l}\text { Bay News } \\
9 \\
\text { SNN } \\
\text { WFLA } \\
\text { WFTS } \\
\text { WTSP } \\
\text { WTVT } \\
\text { WWSB }\end{array}$ & $\begin{array}{l}\text { Cable } \\
\text { Regional } \\
\text { NBC } \\
\text { ABC } \\
\text { CBS } \\
\text { Fox } \\
\text { ABC }\end{array}$ & $\begin{array}{l}\text { Bright House Networks } \\
\text { LDB Media, LLC } \\
\text { Media General, Inc. } \\
\text { E.W. Scripps Company } \\
\text { TEGNA Inc. } \\
\text { Fox Television Stations, Inc. } \\
\text { Calkins Media }\end{array}$ \\
\hline 14 & $\begin{array}{l}\text { Seattle - } \\
\text { Tacoma }\end{array}$ & $\begin{array}{l}\text { KCPQ } \\
\text { KING } \\
\text { KONG } \\
\text { KIRO } \\
\text { KOMO } \\
\text { NWCN }\end{array}$ & $\begin{array}{l}\text { Fox } \\
\text { NBC } \\
\text { Independent } \\
\text { CBS } \\
\text { ABC } \\
\text { Cable }\end{array}$ & $\begin{array}{l}\text { Tribune Media Company } \\
\text { TEGNA Inc. } \\
\text { TEGNA Inc. } \\
\text { Cox Media Group } \\
\text { Sinclair Broadcast Group } \\
\text { TEGNA Inc. }\end{array}$ \\
\hline 15 & $\begin{array}{l}\text { Minneapolis - } \\
\text { St. Paul }\end{array}$ & $\begin{array}{l}\text { KARE } \\
\text { KMSP } \\
\text { KSTP } \\
\text { KSTC } \\
\text { WCCO }\end{array}$ & $\begin{array}{l}\text { NBC } \\
\text { Fox } \\
\text { ABC } \\
\text { Independent } \\
\text { CBS }\end{array}$ & $\begin{array}{l}\text { TEGNA Inc. } \\
\text { Fox Television Stations, Inc. } \\
\text { Hubbard Broadcasting, Inc. } \\
\text { Hubbard Broadcasting, Inc. } \\
\text { CBS Television Stations }\end{array}$ \\
\hline
\end{tabular}


News Work 188

\begin{tabular}{|c|c|c|c|c|}
\hline 16 & $\begin{array}{l}\text { Miami - } \\
\text { Ft. Lauderdale }\end{array}$ & $\begin{array}{l}\text { WFOR } \\
\text { WPLG } \\
\text { WSVN } \\
\text { WTVJ }\end{array}$ & $\begin{array}{l}\text { CBS } \\
\text { ABC } \\
\text { Fox } \\
\text { NBC }\end{array}$ & $\begin{array}{l}\text { CBS Television Stations } \\
\text { BH Media } \\
\text { Sunbeam Television } \\
\text { Corporation } \\
\text { NBC Owned Television } \\
\text { Stations }\end{array}$ \\
\hline 17 & Denver & $\begin{array}{l}\text { KCNC } \\
\text { KDVR } \\
\text { KWGN } \\
\text { KMGH } \\
\text { KUSA }\end{array}$ & $\begin{array}{l}\text { CBS } \\
\text { Fox } \\
\text { CW } \\
\text { ABC } \\
\text { NBC }\end{array}$ & $\begin{array}{l}\text { CBS Television Stations } \\
\text { Tribune Media Company } \\
\text { Tribune Media Company } \\
\text { E.W. Scripps Company } \\
\text { TEGNA Inc. }\end{array}$ \\
\hline 18 & $\begin{array}{l}\text { Orlando - } \\
\text { Daytona } \\
\text { Beach - } \\
\text { Melbourne }\end{array}$ & $\begin{array}{l}\text { CFN } \\
\text { WESH } \\
\text { WFTV } \\
\text { WKMG } \\
\text { WOFL }\end{array}$ & $\begin{array}{l}\text { Cable } \\
\text { NBC } \\
\text { ABC } \\
\text { CBS } \\
\text { Fox }\end{array}$ & $\begin{array}{l}\text { Bright House Networks } \\
\text { Hearst Television, Inc. } \\
\text { Cox Media Group } \\
\text { Graham Media Group } \\
\text { Fox Television Stations, Inc. }\end{array}$ \\
\hline 19 & $\begin{array}{l}\text { Cleveland - } \\
\text { Akron } \\
\text { (Canton) }\end{array}$ & $\begin{array}{l}\text { WEWS } \\
\text { WJW } \\
\text { WKYC } \\
\text { WMFD } \\
\text { WOIO } \\
\text { WUAB }\end{array}$ & $\begin{array}{l}\text { ABC } \\
\text { Fox } \\
\text { NBC } \\
\text { Independent } \\
\text { CBS } \\
\text { MyNetworkTV }\end{array}$ & $\begin{array}{l}\text { E.W. Scripps Company } \\
\text { Tribune Media Company } \\
\text { TEGNA Inc. } \\
\text { Mid-State Television, Inc. } \\
\text { Raycom Media, Inc. } \\
\text { Raycom Media, Inc. }\end{array}$ \\
\hline 20 & $\begin{array}{l}\text { Sacramento - } \\
\text { Stockton - } \\
\text { Modesto }\end{array}$ & $\begin{array}{l}\text { KCRA } \\
\text { KMAX } \\
\text { KOVR } \\
\text { KTXL } \\
\text { KXTV }\end{array}$ & $\begin{array}{l}\text { NBC } \\
\text { CW } \\
\text { CBS } \\
\text { Fox } \\
\text { ABC }\end{array}$ & $\begin{array}{l}\text { Hearst Television, Inc. } \\
\text { CBS Television Stations } \\
\text { CBS Television Stations } \\
\text { Tribune Media Company } \\
\text { TEGNA Inc. }\end{array}$ \\
\hline 21 & St. Louis & $\begin{array}{l}\text { KMOV } \\
\text { KSDK } \\
\text { KTVI } \\
\text { KDNL }\end{array}$ & $\begin{array}{l}\text { CBS } \\
\text { NBC } \\
\text { Fox } \\
\text { ABC }\end{array}$ & $\begin{array}{l}\text { Meredith Corporation } \\
\text { TEGNA Inc. } \\
\text { Tribune Media Company } \\
\text { Sinclair Broadcast Group }\end{array}$ \\
\hline 22 & Pittsburgh & $\begin{array}{l}\text { KDKA } \\
\text { WPXI } \\
\text { WTAE }\end{array}$ & $\begin{array}{l}\text { CBS } \\
\text { NBC } \\
\text { ABC }\end{array}$ & $\begin{array}{l}\text { CBS Television Stations } \\
\text { Cox Media Group } \\
\text { Hearst Television, Inc. }\end{array}$ \\
\hline 23 & $\begin{array}{l}\text { Portland, } \\
\text { Oregon }\end{array}$ & $\begin{array}{l}\text { KATU } \\
\text { KGW } \\
\text { KOIN } \\
\text { KPTV } \\
\text { KPDX }\end{array}$ & $\begin{array}{l}\text { ABC } \\
\text { NBC } \\
\text { CBS } \\
\text { Fox } \\
\text { MyNetworkTV }\end{array}$ & $\begin{array}{l}\text { Sinclair Broadcast Group } \\
\text { TEGNA Inc. } \\
\text { Media General, Inc. } \\
\text { Meredith Corporation } \\
\text { Meredith Corporation }\end{array}$ \\
\hline
\end{tabular}


News Work 189

\begin{tabular}{|l|l|l|l|l|}
\hline 24 & Charlotte & TWC Char & Cable & Time Warner Cable \\
& & WBTV & CBS & Raycom Media, Inc. \\
& & WCCB & CW & Bahakel Communications \\
& & WCNC & NBC & TEGNA Inc. \\
& & WJZY & Fox & Fox Television Stations, Inc. \\
& & WSOC & ABC & Cox Media Group \\
& & WAXN & Independent & Cox Media Group \\
& & WHKY & Independent & Long Communications, LLC \\
\hline 25 & $\begin{array}{l}\text { Raleigh }- \\
\text { Durham } \\
\text { (Fayetteville) }\end{array}$ & WWC Ral & Cable & Time Warner Cable \\
& WRAL & NBC & Fodia General, Inc. \\
& & Fox & Capitol Broadcasting \\
& & WTVD & ABC & Company \\
& & & & ABC Owned Television \\
& & & \\
\hline
\end{tabular}

Note. Ownership is as of 2016, when data collection concluded. 
News Work 190

\section{Appendix B}

\section{Web Survey Questions}

1. What market do you currently work in? (drop down choice of targeted markets) *required

2. How long have you worked in local television news?

3. Job title *required

4. Do you work for a commercial station?

Yes

No

5. Are you

Male

Female

6. Do you work

Full time (30+ hours/week)

Part time (with benefits)

Part time (no benefits)

Freelance/contract

Temporary

Other (please explain briefly):

7. Are you happy with that status?

Yes

No

8. Are you concerned with job security?

Yes

No

9. Have you ever had your work hours cut or been downsized from a local television news job?

Yes

No

10. Are you currently a member of a union?

Yes

No

11. (If no to question 10): Have you ever been a member of a union?

Yes

No

12. Has technology changed how you do your job?

Yes

No

13. (If yes to question 12): Have these changes helped or hindered your ability to do your job?

Helped

Hindered 
Both

Neither/No effect

14. Briefly, how?

15. Are you expected to engage with social media as part of your job?

Yes

No

16. (If yes to question 15): Are you given specific parameters for such engagement? (i.e. are you expected to tweet or Facebook, etc. a certain number of times per day?)

Yes

No

17. (If no to question 15): Do you expect to add social media to your job duties in the next year?

Yes

No

Not sure

18. Are you expected to put stories and/or video on the station's website?

Yes

No

19. Are you providing content and/or technical support for more newscasts than you have in the past?

Yes

No

20. Has your salary been adjusted to account for any changes in work load?

My pay and work load have not changed.

Yes. I get paid more to do more work.

No. I get paid the same amount to do more work.

No. I took a pay cut to do more work.

I get paid more but my work load has not changed or has decreased.

21. Do you think workplace changes you have experienced have affected your job performance?

Yes. Positively.

Yes. Negatively.

No effect.

Not sure.

I have not experienced any workplace changes.

22. Do you think workplace changes you have experienced are negatively or positively affecting the news product?

Positively affecting news product.

Negatively affecting news product.

Both positively and negatively affecting news product.

Not affecting the news product.

Not sure.

I have not experienced any workplace changes. 
23. Have you ever felt pressure to cover a story because it might be financially beneficial to your station, owner, or network?

Yes.

No.

Not applicable to my job description.

24. Have you ever felt pressure to NOT cover a story because it might be financially detrimental to your station, owner, or network?

Yes.

No.

Not applicable to my job description.

25. Do you feel like you have enough preparation time to do your job well?

Yes

No

Other (please explain briefly)

26. Do you feel like you have enough resources available to do your job well?

Yes

No

Other (please explain briefly)

27. Do you think your station's television news output over the next 2 years will Increase

Decrease

Stay the same

Not sure

28. Do you think your station's output on the web and/or mobile device over the next 2 years will

Increase

Decrease

Stay the same

Not sure

Thank you for your input. If you would be willing to be contacted for a more in-depth interview about this project (approximately one hour, online, at your convenience), please include your contact information on the next page. This information will not be linked to your previous answers. 


\section{Appendix C}

\section{Interview Recruitment Letter}

College of Urban Studies \& Public Affairs

Nohad A. Toulan School of Urban Studies \& Planning

Post Office Box 751 - USP

503-725-5176 tel

Portland, Oregon 97207-0751 503-725-8770 fax

careyh@pdx.edu

May 1, 2015

Dear [Potential Participant]:

My name is Carey Higgins-Dobney, and I am a PhD candidate in Urban Studies at Portland State University. Under the supervision of Dr. Gerald Sussman, I am conducting dissertation research on labor practices in local television newsrooms. I would like to invite you to participate.

You are being asked to take part because of you work in a newsroom in a top 25 local television market. I am interested in your experiences regarding changes in work practices you have witnessed in the newsroom, and the impact these may have had on your news output. If you decide to participate, you will take part in a one-on-one interview via Skype or a similar online video service that will last approximately an hour. This will involve answering questions about unions, layoffs, technology, workloads, beats, and other topics related to local television newsroom work. You will only participate in one interview, and it will be scheduled at a mutually convenient time.

Neither your name nor station affiliation will be attached to your answers in recordings, notes, or write-ups. You will be identified only by a generic job title held by numerous people within your profession (for example, "reporter”). You may not receive any direct benefit from taking part in this study, but the study may help to increase knowledge that may help others in the future.

Participation is entirely voluntary. Your decision to participate or not will not affect your relationship with the researcher or with Portland State University in any way. If you decide to take part in the study, you may choose to withdraw at any time without penalty. 
If you have concerns about your participation in this study or your rights as a research subject, please contact the PSU Office of Research Integrity, 1600 SW 4th Ave., Market Center Building, Ste. 620, Portland, OR, 97201; phone (503) 725-2227 or 1 (877) 4804400.

If you have questions about the study itself, contact Carey Higgins-Dobney at careyh@pdx.edu or 503-432-9438.

Thank you for your time.

Sincerely,

Carey L. Higgins-Dobney 


\title{
Appendix D \\ Interview Consent Form
}

\section{P Portland $\underset{\text { UNIVERSITY }}{\text { State }}$}

\begin{abstract}
College of Urban Studies \& Public Affairs
Nohad A. Toulan School of Urban Studies \& Planning

Post Office Box 751 - USP 503-725-5176 tel

Portland, Oregon 97207-0751 503-725-8770 fax

careyh@pdx.edu
\end{abstract}

May 1, 2015

\section{Dear $\{$ Participant $\}$}

You are being invited to participate in a research study conducted by $\mathrm{PhD}$ candidate Carey Higgins-Dobney, under the supervision of Dr. Gerald Sussman, from Portland State University, Department of Urban Studies. The aim is to learn about work routines and labor practices in local television newsrooms.

You have been selected as a possible participant in this study because you work in a local television newsroom in one of the 25 largest media markets in the United States. You therefore have direct knowledge of the state of working conditions in such an environment.

If you decide to participate, you will be asked to take part in an online video interview (via a service such as Skype) to answer some questions about your work day, and how it may have changed over the course of your career. Subjects will include technology, routines, unions, station ownership, and news sources. Your answers will be audiotaped for ease of notetaking. The interview should take approximately an hour of your time. You will only participate in one interview.

Any information that is obtained in connection with this study and that can be linked to you or identify you will be kept confidential. Your name and station affiliation will not be used in conjunction with your answers, and will not be part of the audio recordings. Any descriptors will be kept to a generic job title, such as "reporter” or "photographer.” Even so, there is the possibility that specific elements of your answers might make you more identifiable.

While risks will be minimal, participating in this study means that you might discuss topics that will be upsetting to you. You will not be required to answer any question, and 
you may end the interview at any time. You may not receive any direct benefit from taking part in this study, but the study may help to increase knowledge which may help others in the future.

Your participation is voluntary. You may withdraw from this study at any time without affecting your relationship with the researchers or Portland State University.

If you have concerns or problems about your participation in this study or your rights as a research subject, please contact the PSU Office of Research Integrity, 1600 SW 4th Ave., Market Center Building, Ste. 620, Portland, OR, 97201; phone (503) 725-2227 or 1 (877) 480-4400.

If you have questions about the study itself, contact Carey Higgins-Dobney at careyh@pdx.edu or 503-432-9438.

Your signature indicates that you have read and understand the above information and agree to take part in this study. Please understand that you may withdraw your consent at any time without penalty, and that, by signing, you are not waiving any legal claims, rights or remedies. The researcher will provide you with a copy of this form for your own records. 


\section{Appendix E}

\section{Potential Base Interview Questions}

Preliminary information:

How long have you worked in tv news? Other media?

What positions have you held?

Current market?

How long in this market?

Interview:

1. What brought you to this line of work?

2. What part of your job do you value the most?

3. Has this changed over the course of your career?

4. Has what is considered "news" changed over the course of your career?

5. Are you happy with the type of news your newsroom covers? What would you change if you could?

6. How has news gathering changed over the course of your career?

7. What obstacles do you encounter when covering/producing the news? Have these changed over the course of your career?

8. Has technology impacted how you or your colleagues do your jobs?

9. Do you have a say when technology, routine, or job description changes are implemented in your newsroom?

10. Do you generally receive training when substantial changes are implemented in your newsroom?

11. Does your newsroom have a "beat” system? Are beats useful?

12. Do you have "go-to" sources for certain types of stories? How are these sources chosen?

13. Has the role of investigative reporting changed during your career? 
14. Does your newsroom use video news releases? Are these treated any differently than other news content?

15. How much content is provided by the audience or other non-journalists? What are your thoughts on this practice?

16. Have you ever felt pressure to cover (or not cover) a story? What were the circumstances?

17. Has the news cycle changed over the course of your career? Has this affected your work?

18. Does your newsroom use consultants? Is it a company-wide consultant? Are you obligated to follow their suggestions? What does this do you your stories/presentation?

19. Who dictates what the newscast presentation looks like?

20. Who decides what stories will be pursued for the newscasts?

21. What is the role of social media in your newsroom?

22. Do you have to produce content for multiple formats? Do you receive added compensation for this addition to your workload?

23. For those in commercial newsrooms: Have you ever worked for a noncommercial newsroom? How was that different?

24. For those in noncommercial newsrooms: Have you ever worked for a commercial newsroom? How was that different?

25. For those in a corporate-owned newsroom: Have you ever worked for a familyowned station? Is that different than working for a corporate-owned station? How?

26. Have you experienced a station ownership change? Did it affect how you do your job?

27. Are you a member of a union? Have you ever been? Have you ever been at a station with workers who tried to unionize? Are union workers treated any differently?

28. Have you seen job consolidation? Did this impact how you do your job? 
News Work 199

29. Have you been laid off or had hours cut because of newsroom or ownership changes?

30. Are you happy with the current configuration of your job? (full time/part time/etc status, tv vs web output, other). Does this affect how you go about doing your job?

31. Do you feel secure in your job?

32. What changes do you anticipate in television newsrooms in the near future?

33. Is there anything else you'd like to add? 